\title{
GENETIC LINKAGE OF MULTIPLE MODIFICATIONS IN THE PIG
}

\author{
A Dissertation \\ presented to \\ the Faculty of the Graduate School \\ at the University of Missouri-Columbia
}

In Partial Fulfillment

of the Requirements for the Degree

Doctor of Philosophy

by

BENJAMIN PAUL BEATON

Dr. Kevin Wells, Dissertation Supervisor

MAY 2015 
The undersigned, appointed by the dean of the Graduate School, have examined the dissertation entitled

\section{GENETIC LINKAGE OF MULTIPLE MODIFICATIONS IN THE PIG}

presented by Benjamin Paul Beaton,

a candidate for the degree of doctor of philosophy, and hereby certify that, in their opinion, it is worthy of acceptance.

Dr. Kevin D. Wells

Dr. Elizabeth Bryda

Dr. Randall S. Prather

Dr. Monique Lorson

Dr. Eric Walters 


\section{DEDICATION}

This is dedicated to my wife, Whitney Beaton, whose love, companionship, support and patience have made the rough times bearable, and the good times memorable. I could not be where I am today without you and I appreciate your continued support of my future endeavors. 


\section{ACKNOWLEDGEMENTS}

I would like to express my deepest appreciation to my mentor, Dr. Kevin Wells, for his support and guidance through the course of this research. I would also like to acknowledge the important contributions of my committee members, Drs. Elizabeth Bryda, Randall Prather, Eric Walters, and Monique Lorson. Each of these individuals has mentored me throughout my advanced degrees and their advice has been extraordinary.

All of this work could not have been accomplished if it was not for the help of my fellow lab members, Shasta Grotewiel (Cernea), Anna Spate (Lichtenauer), Addison Byrne, Magie Steinhoff, and Chad O'Gorman. Tina Egen contributed greatly in the advice of molecular techniques and assay development. For the pig production component of this project, members of Dr. Prather's lab were invaluable. So for that I would like to thank: Lonnie Dowell, Jason Dowell, and Keith Giroux for care of the surrogates; Dr. Clifton Murphy and Lee Spate for performing the embryo transfers; Dr. Juide Mao, and Dr. Kim Tessane for SCNT; Melissa Samuel for piglet care and tissue collection assistance; and Dr. Kristin Whitworth with assay development. 


\section{TABLE OF CONTENTS}

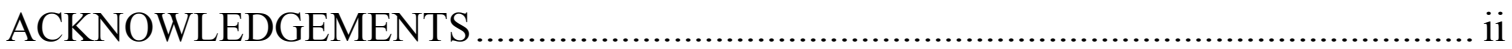

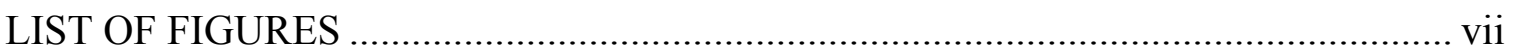

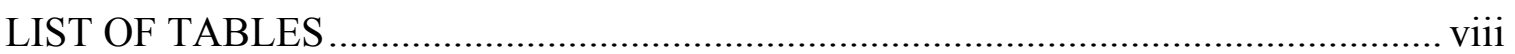

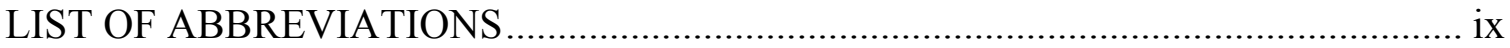

\section{CHAPTER}

I. INTRODUCTION AND LITERATURE REVIEW .......................................

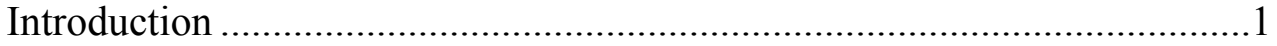

Brief History of Pig Transgenesis ...........................................................2

Gene Targeting ................................................................................. 6

Programmable Nucleases ................................................................ 10

Recombinase-Mediated Exchange ................................................. 11

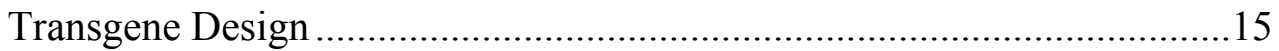

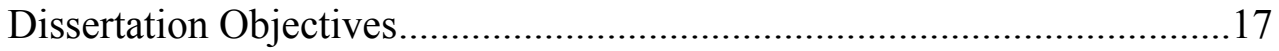

II. COMPOUND TRANSGENICS: RECOMBINASE-MEDIATED GENE

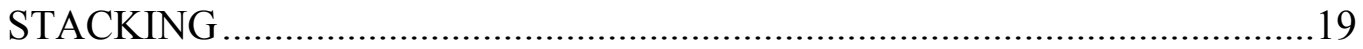

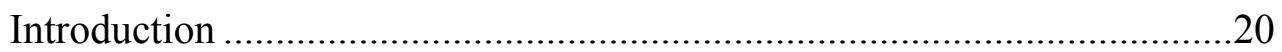

Gene-Stacking Strategy .................................................................25

Materials and Methods ......................................................................29

PhiC31 Vector Maps and Details..................................................29

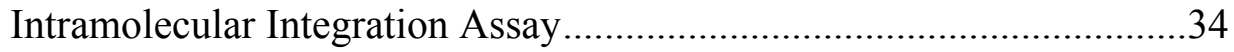

Culture and Transfection of Porcine Fibroblast Cells.............................38 
Cre-loxP-Mediated Excision of Unwanted DNA by Transient Expression of Cre Recombinase .......................................................................4

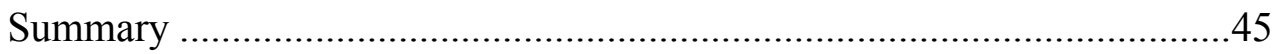

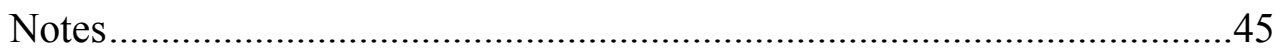

III. THE EFFECT OF DONOR DNA HOMOLOGY LENGTH ON THE OUTCOME OF NUCLEASE-MEDIATED GENE TARGETING...

Abstract

Introduction .48

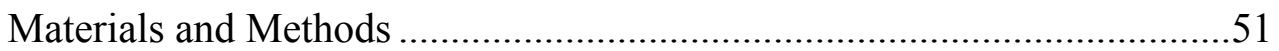

ZFN Design and Construction ......................................................51

Production of CMAH Small Donor DNAs...........................................51

Transfection of CMAH Donor DNAs and ZFNs ...............................53

DNA Isolation and Quantitative real-time PCR .................................53

TALEN Design and Construction..................................................55

Targeting Vector Construction and Production of Small Donor DNAs .55

Preparation of Porcine Fibroblast Cells and Culture Conditions............58

Transfection of Donor DNAs and TALENs Plasmids..........................58

Screening and Analysis of Knock-out Cells and Pigs .........................59

Somatic Cell Nuclear Transfer (SCNT) ...........................................62

RNA Isolation and real-time RT-PCR ..............................................63

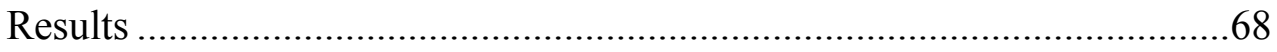

Effects of the Homology Length of Donor DNA in ZFN-Mediated Gene

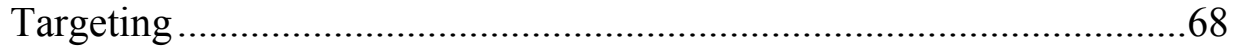

Effects of the Homology Length of Donor DNA in TALEN-Mediated Bi-allelic Modifications ......................................................................68

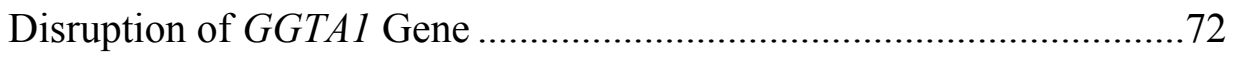


Production of Bi-allelic GGTA1 Knock-out Miniature Pigs in a CMAH-

Decreased transcript level of H-D and Tn-related Genes in $C M A H$ and GGTA1 DKO Pig Cells....

Discussion

IV. CRISPR/CAS9-MEDIATED GENE STACKING/GENE TARGETING PRODUCES SWINE WITH HIGH UBIQUITOUS EXPRESSION OF HUMAN CD55 AND HIGH ENDOTHELIAL-SPECIFIC EXPRESSION OF HUMAN CD39

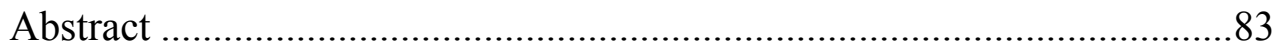

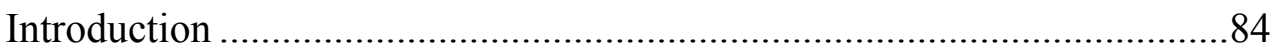

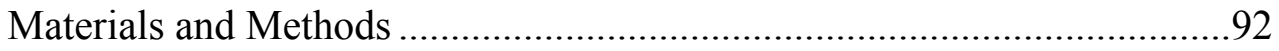

Targeting Vector Construction .....................................................92

Design and Construction of CRISPR/gRNA Expression Vectors ..........94

Preparation of Porcine Fibroblast Cells and Culture Conditions............97

Transfection of Targeting Vector and PhiC31/attB CRISPR Expression

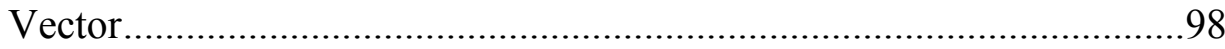

Transfection of Targeting Vector and GGTA1 CRISPR Expression

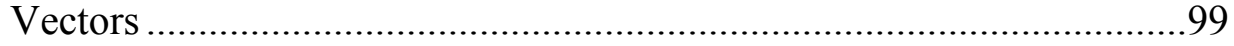

Screening and Analysis of Knock-out Cells and Pigs .........................99

Cre/loxP-Mediated Excision of Selectable Marker..............................101

Somatic Cell Nuclear Transfer (SCNT) ..........................................102

RNA Isolation, Reverse Transcriptase, and PCR Analysis of $h C D 39$

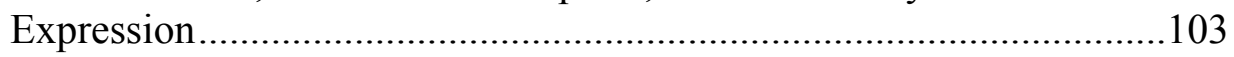

Characterization of $h C D 55$ and $h C D 39$ Ectopic Expression................104

Results .104

CRISPR/Cas9-Mediated Gene Stacking/Knock-in into PhiC31 attB ..104

CRISPR/Cas9-Mediated Gene Targeting into GGTA1 .......................108 
Production of Gene-Stacked / Gene-Targeted Fetus and Pigs Through

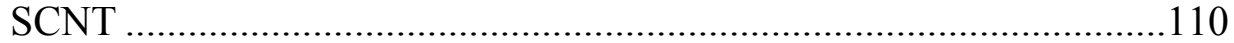

Transcript Expression of $h C D 39$ in GGTA1 Targeted Pig Tissues ......115 Immunohistochemistry - Cell Surface Expression of $h C D 39$ and $h C D 55$ in GGTA1 Targeted Pig Organs ...........................................................115

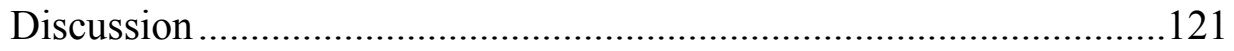

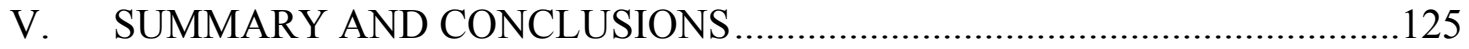

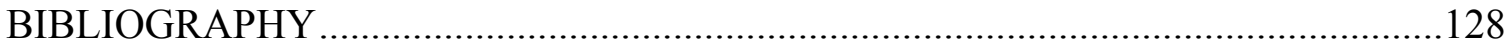

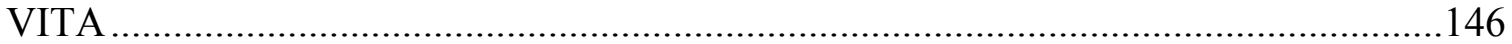




\section{LIST OF FIGURES}

FIGURE

PAGE

1. Strategy To Sequentially Stack Transgenes In A Site-Specific Manner Through

The Use Of A Dual Recombinase-Mediated Gene Stacking System.... .23

2. Site-specific integration of PhiC31 att $\mathrm{P}$ into preintegrated chromosomal att $\mathrm{B}$....27

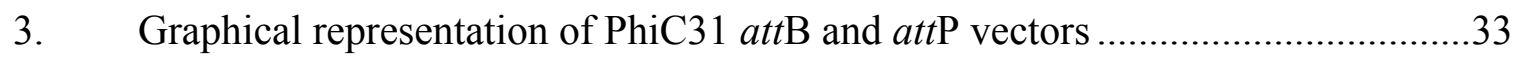

4. Determination of the culture temperature and the DNA ratios of PhiC31 integrase

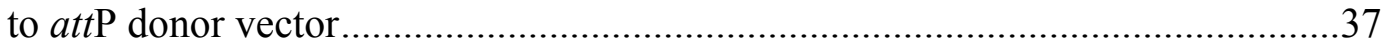

5. Designed ZFN and comparison of Donor DNA homology length ......................65

6. Designed TALENs and comparison of homology length of Donor DNA....... 66-67

7. Targeting of GGTA1 locus via TALENs and varying lengths of Donor DNA 70-71

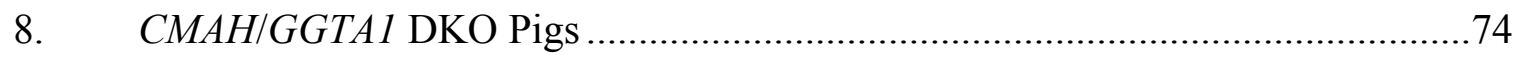

9. Sialyltransferase gene expression levels in control, biallelic $C M A H \mathrm{KO}$, and biallelic $C M A H$ and GGTA1 DKO pigs $77-78$

10. Graphical representation of PhiC31 attB specific CRISPR/Cas9-mediated gene targeting

11. Graphical representation of GGTA1 EcoRV specific CRISPR/Cas9-mediated gene targeting ...... 90-91

12. CRISPR/Cas9-Mediated Gene Stacking/Targeting into the unique PhiC31 attB previously targeting into the GGTA1 locus 106-107

13. CRISPR/Cas9-Mediated Gene Targeting the unique EcoRV site on exon 9 of the GGTA1 locus

14. GGTA1 $1^{\mathrm{IRES}-\mathrm{Neo} ; \text { PGK-Hygro; CAG- } h C D 55 ; \text { Tie2-hCD39/+ }}$ Pigs. 113-114

15. Reverse Transcriptase PCR Analysis of Tie2-hCD39 Transgene Expression.....116

16. Representative immunohistochemistry analysis of human CD55 and human CD39 expression 117-120 


\section{LIST OF TABLES}

TABLE

PAGE

1. The Basic Steps Needed to Perform Irreversible Gene Stacking .........................28

2. Results of Cre-loxP-Mediated Deletion of a Selectable Marker............................44

3. Primer sets used to generate small $C M A H$ donor DNA with minimal homology length in ZFN-mediated gene targeting .....................................................5

4. $\quad$ Primer sets used for genotyping $C M A H \mathrm{KO}$ cells and pigs..............................54

5. Primer sets used for donor DNA with minimal homology length in the TALEN

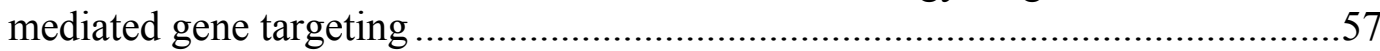

6. Primer sets used for screening and genotyping GGTA1 KO cells and pigs..........61

7. Primer sets used for detection of sialyltransferases mRNA expression ...............64

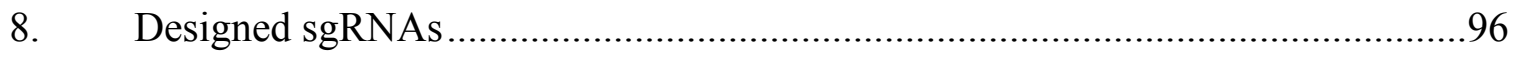

9. Cloned fetus produced following SCNT on gene-stacked cells ........................111

10. Cloned piglets following SCNT on gene-targeted cells ................................112 


\section{LIST OF ABBREVIATIONS}

\begin{tabular}{|c|c|}
\hline$a t t \mathrm{~B}$ & attachment Bacteria \\
\hline att $\mathrm{L}$ & attachment Left \\
\hline att $\mathrm{P}$ & attachment Phage \\
\hline$a t t \mathrm{R}$ & attachment Right \\
\hline BES & $\begin{array}{l}\text { N,N-Bis(2-hydroxyethyl)-2- } \\
\text { Aminoethanesulfonic Acid }\end{array}$ \\
\hline$C M A H$ & $\begin{array}{l}\text { Cytidine Monophosphate-N- } \\
\text { Acetylneuraminic Acid Hydroxylase }\end{array}$ \\
\hline CRISPR & $\begin{array}{l}\text { Clustered Regularly Interspaced Short } \\
\text { Palindromic Repeats }\end{array}$ \\
\hline $\mathrm{DC}$ & Direct Current \\
\hline DKO & Double Knockout \\
\hline DMEM & Dulbecco's modified Eagle's medium \\
\hline DMSO & Dimethyl Sulfide \\
\hline DSB & Double-Strand Breaks \\
\hline FACS & Fluorescence-Activated Cell Sorting \\
\hline FBS & Fetal Bovine Serum \\
\hline Gal & $\alpha-1,3$-Galactose \\
\hline GGTA1 & $\alpha-1,3$-Galactosyltransferase \\
\hline H-D & Hanganutziu-Deicher \\
\hline
\end{tabular}




\begin{tabular}{|c|c|}
\hline HAR & Hyper Acute Rejection \\
\hline HR & Homologous Recombination \\
\hline IRES & Internal Ribosome Entry Site \\
\hline $\mathrm{KO}$ & Knockout \\
\hline MCS & Multiple Cloning Site \\
\hline NEB & New England Biolabs \\
\hline NHEJ & Non-Homologous End Joining \\
\hline NSRRC & $\begin{array}{l}\text { National Swine Resource and Research } \\
\text { Center }\end{array}$ \\
\hline PAM & Protospacer adjacent motif \\
\hline PCR & Polymerase Chain Reaction \\
\hline PIPES & 1,4-Piperazinediethanesulfonic acid \\
\hline RDA & Rural Development Administration \\
\hline RT-PCR & $\begin{array}{l}\text { Reverse Transcriptase Polymerase Chain } \\
\text { Reaction }\end{array}$ \\
\hline SCNT & Somatic Cell Nuclear Transfer \\
\hline $\operatorname{sgRNA}$ & Single Guide RNA \\
\hline TALENs & $\begin{array}{l}\text { Transcription Activator-Like Effector } \\
\text { Nucleases }\end{array}$ \\
\hline $\mathrm{TF}$ & Thomsen-Friedenreich \\
\hline WT & Wild-Type \\
\hline ZFN & Zinc-Finger Nucleases \\
\hline
\end{tabular}




\section{CHAPTER I}

\section{INTRODUCTION AND LITERATURE REVIEW}

\section{Introduction}

Since the 1980's, techniques have rapidly developed and provided improved platforms for the generation of transgenic animals. These techniques provide for the accurate manipulation of endogenous and exogenous genes. For an animal to be considered transgenic (genetically modified), its genome must be altered to contain exogenous DNA or an applied modification to the endogenous genome. The term "transgenic" was first described by Gordon and Ruddle (1981) in experiments to generate genetically modified mice. The relative ease of transgenesis and the available techniques used to perform genetic engineering has allowed for its successful use. However, while the manipulation of a genome has become more efficient, recent efforts have been made to control for the site-specific integration of transgenes.

Performing genetic modifications without control for the site of integration can result in expression variation, both level and/or cell variegation. In an attempt to overcome position effects related to transgene expression, investigators have tried to optimize the transgene design as well as the site of integration. With the recent discovery and development of programmable nucleases, the scenario is likely to change dramatically and the generation of transgenic animals by using random methods of 
integration may become obsolete. The ability to remove the uncertainty surrounding random insertion of transgenes will allow for planning of transgene insertion into preselected genomic sites, such as potential "safe-harbors" within the hosts' genome.

\section{Brief History of Pig Transgenesis}

Animal models are commonly used for the studies of science (genetics, physiology, diseases), agriculture (feed efficiency, growth rate, disease resistance), and health (xenotransplantation, pharmaceuticals). Due to their short generation interval, size, and housing cost, rodents, Drosophila melanogaster, and Caenorhabditis elegans are the favored models used for the study of health and science. However, there are distinct anatomical and physiological differences between these models and humans that could inhibit the direct application of gained knowledge to human medicine. Pigs are seen as a potential model in which direct application of gained knowledge can be applied to humans. In many respects pigs are similar to humans physiologically and anatomically, dependent upon age and/or breed, thus can serve as important models for the study of human health and science (Mc \& Tribe, 1954).

There are several disadvantages of using pigs as models, with the major being the relative difficulty of generating genetically modified pigs when compared to other species. The first transgenic pig was produced by pronuclear microinjection of a human growth hormone gene (Hammer et al., 1985). Pronuclear microinjection is a method that delivers exogenous DNA to the male and/or female pronucleus of a newly fertilized 
oocyte. This technique is used to facilitate gain-of-function transgenesis by the incorporation of exogenous DNA into the host genome. There are however, several disadvantages/limitations to this technology; such as random integration, mosaicism, and low efficiency $(\sim 0.5-10 \%$ of offspring are transgenic) (Pursel \& Rexroad, 1993; Clark et al., 1994).

In contrast to pronuclear injection where the resulting modifications are random insertions of exogenous DNA, sometimes a more detailed and precise modification is required. These precise modifications can be achieved with gene targeting via homologous recombination. In 1981, two groups derived pluripotent cells from the inner cell mass of mouse blastocysts (Evans \& Kaufman, 1981; Martin, 1981). The established cells became known as embryonic stem (ES) cells. ES cells have the unique ability to grow as immortal cells and maintain both a normal karyotype and an undifferentiated state. However, given the proper stimulus, ES cells can be manipulated in vitro to develop into various cells types. ES cells were first used for early development and cell lineage studies until 1984 when Bradley et al. (1984) demonstrated the ability of ES cells to transmit to the germ line of chimeric mice produced from the injection of ES cells into recipient blastocysts. Due to these characteristics, gene targeting techniques were developed and the efficacy of gene targeting was initially tested and demonstrated in ES cells. After ES cells have been genetically modified, the ES cells are injected into the blastocoel cavity of a blastocyst stage embryo. The ES cells will incorporate amongst the other cells inside the recipient blastocyst and contribute to all cell lineages, generating a chimeric animal. Since, ES cells can contribute to the germ cell population, the breeding of founder animals can lead to transmission of new genes through the germ line. 
However, germline transmission does not always occur, thus is an obvious disadvantage of this technique. Another major disadvantage is that despite considerable efforts, ES cells capable of contributing to the germline of any species, other than rodents, have not been isolated (Notarianni et al., 1991; Stice et al., 1996). Even though authentic ES cells have not been isolated from pigs, the genetic manipulation technologies and techniques developed in the mouse (Capecchi, 1989) are transferrable to pigs.

In the absence of non-murine ES cells, transgenic animal technology (excluding rodents) was hindered in other species. However, in 1996 Dolly the sheep was produced through somatic cell nuclear transfer (SCNT) (Campbell et al., 1996; Wilmut et al., 1997). Dolly was a viable lamb that resulted from the transfer of a somatic cell to an enucleated oocyte. SCNT involves the addition of a somatic cell into the perivitelline space of an enucleated oocyte. An electrical pulse was used to fuse the cell to the oocyte. Following fusion, the oocyte was activated by either electrical or chemical means to start embryo development. The embryo was then transferred into a surrogate; where the time of the transfer is in coordination with embryo development and the cycle of surrogate recipient (Campbell et al., 1996; Schnieke et al., 1997; Cibelli et al., 1998; Baguisi et al., 1999; McCreath et al., 2000; Polejaeva et al., 2000; Denning et al., 2001). The significance of SCNT is that for the first time, Campbell et al. (1996) demonstrated that NT could reset the program of a cell and generate viable offspring. This opened up the possibility of bypassing the ES cell technology. SCNT was a major scientific discovery that allowed genetic modifications to be conducted on somatic cells and subsequently used to produce transgenic animals. There are many advantages of cloning through SCNT over that of pronuclear injection and producing ES cell chimeras. The most obvious is that every cell 
of the resulting transgenic animal contains the transgene; this reduces the time involved in analysis and production of a transgenic animal, which is a major advantage when working with a species such as the pig where the interval to return offspring from the birth of the founder animals is $12-16$ months. However, there are also many pitfalls associated with this technology. In particular, efficiency of cloning in livestock species is low due to high embryo loss, developmental problems, and even post-parturition mortality.

In 1997, the first transgenic livestock produced by SCNT was a transgenic sheep that expressed human clotting factor IX in its milk (Schnieke et al., 1997). In 2000, SCNT was combined with gene targeting in sheep. The resulting animals contained a targeted knock-in of a therapeutic transgene into the ovine alpha-I procollagen locus (McCreath et al., 2000). The first reports of pigs with targeted genetic modifications to knockout an endogenous gene were published in 2002 (Dai et al., 2002; Lai et al., 2002). The resulting pigs lacked one functional copy of a gene encoding for alpha1,3-galactosyl residue on the surface of pig cells. These pigs were designed for potential use in pig-tohuman xenotransplantation.

Reports about other transgenic pigs with specific genetic modifications for various purposes have followed. For the study of human diseases, genetically modified pigs have been generated to model cystic fibrosis (Rogers et al., 2008). These pigs possessed a synonymous mutation of the cystic fibrosis transmembrane conductance receptor gene. As the mouse model does not recapitulate the human phenotypic defects, these pigs are a better model to aid in the discovery of a cure for the disease (Grubb \& Boucher, 1999). For the study of animal agriculture, pigs have been produced that 
express polyunsaturated fatty acids (Saeki et al., 2004; Lai et al., 2006). These pigs contain fatty acid desaturases, enzymes that are normally not expressed in mammals, and as a result have higher polyunsaturated fatty acid content in their bodies. The meat from these pigs would be considered healthier as meats that are high in polyunsaturated fatty acids are recognized as having health benefits in reducing the incidences of coronary artery disease and diabetes (Dyerberg \& Bang, 1979; Kinsella et al., 1990). There have even been reports of pigs that can be used to produce recombinant proteins important for human medicine, such as erythropoietin - a glycoprotein used to treat erythropoietinrelated anemia (Park et al., 2006).

It is easy to recognize that genetically modified pigs can be valuable in many fields. However, the number of transgenic pigs that have been produced, in comparison to mice, is limited due to the difficulties associated with their production. Thus advances in transgenic pig production are needed to better utilize pigs as a model organism.

\section{Gene Targeting}

In 1980, the first description of a "transgenic" animal produced by injected foreign DNA into the pronuclei of mouse zygotes was reported (Gordon \& Ruddle, 1981). This was followed by the generation of the first transgenic livestock in 1985 (Hammer et al., 1985). A major limitation in the generation of the first transgenic animals was random integration of exogenous DNA that resulted in unpredictable transgene 
expression (Clark et al., 1994; Bonifer et al., 1996). In an attempt to overcome these position effects and to direct specific genetic modifications, gene targeting was developed. In addition, several applications can utilize gene targeting: 1) the precise integration of a functional foreign gene into a chosen genomic region (gene knock-in), 2) the replacement of an allele by another allele (point mutagenesis), and 3) the replacement of a gene by a nonfunctional DNA sequence leading to the inactivation of the targeted gene (gene knockout).

Gene targeting was initially discovered in mammalian cells after integration of plasmid DNA in the cells occurred (Folger et al., 1982). Shortly thereafter, another group reported gene targeting of an endogenous gene in mammalian cultured cells; thus proving gene targeting is possible (Smithies et al., 1985). It was later determined that mammalian cells contain an enzymatic machinery that mediates homologous recombination (HR). HR is the process that mediates gene targeting.

Homologous recombination is the exchange of homologous sequence between two DNA molecules. This is a natural phenomenon during meiosis and mitosis when the exchange of genetic information between complementary DNA strands occurs. HR was first identified in a mutant Escherichia coli strain (Clark \& Margulies, 1965). HR is present in many species and is involved in many cellular mechanisms (Heyer et al., 2010). HR is a critical activity that is involved with the exchange of information between maternal and paternal alleles to provide genetic diversity. During mitosis, HR's main function is to provide genome stability and repair damaged DNA during replication or damage incurred from exogenous stress (Takata et al., 1998). 
Even though mammalian cells have the cellular machinery to direct exogenous DNA into an endogenous target site, it is known that the exogenous DNA is also inserted into random sites within the host genome by non-homologous recombination. It has been estimated that random integration occurs approximately 30,000 - 40,000 times more frequently than HR (Brinster et al., 1989; Hasty, Rivera-Perez, Chang, et al., 1991) and the efficiency of gene targeting is approximately $1 \times 10^{-6}$ (Reid et al., 1991; Templeton et al., 1997). Gene targeting is an extremely rare event, due in part to the need for a double strand break (DSB) where the desired exogenous DNA is to be inserted.

Strategies to increase gene targeting efficiency begin with the construction of a gene targeting vector. A targeting vector is designed to have homologous arms that flank an extrinsic sequence (transgene, subtle mutation). Generally, the targeting arms range in length of $1-6 \mathrm{~kb}$ and the length of contiguous sequence identity has been shown to be a major determinant in HR efficiency (Waldman \& Liskay, 1988). Additionally the efficiency of HR is correlated with the length of homology; therefore as homology length increases so does gene targeting efficiency. It should also be noted that successful HR has been reported by using less than $0.5 \mathrm{~kb}$ of homology per arm (Hasty, Rivera-Perez, \& Bradley, 1991).

Additional approaches have been developed to enhance for the isolation of targeted clones; positive selection, negative selection, and trapping endogenous elements. Positive selection utilizes a marker, such as a drug resistant gene to facilitate the isolation of targeting events. The addition of a positive selection marker provides enrichment towards isolating cells that contain the targeting construct, allowing only cells that express the marker to grow under selection. However, a standard positive selection 
cassette does not differentiate a targeting event from a random integrant. Another enrichment strategy uses the addition of a negative selectable marker, such as Thymidine Kinase or Diphtheria Toxin (Yagi et al., 1990). The negative marker flanks one of the homology arms and provides selection against random integrants by inducing death of such cells. Since the negative marker does not integrate during homologous recombination, cells that have undergone a targeting event remain alive. The simultaneous use of both positive and negative selection strategies is referred to as positive-negative selection (Mansour et al., 1988).

Some other strategies attempt to "trap" functions that are provided by the endogenous gene but are omitted from the targeting vector (promoter trap, poly (A) trap, etc.). In the strategy of a promoter trap, the selectable marker gene will only be expressed if inserted in the correct orientation relative to the promoter of an endogenous gene, thereby substantially reducing the number of random integrations recovered after positive selection (Doetschman et al., 1988). This strategy has yielded an estimated enrichment of 20 - 120 fold when compared to a selectable marker that contains its own promoter. However, there are some potential problems with this technique. There is still the possibility that the targeting construct will randomly insert into another active gene; therefore the selectable marker is still expressed. In addition, only actively transcribed genes are available for gene targeting by using this method. To allow for the translation of a selectable marker without a promoter, an internal ribosomal entry site (IRES) can be inserted upstream of the selectable marker. An IRES is found in picornaviruses, such as encephalomyocarditis virus and foot-and-mouth disease virus and is responsible for the initiation of mRNA translation (Macejak \& Sarnow, 1991). In the context of a transgene, 
an IRES is located $5^{\prime}$ of the initiation codon and initiates translation of the subsequent coding sequence following the IRES sequence.

The poly(A) trap enrichment can be useful in targeting non-expressing genes as this method relies on the integration site providing the poly(A) signal for the positive selectable marker gene (Thomas \& Capecchi, 1987). This strategy has yielded an increase in enrichment of $2-5$ fold. Due to the limited increase in efficiency, this enrichment strategy is not used as frequently as other enrichment strategies (Jasin \& Berg, 1988; Waldman \& Liskay, 1988; Sedivy \& Sharp, 1989). Enrichment strategies can be combined, but the combination does not always further increase enrichment (Beaton et al., 2013). Although various strategies have been developed to screen for cells with targeted insertion of exogenous DNA, an effective method is still needed to promote gene targeting.

\section{Programmable Nucleases}

Given that gene targeting is an extremely rare event, several groups have tried various strategies to increase the efficiency of HR. The most promising of those strategies was through the use of "molecular scissors". The basic concept is that an endonuclease can be site-specifically directed and produce a DSB in the targeted DNA location. This was first shown using the yeast I-SceI meganuclease, where it was demonstrated that DSBs within the targeted region of the target gene is compatible with efficient HR (Rouet et al., 1994). In various species, the rate of HR has increased to $1-$ 
$18 \%$ events per mammalian cell when targeted a DSB was introduced when compared to $0.000001 \%$ (a one in a million) HR events without the use of any molecular scissor (Smih et al., 1995).

Currently, there are three major meganuclease methodologies that are currently and successfully being used to make genetic modifications. These approaches are zincfinger nucleases (ZFNs) (Hauschild et al., 2011; Whyte et al., 2011; Yang et al., 2011), transcription activator-like effector nucleases (TALENs) (Carlson et al., 2012; Tan et al., 2013; Lee et al., 2014), and CRISPR/Cas9 (Tan et al., 2013; Whitworth et al., 2014). ZFNs and TALENs both consist of a non-specific cleavage domain of FokI endonuclease with a zinc finger domain (specific DNA binding zinc fingers) or transcription activatorlike effectors (TALEs) specific to a target DNA sequence, respectively. The

CRISPR/Cas9 system is a nuclease guided by a short RNA that pairs with the target DNA. Once paired the Cas9 enzyme cleaves both strands of DNA creating a DSB (Jinek et al., 2012). All of these approaches induce DSBs at predetermined locations within the host genome. This genomic breakage can be repaired imprecisely by non-homologous end joining (NHEJ) to generate random mutations or can be repaired precisely when exogenous donor DNA is template for HR (Gaj et al., 2013).

\section{Recombinase-Mediated Exchange}

Site-specific recombination systems mediate control of a variety of biological functions by catalyzing precise excision, inversion, or integration of defined DNA 
fragments. Due to the accuracy of recombination and relative simplicity of use, sitespecific recombination systems have been the focus of studies in plants, flies, and mice. These systems are generally denoted by the name of recombinase protein, followed by the name of the DNA recognition sequence. Two of the most widely used site-specific recombination systems for eukaryotic applications are Cre/loxP from bacteriophage P1 (Sternberg et al., 1981) and FLP-FRT from the $2 \mu$ plasmid of Saccharomyces cerevisiae (Andrews et al., 1985). Both of these recombinases belong to the tyrosine recombinase family and can be used to promote DNA integration events, but deletion events are kinetically favored and thus are commonly used for the deletion characteristic in many genetic engineering strategies. In contrast, the serine recombinase family is solely devoted to DNA integration. The most widely used member of this family is PhiC31 (Thorpe \& Smith, 1998).

All three of these systems are characterized by their ability to function independently of DNA topology, through the interaction of a single recombinase with a pair of specific recognition sites. In the case of loxP and FRT, the recombination site required on both DNA substrates is a 34 bp palindromic sequence comprised of $13 \mathrm{bp}$ inverted repeats surrounded by an 8 bp asymmetric spacer region that confers directionality to the site and thus to the recombination reaction. In contrast to identical recombination target substrates of the Cre-loxP and FLP-FRT systems, the PhiC31 system recognizes non-identical att $\mathrm{B}$ (attachment $\underline{B}$ acteria) and attP (attachment Phage) sequences and upon recombination generates two new sites denoted att $\mathrm{L}$ (att Left) and att $\mathrm{R}$ (att Right). The newly generated sites are chimeric compositions of att $\mathrm{P}$ and at $\mathrm{B}$ sites. Thus, att $\mathrm{P}$ and $a t \mathrm{~B}$ are destroyed upon recombination and cannot further serve as 
substrates for the PhiC31 recombinase. This type of specificity and unidirectionality allow for the PhiC31 system to be used as a tool for site-specific genome manipulations.

Orientation of the loxP and/or FRT (loxP / FRT) sites determines the outcome of the recombination event in that the loxP / FRT sites oriented in the same direction on a chromosomal segment result in a cyclization; excision of one of the loxP / FRT sites and the sequence that lies in between the two sites. Alternatively, two lox / FRT sites oriented in opposite directions on a chromosomal segment result in an inversion of the intervening segment upon Cre / FLP-mediated recombination, respectively. loxP / FRT sites in the same orientation are commonly used to generate removable gene disruption cassettes as well as deletions of chromosomal segments for analysis of gene function in a variety of organisms by gene-targeting methods to flank a gene or promoter elements with loxP / FRT sites (Sauer, 1987; Orban et al., 1992). Since the gene encoding Cre and/or FLP recombinase, is not found in eukaryotes, engineered regulation of transgenic expression enables this system to delete sequences flanked by loxP / FRT sites, in an inducible as well as temporal- and tissue-specific manner. In traditional gene targeting, a selectable marker remains in the targeted genome. Site-specific recombination systems have been used to remove the selectable marker after an insertion event (Meyers et al., 1998; Nagy et al., 1998). The removal of a selectable marker is advantageous for two main reasons: 1) to circumvent any concerns that the presence of a selectable marker cassette may affect the expression of neighboring genes (Fiering et al., 1995), and 2) to "recycle" the original targeting vector (or the marker gene contained within it) to create a homozygous $\mathrm{KO}$ cell line. In the case of Cre-loxP mediated deletion, the vector must be designed to include lox $\mathrm{P}$ sites that flank the selectable marker. 
Utilization of a recombinase to stack genes as part of mammalian transgenesis could improve the ability to predict transgene expression as well as provide a means to link multiple transgenes. This strategy requires that a chromosomal location be known to facilitate appropriate transgene expression levels for the transgene promoter of interest and that the target locus is "tagged" with an appropriate recombination sequence. The PhiC31 integrase for example is a site-specific recombinase that normally performs precise, unidirectional recombination between two aforementioned attachment sites. Keravala and Calos (2008) demonstrated that when an attP site is pre-integrated into a mammalian chromosome it can serve as a target for integration of an introduced plasmid carrying an attB site. Once recombination occurs, it leads to the precise integration of the att $\mathrm{B}$ plasmid into the chromosome at the att $\mathrm{P}$ site and will provide a high net efficiency of net integration. Previous work by the Calos lab showed that the PhiC31 integrase works in humans, mice, and Drosophila (Groth et al., 2000; Olivares et al., 2001; Thyagarajan et al., 2001; Groth et al., 2004; Bertoni et al., 2006; Chalberg et al., 2006; Fish et al., 2007). In principle, site-specific integration can be used to deliver a second transgene next to a previously inserted transgene; therefore genetically linking the transgenes. To enable this process the first transgene would have to include an appropriate recombination site and retain the ability to add additional transgenes, and each new transgene must contain an appropriate recombination site. 


\section{Transgene Design}

Animal transgenesis is used to create models for multiple purposes: 1) the study of gene function, 2) modify organs and tissues for xenotransplantation, 3) prepare recombinant proteins, and 4) improve animal production characteristics (Wheeler \& Walters, 2001). In general, the addition of genes is required to yield the desired phenotype. This requires the ability to control transgene expression. However, gene targeting and targeted mutation, which includes gene knockout and gene knock-in, is becoming more common as techniques to provide the desired phenotype. From the earliest gene transfer studies; it became apparent that expression of transgenes from randomly integrated transgenes was variable between different lines of transgenic animals. The variability had an effect on the desired level, location, and/or timing of expression.

In general, a transgene expression cassette is designed to contain all of the necessary components of a functional gene. The minimum requirements to construct a transgene include three main components: 1) a promoter, with the purpose to facilitate the transcription of the transgene, 2) a region of DNA that encodes the desired gene product, with the most common form being generated from cDNA (complementary DNA that has been synthesized from messenger RNA), and 3) a termination signal, which terminates translation of the transgene. These three components are the minimal requirements for a transgene.

Beyond the minimum requirements of a transgene several approaches have been explored to improve the expression of transgenes, such as to: add known regulatory 
elements that favor transcription; use genomic DNA fragments expected/known to contain most of the transcriptional regulatory elements; target an endogenous gene known to favor the desired transgene expression. Included within these major approaches, are some "rules" in regard to obtaining efficient and desired transgene expression. These rules include and/or are related to: the addition of introns, optimization of the transcribed region, addition of insulators, and control of transgene expression by exogenous inducers.

The inclusion of introns in the transgene construct has been shown to increase the levels of transgene expression dramatically (Brinster et al., 1988). The mechanism for the increased expression is not entirely known, but it has been proposed that at least one intron is required to favor the transfer of mRNA to the cytoplasm and/or introns of many genes contain binding sites for transcription factors and thus aid in transgene expression. It appears that the location of intron(s) is desired before the coding region, but it should also be noted that the addition of intron(s), no matter the location, is advantageous (Chang et al., 2007). The structure of the gene or coding region can also have an effect on gene expression; there have been several studies to demonstrate that higher levels of gene expression can be obtained with genomic DNA than that of those obtained with cDNA (Brinster et al., 1988). This makes sense, as the transcribed regions of genes contain multiple signals that control mRNA translation and stability (Beelman \& Parker, 1995; Chkheidze et al., 1999; Knirsch \& Clerch, 2000). Additionally, the introns included in the transgene need not necessarily be derived from the gene of interest as expression from transgenes can be subsequently enhanced by the inclusion of heterologous introns in the transgene cassette (Palmiter et al., 1991). 
It should also be noted that in addition to the transgene cassette design, some integration sites may partially or completely suppress transgene expression, whereas other sites may actually facilitate expression (Clark et al., 1994; Bonifer et al., 1996). In addition to mis-regulated expression, in some cases the loss in function of an endogenous gene occurs. In this instance, the sites of integration could knockdown or $\mathrm{KO}$ an important regulatory gene that is required for development, for example, mice resulting in male sterility (Magram \& Bishop, 1991; Walters et al., 2009). In addition, multiple copies of the transgene, even in tandem, may be less efficiently transcribed than if a single copy is inserted (Garrick et al., 1998). It should also be noted that transgene expression is not necessarily transferrable from cultured cells to transgenic animals. In some instances, transgenes are expressed in cultured cells, but not in the transgenic animals. Dependent upon the regulatory elements (i.e., cell specificity), the reverse is generally not true, an active transgene that is expressed in an animal is generally expressed in cultured cells.

\section{Dissertation Objectives}

The overall objective of this dissertation is to develop an efficient method(s) to sequentially stack multiple transgenes into a single target site, inherently genetically linking multiple modifications. The main objectives addressed herein are in relation to swine genetic engineering, but could be applied to other species, and are as follows: 1) to 
evaluate the PhiC31 Recombinase system as a strategy to sequentially stack transgenes into a preselected $a t t \mathrm{~B}$ site, 2) to evaluate the effect of donor DNA homology length on the outcome of nuclease-mediated gene targeting, 3) to evaluate the clustered regularly interspaced short palindromic repeats (CRISPR)/ CRISPR associated protein 9 (Cas9) (CRISPR/Cas9) system as a tool to mediate gene stacking and gene targeting, and 4) to examine the functionality and expression of transgenes in a multi-transgenic pig. 


\section{CHAPTER II}

\section{COMPOUND TRANSGENICS: RECOMBINASE-MEDIATED GENE STACKING}

Reference: Beaton BP and Wells KD. (2014) Compound Transgenics:

Recombinase-Mediated Gene Stacking. In CA Pinker (Ed.), Transgenic Animal Technology $3^{\text {rd }}$ Edition (p.565 - 578). Waltham, MA: Elsevier. 


\section{INTRODUCTION}

Genetic engineering technologies have matured to a point where there are no technological barriers that differentiate mammalian models, from mice to pigs, in regard to the types or extent of genetic modifications that can be accomplished. Due to the physiological and anatomical similarities between pigs and humans, it is likely that pigs will continue to increase in importance as a biomedical model for both discovery and for clinical trials. However, due to timeline differences between mice and pigs associated with development and generation interval, genetic engineering in swine requires special consideration for the impact of genetic engineering strategies on future logistics and costs. This consideration is particularly important in regard to maintenance and propagation of animals with multiple genetic modifications.

For example, suppose that a project required four genetic modifications, and for breeding purposes, suppose that these modifications needed to be in a homozygous state. Further, suppose that for each transgene a particular range of transgene expression is acceptable. This scenario is likely to be required for xenotransplantation (Zhou et al., 2005) or for engineered biosynthetic pathways (Rees et al., 1990). One strategy could involve cointegration of all four transgenes through random concatenation and integration via pronuclear microinjection or transfection of cultured cells followed by somatic cell nuclear transfer (SCNT). However, this strategy relies on the assumption that a sufficient number of founder animals could be produced to identify an individual animal that has acceptable levels of expression of each of the four transgenes. Although this strategy is technically possible, it does not appear likely that success would be guaranteed within the 
scope of most budgets. For those projects in which all four of the transgenes require expression in the same cell type, it may be possible to develop screening methods for expression in cultured cells prior to SCNT to enrich for founders that provide appropriate expression of the transgenes. However, when expression of the transgenes is required in separate cell types or when the target cell type cannot be cultured, this strategy is not feasible. Yet when this strategy is successful, all of the transgenes are genetically linked and will be inherited as a single linkage group: an animal that inherits one transgene inherits all transgenes.

A second strategy may be to produce founder animals in a stepwise progression, such that each transgene is added individually and a founder with acceptable expression is selected as the genetics for the next step. In the end, it is likely that a combination of transgene integrations could be obtained that provided an appropriate expression pattern and level for each transgene. However, upon propagation of this genotype, each transgene would segregate independently. In an outcross between a wild-type animal and a founder that is hemizygous for four transgenes, only $1 / 16$ of the progeny would inherit all four transgenes based on Mendelian inheritance and independent assortment. Although this proportion of the progeny may be acceptable in mice for some projects, it will rarely be practical in swine. However, the scenario at hand supposes that each transgene needs to be rendered homozygous. Upon breeding of two animals that carry all four transgenes in a hemizygous state, only $1 / 256$ of the progeny are expected to harbor all four transgenes in a homozygous state. It does not seem likely that independent integration would be a feasible approach for most goals. Similar issues arise if a viral-, retroviral-, or transposon-based strategy is selected. 
A third approach, and the interest of this chapter, would be a stepwise strategy that placed each new transgene adjacent to the previous transgene(s) such that each modification becomes genetically linked to all previous modifications. At each step, the additional transgene could be evaluated for expression and impact on previously inserted transgenes. Each new transgene could be modified for increased or decreased expression as well as genetically insulated when transgenes were found to interact in an unwanted way. In the end, transmission of the desired genotype in a wild-type cross would be to one-half of the progeny. Upon breeding of two hemizygous animals, one-quarter of the progeny would be expected to be homozygous. These efficiencies are comparable to single gene modifications and are therefore well within the realm of feasibility.

Currently, there are two methods that can enable this third strategy of stacking each transgene within a previously selected locus. The first strategy would be through the use of homologous recombination. The second strategy would be through the use of a site-specific recombinase. This chapter describes a methodology for the use of bacterial recombinases for transgene stacking. In addition, the project described here combines gene stacking with gene targeting such that a series of transgenes will be placed within a disrupted locus, alpha-1,3-galactosyltransferase (GGTA1) (Figure 1). 
A)

Host Genomic Allele
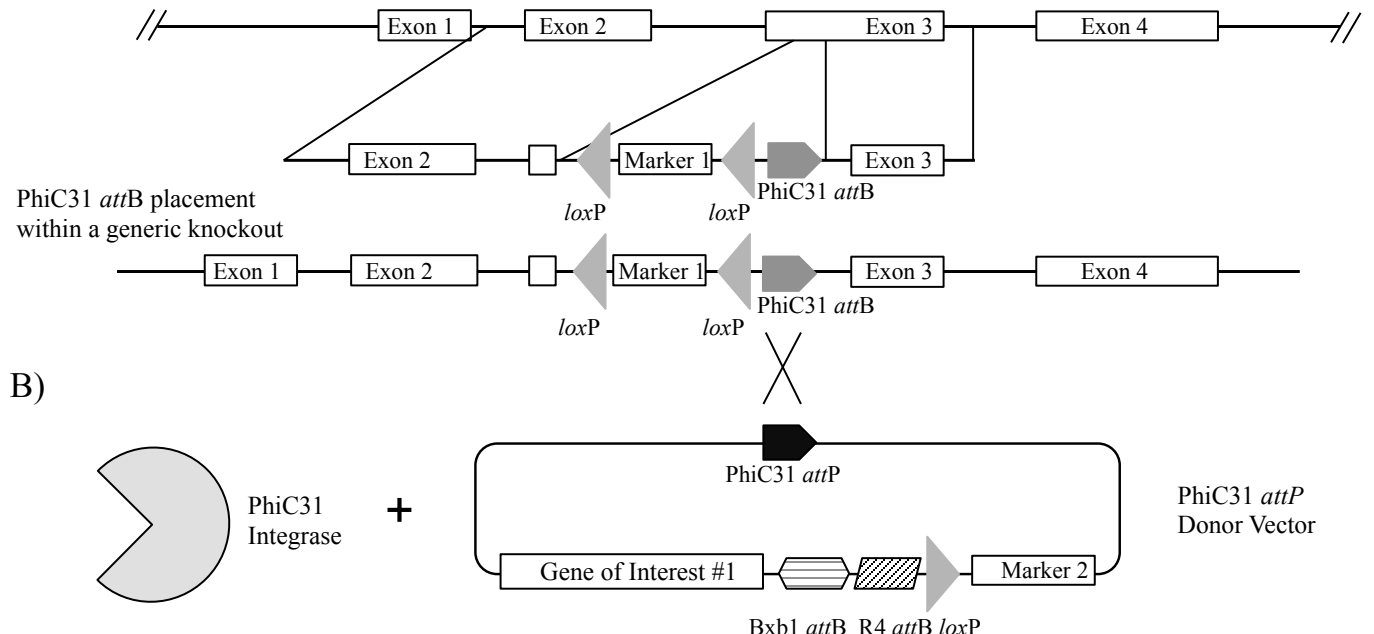

Bxb1 attB R4attB $\operatorname{lox} \mathrm{P}$

PhiC31 Mediated Allele

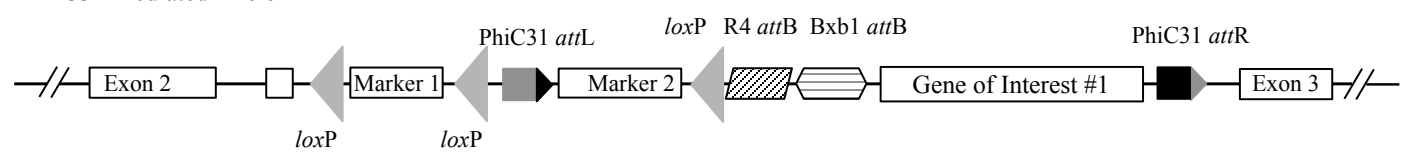

C)

PhiC31 Mediated Allele

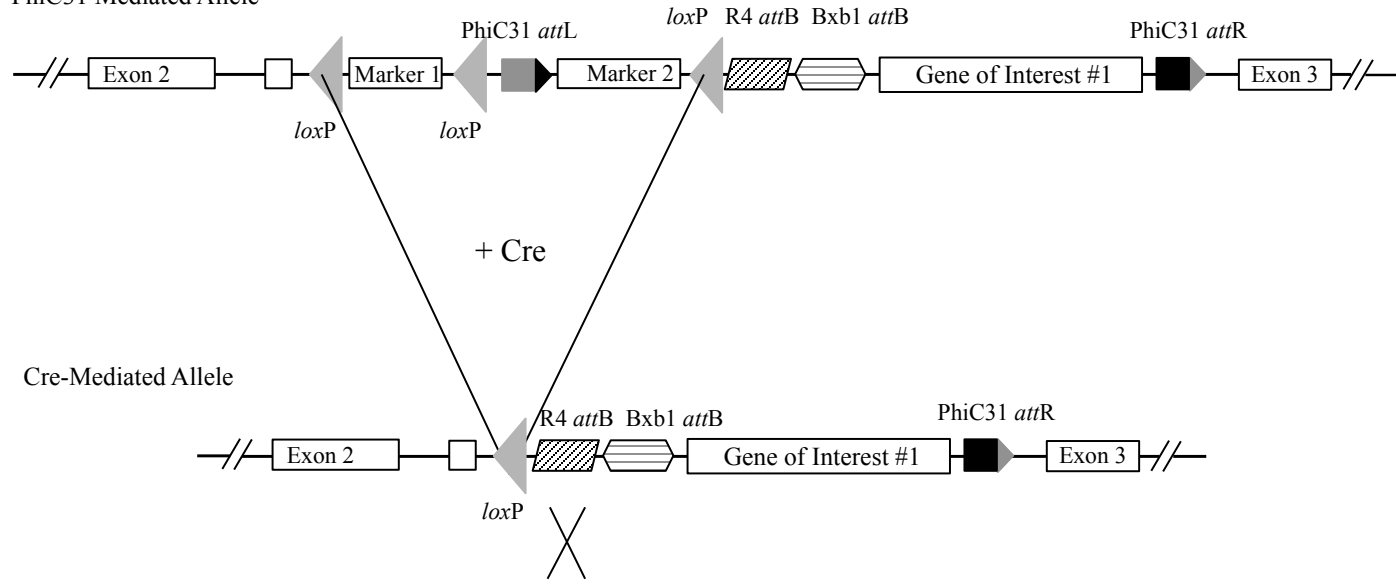

D)

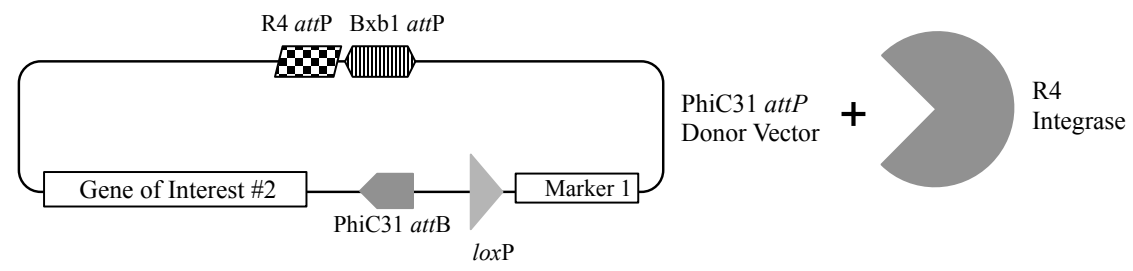

R4 Mediated Allele

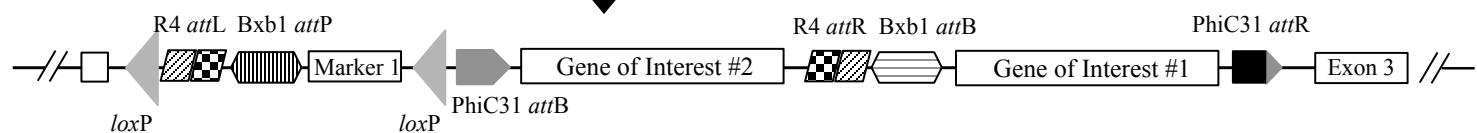


Figure 1. Strategy to sequentially stack transgenes in a site-specific manner through the use of a dual recombinase-mediated gene-stacking system.

(A) A PhiC31 attB site is inserted into the host genome, represented by site-specific integration by homologous recombination. The marker gene is flanked by lox $\mathrm{P}$ sites and will be excised at a later time by the use of Cre recombinase. (B) The PhiC31 integrase mediates recombination between the att $\mathrm{B}$ docking site (integrated into the genome) and the $a t t \mathrm{P}$ donor site (plasmid). The donor vector contains the gene of interest to be inserted, a PhiC31 att $\mathrm{P}$ site, a selectable marker, a loxP site, and two heterologous docking sites ( $\mathrm{R} 4$ at $\mathrm{B}$ and $\mathrm{Bxb} 1$ att $\mathrm{B}$ ). The PhiC31 attP site will recombine with the PhiC31 att $\mathrm{B}$ docking site that was previously inserted into the genome. The marker gene will allow for selection to isolate cells that have undergone the PhiC31 recombination event. The lox $\mathrm{P}$ site will allow the removal of unwanted DNA (vector backbone and the marker). The R4 at $\mathrm{B}$ and $\mathrm{Bxb} 1$ att $\mathrm{B}$ sites are introduced for the future addition of genes. (C) The unwanted DNA that has been introduced in (A) and (B) above can be removed using the Cre-loxP system. In the presence of Cre recombinase, sequence between lox $\mathrm{P}$ sites is excised. In this case, the two outermost lox $\mathrm{P}$ sites facilitate removal of the unwanted DNA (the two selectable markers, a PhiC31 attL site, and vector plasmid components). It should be noted that there are three possibilities for the Cre excision. In addition to the excision described previously (the first and third loxP sites), excision can also occur between the first and second loxP sites, and between the second and third lox $\mathrm{P}$ sites. Although recombination with the internal $\operatorname{lox} \mathrm{P}$ will not be the predominant recombination, screening strategies must be designed to confirm removal of all unwanted DNA. (D) Additional genes of interest can be added through the use of alternating recombinase. An R4-mediated event is depicted. The components and mechanism are the same as in (B), with the exception that the recombination att sites originate from phage R4 and the PhiC31 attB site is reintroduced for future use. Since the various phage systems do not cross-react, the different integrases can be used in any order in subsequent steps. 


\section{Gene-Stacking Strategy}

There are several recombination systems that work efficiently for genetic engineering strategies, and each has individual strengths and weaknesses. The Flp-FRT and Cre-loxP recombinase systems are reversible and thus facilitate both site-specific integration and excision (Nagy, 2000; Wang et al., 2011). However, these systems favor excision rather than insertion (Nagy, 2000; Wang et al., 2011). While some recombination systems have reversible reactions, several do not. When integration alone is the goal, recombinases that perform only the integration reaction would be advantageous. In this instance, once a transgene is integrated, the transgene cannot be excised by the recombinase alone. There are several phage integrases that have this property: PhiC31 (Groth et al., 2000), Bxb1 (Mediavilla et al., 2000; Kim et al., 2003) and R4 (Matsuura et al., 1996; Olivares et al., 2001).

Recombination by these phage integrases is carried out between two recognition sites, the bacterial attachment (attB) and phage attachment (attP) sites (Figure 2). After the reaction, the recombined attachment sites create two unique sequences/sites, attachment Left (att $\mathrm{L})$ and attachment Right (att $\mathrm{R})$ sites. The newly created $a t t \mathrm{~L}$ and $a t t \mathrm{R}$ sites are unrecognizable by the phage integrase, thus creating an irreversible integration reaction (Thorpe \& Smith, 1998; Thorpe et al., 2000). The phage integrases therefore provide an opportunity for site-specific integration without the possibility of excision by the same enzyme.

This chapter describes a gene-stacking system that uses an integrating recombinase system (PhiC31/att) for transgene insertion, and in conjunction, an excision 
favoring recombinase system (Cre-loxP) to remove DNA that becomes superfluous after integration. Although the overall strategy is likely feasible in any eukaryotic cell, this protocol references porcine fibroblasts. Methods are described to: (i) generate cells that contain a prepositioned PhiC31 attB site (PhiC31 docking site); (ii) transfect a PhiC31 expression vector and a PhiC31 attP donor plasmid (PhiC31 donor site, with transgene); (iii) remove undesirable DNA (E. coli vector backbone and selectable marker) by the Cre-loxP system; and (iv) a strategy to stack multiple genes using a dual recombinase system (PhiC31 and R4 or Bxb1). See Figure 1 for a graphical outline of the methods listed. Table 1 provides an experimental outline. 
A) attB: 5’ - GGTGCCAGGGCGTGCCC TTG GGCTCCCCGGGCGCG- 3’ attP: 5' - ccccaactggggtaacct TTG agttctctcagttggggg- 3' attL: 5' - GGTGCCAGGGCGTGCCC TTG agttctctcagttggggg - 3' attR: 5' - ccccaactggggtaacet TTG GGCTCCCCGGGCGCG - 3'

\section{B)}

Targeted Allele containing att $\mathrm{B}$ site

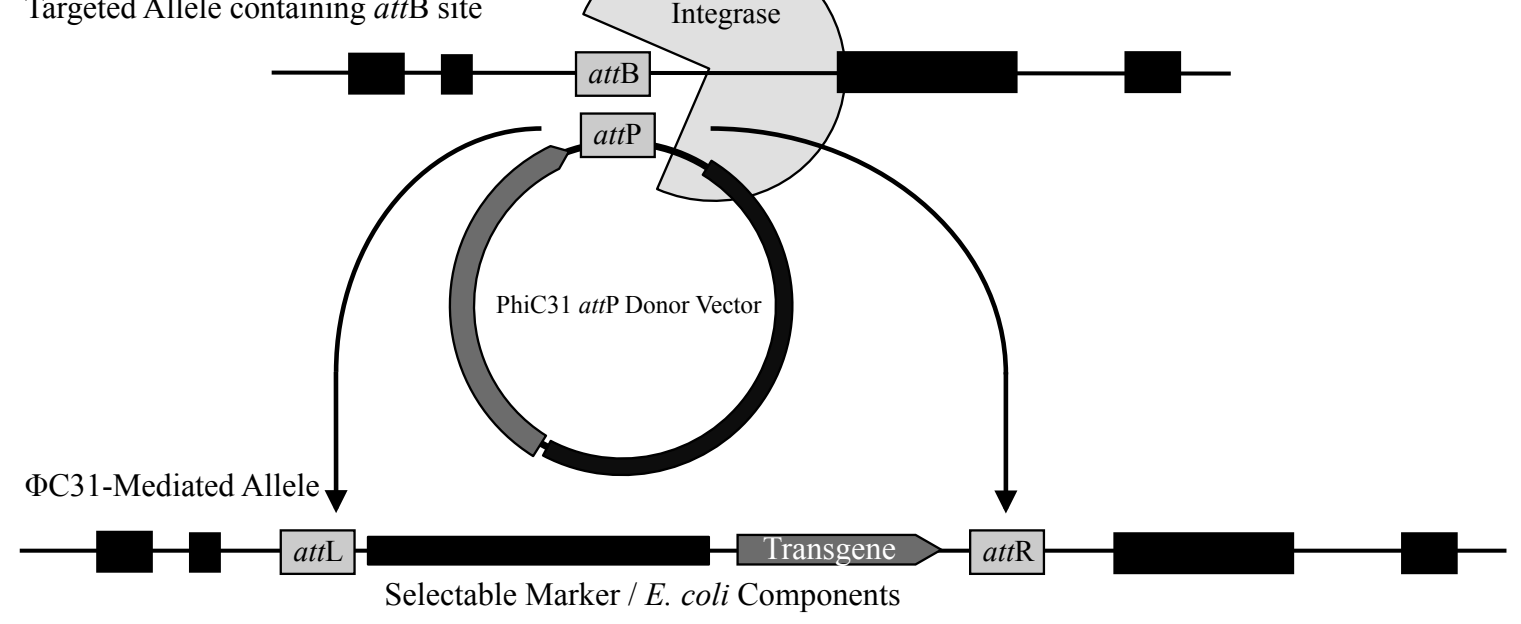

Figure 2. $\quad$ Site-specific integration of PhiC31 attP into preintegrated chromosomal attB. (A) The heterotypic att $\mathrm{B}$ (35 bp) and att $\mathrm{P}(39 \mathrm{bp})$ sequences for PhiC31 attachment sites. (B) Graphical representation of PhiC31 integrase mediating the integration of a transgene donor plasmid that contains an attP site into a previously chromosomally integrated $a t t \mathrm{~B}$ site within a targeted location. Once integrated, the donor plasmid is flanked by att $\mathrm{L}$ and att $\mathrm{R}$ sequences. 
Table 1. The Basic Steps Needed to Perform Irreversible Gene Stacking

\begin{tabular}{|c|c|}
\hline Step & Action \\
\hline 1 & $\begin{array}{l}\text { Develop a strategy for stable integration of a PhiC31 attB-docking } \\
\text { site. }\end{array}$ \\
\hline 2 & Generation of cell lines that contain docking site. \\
\hline 3 & $\begin{array}{l}\text { Develop and execute a strategy to ligate gene of interest into the } \\
\text { pBB53 vector (donor PhiC31 attP vector). }\end{array}$ \\
\hline 4 & $\begin{array}{l}\text { Transfect a PhiC31 expression vector, a donor att } \mathrm{P} \text { vector, and a } \\
\text { docking att } \mathrm{B} \text { vector to determine intramolecular integration } \\
\text { between the } \text { att } \mathrm{P} \text { and } \text { att } \mathrm{B} \text { vectors. }\end{array}$ \\
\hline 5 & $\begin{array}{l}\text { Transfection and generation of individual stable integration events } \\
\text { mediated by PhiC } 31 \text { recombination. }\end{array}$ \\
\hline 6 & Analysis of stable integrations. \\
\hline 7 & $\begin{array}{l}\text { Removal of unneeded DNA (E. coli vector backbone and } \\
\text { selectable marker). }\end{array}$ \\
\hline
\end{tabular}




\section{Materials and Methods}

\section{PhiC31 Vector Maps and Details}

Three components are required to achieve gene stacking mediated by a sitespecific integration. These components include the bacterial attachment site (attB), the phage attachment site (attP), and an integrase that mediates recombination between the two short att sites (Kuhstoss and Rao, 1991; Rausch and Lehmann, 1991; Thorpe et al., 2000). This system is best described for the integrase of Streptomyces phage PhiC31, which normally mediates the integration of the phage genome into the bacterial chromosome through the host att $\mathrm{B}$ and phage att $\mathrm{P}$ recombination sites. The minimal functional size has been determined to be 34 and $39 \mathrm{bp}$ for the att $\mathrm{B}$ and $\operatorname{att} \mathrm{P}$ sites, respectively (Groth et al., 2000). The two sequences share only a common three-bp central region (TTG), which is flanked by imperfect repeats. Recombination between the two attachment sites creates two hybrid sites, which are referenced as $a t t \mathrm{~L}$ and $a t t \mathrm{R}$ (Thorpe et al., 2000; Smith et al., 2004). The att $\mathrm{L}$ and $a t t \mathrm{R}$ sequences are not substrates for the PhiC31 recombinase, thus making this a unidirectional tool. In our gene-stacking approach, we have chosen to follow in suit with the natural context of the attB located in the host genome, where it serves as a docking site (see Figures 1 and 2). The attP site is located in the incoming donor vector, to mimic the phage att $\mathrm{P}$ integration into the bacterial host $a t t \mathrm{~B}$. This selection is arbitrary, since the integration can be accomplished in either direction (Groth et al., 2000; Thyagarajan et al., 2001). Several mammalian expression vectors have been generated and proven functional in mammalian cells. We 
have been able to confirm the utility of two different vectors (Groth et al., 2000; Raymond \& Soriano, 2007) in pig cells. The data presented in this chapter were generated with the integrase-expression vector, pCMVint (Groth et al., 2000).

\section{a. PhiC31 gene-stacking vectors}

i. The PhiC31 expression vector, pCMVint, was previously described (Groth et al., 2000).

ii. To generate the PhiC31 attB docking site, we chose to use a gene-targeting strategy via homologous recombination. We generated a vector to target the porcine GGTAlgene. The method to generate a GGTA1 gene-targeting vector has previously been described (Beaton et al., 2013). We have since made a modification to the targeting vector used in that experiment. The minimum PhiC31 attB docking site (Groth et al., 2000) was inserted into pBB7 to make pBB18 (Figure 3A) and used to create a heterozygous GGTA1 targeted allele that harbors a PhiC31 attB. A similar strategy can be applied to any genomic target of interest.

iii. To generate a universal PhiC31 attP donor plasmid, we modified an attPcontaining plasmid, pDRAV-3 (Osterwalder et al., 2010). The generated plasmid (pBB53) was created with a strategically located multiple cloning region that is ready to receive a user's gene of interest (Figure 3B). The donor plasmid contains a selectable marker (Hygromycin B; Invitrogen) to select for integration.

b. Cloning and preparation of plasmids 
i. Clone the gene of interest (must be a self-contained functional unit) into the multiple cloning region of pBB53 using the appropriate restriction enzymes and buffers.

1. Ligation of transgene into pBB53. (See Notes 1 and 2)

a. Set up $20 \mu \mathrm{L}$ ligation reaction.

\begin{tabular}{ll}
\hline Ingredient & Volume \\
\hline PhiC31 empty donor vector (pBB53) & $1.0 \mu \mathrm{L}(150-200 \mathrm{ng})$ \\
DNA insert & $1.0 \mu \mathrm{L}(250-300 \mathrm{ng})$ \\
10 X T4 DNA Ligase buffer & $2.0 \mu \mathrm{L}$ \\
T4 DNA Ligase & $1.0 \mu \mathrm{L}$ \\
$\mathrm{H}_{2} \mathrm{O}$ & $16 \mu \mathrm{L}$ \\
Total reaction & $20.0 \mu \mathrm{L}$ \\
\hline
\end{tabular}

b. Incubate reaction at $24-26^{\circ} \mathrm{C}$ for $1 \mathrm{~h}$ (sticky-end ligation) or overnight at $16^{\circ} \mathrm{C}$ (for blunt-end ligations).

2. Transform ligation product into E. coli.

We recommend transforming high-efficiency competent cells with $2 \mu \mathrm{L}$ of the $20 \mu \mathrm{L}$ reaction following the protocol provided with the competent cells. Plate the transformed bacteria on $50-100 \mu \mathrm{g} / \mathrm{mL}$ ampicillin LB agar plates and allow single colony clones to form overnight at $37^{\circ} \mathrm{C}$.

3. Isolate and identify clones with the correct insert.

a. Depending on the total colony counts (generally expect $50-500$ colonies), randomly pick $5-30$ colonies and grow each clone in 3 $\mathrm{mL}$ of LB broth with $50-100 \mu \mathrm{g} / \mathrm{mL}$ ampicillin at $37^{\circ} \mathrm{C}$ overnight, with shaking. 
b. The following day, purify the construct using a plasmid purification kit or alkaline lysis protocol. Verify insert using either polymerase chain reaction (PCR) or restriction enzyme diagnostics.

c. Grow a positive clone containing the insert in an appropriate amount of LB ampicillin broth $(500 \mathrm{~mL}$ culture to produce a large quantity of plasmid DNA), and purify the construct using a plasmid purification kit or alkaline lysis protocol. Verify clone with either PCR or restriction enzyme diagnostics. 
A)

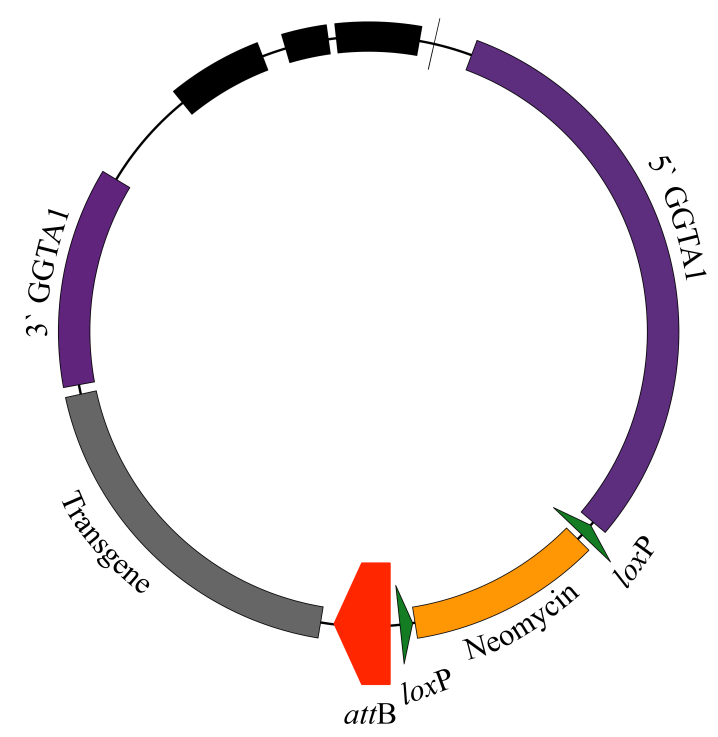

B)

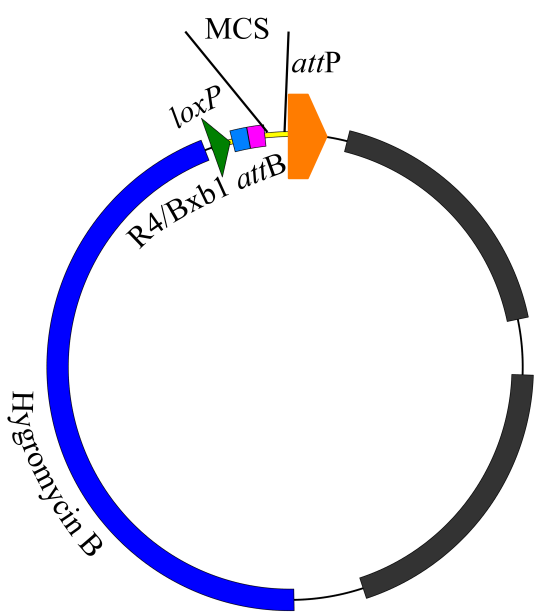

Figure 3. Graphical representation of $\mathrm{PhiC} 31$ att $\mathrm{B}$ and att $\mathrm{P}$ vectors.

(A) This plasmid was used to introduce the PhiC31 attB docking site into the pig genome at the GGTA1 locus. This targeting vector consisted of sequence homologous to the porcine GGTAl gene, a mammalianized neomycin-resistant gene flanked by loxP sites, a PhiC31 att B docking site (red block), and a transgene. (B) The PhiC31 attP donor plasmid was created to contain a mammalianized Hygromycin $\mathrm{B}$ resistance gene, a lox $\mathrm{P}$ site, the PhiC31 donor attP site (orange block), an R4 attB site (light blue box), a Bxb1 at $\mathrm{B}$ site (pink box), and a series of multiple cloning sites (MCS). The multiple cloning sites were designed to receive the gene of interest. 


\section{Intramolecular Integration Assay}

We have observed that the efficiency of PhiC31-mediated recombination differs between donor plasmids (and likely integration sites). This efficiency can be estimated prior to experimental procedures by transient transfection. To verify that the precise recombination between the PhiC31 att $\mathrm{B}$ docking site and the PhiC31 attP donor vector has occurred, the following intramolecular integration assay can be performed on crude cell lysate from cells that have been transiently transfected. The cells must be transfected with three pieces of DNA: (i) a PhiC31 expression vector that will transiently express the PhiC31 integrase (i.e., pCMVint); (ii) the PhiC31 attB docking site vector (i.e., pBB18, the GGTA1 targeting vector that contains the PhiC31 attB); and (iii) the PhiC31 attP donor site plasmid (plasmid pBB53 with inserted gene of interest). The goal of this assay is to determine if the reaction between the two att sites is being catalyzed by the recombinase in the cell type and cell culture conditions that are being used. A PCR assay is performed using primers that flank the newly created $a t t \mathrm{~L}$ or $\operatorname{att} \mathrm{R}$ site.

The proper conditions and ratios have been optimized for porcine fibroblasts (see Note 3 and Figure 4). The described protocol is per manufacturer recommendations, FuGENE HD (Promega; Madison, WI). We recommend using a 1:10 ratio of integrase plasmid to donor vector.

a. Culture porcine fibroblast cells in complete medium (Dulbecco's modified Eagle's medium (DMEM) (Cellgro) containing 2.77 mM glucose, 1.99 mM L-glutamine, and 
$0.5 \mathrm{mM}$ sodium pyruvate, supplemented with $1 \mathrm{mM}$ L-alanyl-L-glutamine (Cellgro) and $12 \%$ fetal bovine serum (FBS)). Porcine fibroblasts should be cultured at $38.5^{\circ} \mathrm{C}$, with $5.5 \% \mathrm{CO}_{2}, 5.0 \% \mathrm{O}_{2}$, and $100 \%$ humidity.

b. Passage cells and plate them at a density of 30,000 cells/well in a $24-$ well plate. The cells will be ready to be transfected the next day or when they are at $50-60 \%$ confluency.

c. Transfect the cells according to manufacturer instructions using a lipid-based transfection method (see Note 5). The protocol uses a reagent to DNA ratio of 3.5:1. When transfecting a single well of a 24-well plate, $\sim 600 \mathrm{ng}$ DNA are to be transfected.

1. Allow FuGENE HD Transfection Reagent to reach room temperature.

2. Mix by inverting or vortexing briefly. No precipitate should be visible.

3. Dilute a total of $\sim 600 \mathrm{ng}$ plasmid DNA to a volume of $25 \mu \mathrm{L}$ in water in a 1.5 $\mathrm{mL}$ tube (see below).

Transfection is to be performed with the three DNA components at a 1:10:10 ratio (PhiC31 integrase:attP-containing plasmid:attB containing plasmid). Transfections are to be performed using supercoiled plasmid DNA for all three vectors. Transfect $30 \mathrm{ng}$ PhiC31 vector, $300 \mathrm{ng}$ attB vector, and $300 \mathrm{ng}$ attP vector.

4. Add $2 \mu \mathrm{L}$ FuGENE HD to same tube. Mix by pipetting the entire $27 \mu \mathrm{L}$, eight times.

5. Incubate for 5-10 $\mathrm{min}$ at room temperature.

6. Add $500 \mu \mathrm{L}$ fresh complete medium to the $27 \mu \mathrm{L}$ of the DNA:lipid complex. Mix gently by pipetting. 
7. Aspirate the medium from a well with cells and replace with transfection solution that was prepared in Step 6.

8. Return to gas controlled incubator at $38.5^{\circ} \mathrm{C}$ for $4 \mathrm{~h}$.

9. Transfer plate to a gas controlled incubator at $30^{\circ} \mathrm{C}$ for $\sim 44 \mathrm{~h}$.

10. Harvest cells by trypsinization, resuspend in $40 \mu \mathrm{L}$ lysis buffer $(40 \mathrm{mM}$ Tris, pH $8.9 ; 0.9 \%$ Triton X-100; $0.9 \%$ Nonidet P-40; $0.4 \mathrm{mg} / \mathrm{mL}$ proteinase $\mathrm{K}$ ) and incubate at $65^{\circ} \mathrm{C}$ for $15 \mathrm{~min}$ to lyse the cells followed by $95^{\circ} \mathrm{C}$ for $10 \mathrm{~min}$ to inactivate the proteinase $\mathrm{K}$.

11. Perform $\mathrm{PCR}$ to assay for intramolecular integration between the att $\mathrm{P}$ and att $\mathrm{B}$ vectors. A PCR assay should be designed using primers that detect the junction flanking the newly created $a t t \mathrm{~L}$ or $a t t \mathrm{R}$ site.

12. Evaluate the PCR by electrophoresis on an agarose gel. 


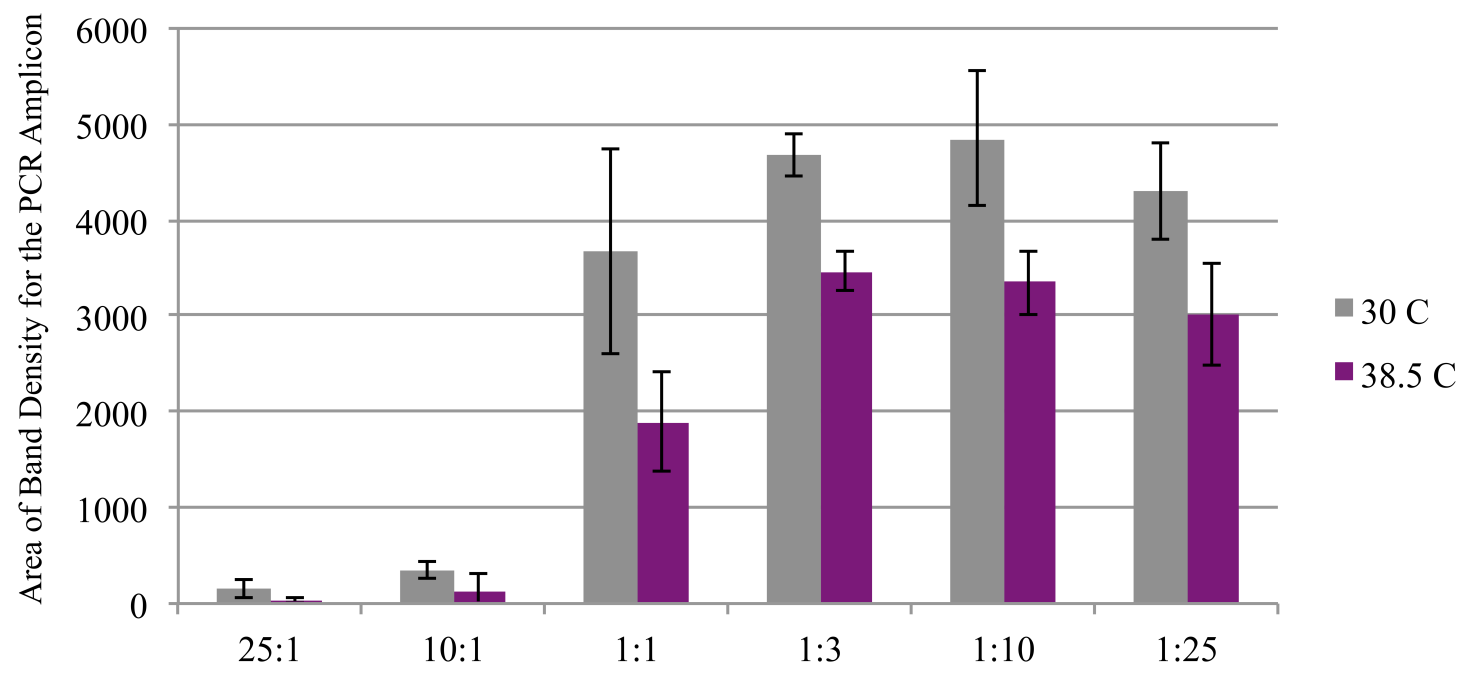

Figure 4. Determination of the culture temperature and the DNA ratios of PhiC31 integrase to attP donor vector.

To calculate the occurrence of the recombination event, a PCR that flanks the junction of a PhiC31 attR was utilized. The yield of PCR product estimates recombination events that occurred in a pool of cells. Analysis was performed using ImageJ software (http://rsbweb.nih.gov/ij/) by calculating the density of the bands (arbitrary units). The data represent mean band density $\pm \mathrm{SD}(\mathrm{n}=4$ transfections). PhiC31 dependent integration is more efficient at $30^{\circ} \mathrm{C}$ as compared to $38.5^{\circ} \mathrm{C}$. 


\section{Culture and Transfection of Porcine Fibroblast Cells}

To demonstrate the efficacy of this protocol, cells were generated that contain the PhiC31 attB site within the GGTA1 locus as per Beaton et al. (2013). These cells serve as a recipient for the second piece of DNA, the donor vector that contains a PhiC31 attP site and a transgene. The third and final DNA is a mammalian expression vector that contains the coding sequence for the PhiC31 recombinase (pCMVint). The strategy for integration of the donor attP vector into the established GGTAl-located attB docking site is to cotransfect the two vectors, pCMVint (PhiC31 expression vector) and pBB53, which includes the gene of interest (PhiC31 attP donor vector).

The transfection method is similar to the previous method outlined in the intramolecular integration assay. The major differences are that after the transfection, the transfected cells are split onto 100-mm tissue culture plates and put under Hygromycin B selection.

a. Culture porcine fibroblast cells in complete medium, (DMEM containing $2.77 \mathrm{mM}$ glucose, $1.99 \mathrm{mM} \mathrm{L-glutamine,} \mathrm{and} 0.5 \mathrm{mM}$ sodium pyruvate, supplemented with $1 \mathrm{mM}$ L-alanyl-L-glutamine and $12 \%$ FBS). Porcine fibroblasts should be cultured at $38.5^{\circ} \mathrm{C}$ with $5.5 \% \mathrm{CO}_{2}, 5.0 \% \mathrm{O}_{2}$, and $100 \%$ humidity.

b. Passage cells and plate them at a density of 30,000 cells/well in a 24-well plate. The cells will be ready to be transfected the next day when they are $50-60 \%$ confluent (see Note 4). 
c. Transfect the cells according to manufacturer instructions using a lipid-based transfection method (see Note 5). The protocol uses a reagent to DNA ratio of 3.5:1. When transfecting a single well of a 24 -well plate, a total of $\sim 600 \mathrm{ng}$ DNA is used.

1. Allow FuGENE HD Transfection Reagent to reach room temperature.

2. Mix by inverting or vortexing briefly. No precipitate should be visible.

3. Dilute a total of $\sim 600 \mathrm{ng}$ plasmid DNA to a volume of $25 \mu \mathrm{L}$ in water in a $1.5-\mathrm{mL}$ tube (see below).

Transfection is to be performed with the PhiC31 expression vector and the att $\mathrm{P}$ donor vector at a 1:10 ratio (PhiC31 integrase:attP-containing plasmid).

Transfections are to be performed using supercoiled plasmid DNA for both vectors. Transfect 55 ng pCMVint and 550 ng att $\mathrm{B}$ donor vector.

4. Add $2 \mu \mathrm{L}$ FuGENE HD to same tube. Mix entire $27 \mu \mathrm{L}$ by pipetting, eight times.

5. Incubate for 5-10 $\mathrm{min}$ at room temperature.

6. Add $500 \mu \mathrm{L}$ fresh, complete medium to the $27 \mu \mathrm{L}$ of the DNA:lipid complex. Mix gently by pipetting.

7. Aspirate the medium from a well with cells and replace with transfection solution that was prepared in Step 6.

8. Incubate the cells at $38.5^{\circ} \mathrm{C}$ under normal porcine cell culture conditions for $4 \mathrm{~h}$.

9. Transfer plate to $30^{\circ} \mathrm{C}$ for $\sim 44 \mathrm{~h}$.

10. Forty-eight hours post transfection, split cells onto ten $100-\mathrm{mm}$ culture plates with 6 $\mathrm{mL}$ complete medium.

11. Twenty-four hours post Step 10, administer Hygromycin B drug selection. Add $1 \mathrm{~mL}$ of complete medium that has Hygromycin B $(1750 \mathrm{mg} / \mathrm{L})$, which is a $7 \times$ 
concentration. The $7 \times$ concentration allows the entire drug selection medium on the plates to be equivalent to $1 \times$ concentration.

12. Culture the cells for 13 days. A medium change can be performed after 7-9 days of culture using $1 \times$ concentration Hygromycin B $(250 \mathrm{mg} / \mathrm{L})$ in complete medium.

13. After a total of 13 days in Hygromycin medium, colonies should range in size from 5 to $15 \mathrm{~mm}$.

14. Harvest the cells by trypsinization. We recommend using cloning cylinders as a method to harvest individual colonies. Two-thirds of cells harvested are transferred to one well of a 24-well tissue culture plate for expansion, and one-third of cells isolated are used for PCR analysis of integration (user-developed assay from the transient assays above).

a. Pellet assay cells by centrifugation.

b. Remove supernatant and resuspend cell pellet in $5 \mu \mathrm{L}$ lysis buffer ( $40 \mathrm{mM}$ Tris, $\mathrm{pH}$ 8.9; $0.9 \%$ Triton X-100; $0.9 \%$ Nonidet P- $40 ; 0.4 \mathrm{mg} / \mathrm{mL}$ proteinase $\mathrm{K}$ ) and incubate at $65^{\circ} \mathrm{C}$ for $15 \mathrm{~min}$ to lyse the cells followed by $95^{\circ} \mathrm{C}$ for $10 \mathrm{~min}$ to inactivate the proteinase $\mathrm{K}$.

15. Perform PCR to assay for intramolecular integration between the att $\mathrm{P}$ and $\operatorname{att} \mathrm{B}$ vectors. A PCR assay is performed using primers that flank the newly created att $\mathrm{L}$ or att $\mathrm{R}$ site.

16. Evaluate the PCR by electrophoresis on an agarose gel.

17. Expand and cryopreserve positive colonies. SCNT can then be performed to generate fetuses for fibroblast collection for additional genetic manipulations or live pigs with the PhiC31 stacked transgene. 
Cre-loxP-Mediated Excision of Unwanted DNA by Transient Expression of Cre Recombinase

To ensure expression of the transgene, it is important to remove plasmid sequences (Shani, 1986). In addition, the presence of a selectable marker can also influence the expression of neighboring genes (Fiering et al., 1995). Further, removal of superfluous DNA presents the possibility of recycling the selectable marker, as demonstrated in mouse embryonic stem cells (Rossant \& Nagy, 1995; Abuin \& Bradley, 1996; Nagy \& Rossant, 1996). In this method, removal of all unwanted sequences is facilitated by Cre recombinase (Nagy et al., 1998). Cre expression is provided by transient expression in cultured cells. The transfection method that has been optimized is a modification of the electroporation methods described by Ross et al. (2010) and Beaton et al. (2013). We have been able to achieve an efficiency of $82.1 \%$ through the transient expression of a mammalianized Cre-expression vector (Table 2).

1. Culture porcine fibroblast cells in complete medium, (DMEM containing $2.77 \mathrm{mM}$ glucose, $1.99 \mathrm{mM} \mathrm{L-glutamine,} \mathrm{and} 0.5 \mathrm{mM}$ sodium pyruvate, supplemented with 1 mM L-alanyl-L-glutamine and 12\% FBS). Porcine fibroblasts should be cultured at $38.5^{\circ} \mathrm{C}$, with $5.5 \% \mathrm{CO}_{2}, 5.0 \% \mathrm{O}_{2}$, and $100 \%$ humidity.

2. Harvest fibroblasts by trypsinization and resuspend the cells at a concentration of $1 \times 10^{6}$ cells $/ \mathrm{mL}$ in an electroporation medium ( $25 \%$ OptiMEM (Invitrogen) $+75 \%$ buffered $\mathrm{KCl}$ (135 mM KCl; 15 mM Tris; $11.3 \mathrm{mM} \mathrm{N}$, N-Bis(2-hydroxyethyl)-2aminoethanesulfonic acid (BES); $3.7 \mathrm{mM}$ 1,4-Piperazinediethanesulfonic acid (PIPES), pH 7.3). 
3. In a 4-mm cuvette, aliquot $400 \mu \mathrm{L}$ of the cell suspension (400,000 cells) and add 7.5 $\mu \mathrm{g}$ of supercoiled pCAG-Cre:GFP (Addgene plasmid 13776), a mammalian Creexpression vector (Matsuda \& Cepko, 2007).

4. Using a square wave generator, electroporate the cells at 490 volts for three pulses at $1 \mathrm{~ms}$ per pulse.

5. After the electroporation, resuspend the cells in a total volume of $10 \mathrm{~mL}$ complete medium.

6. Aliquot $5 \mu \mathrm{L}$ of the $10 \mathrm{~mL}$ suspension to $7 \mathrm{~mL}$ of complete medium in a $100-\mathrm{mm}$ tissue culture plate. This dilution is required in order to have a clonal density of $1-$ 10 colonies per culture plate. Perform this dilution onto $5-20$ plates. Generally, fewer than five plates are required.

7. After 7 days, change medium with fresh complete medium (as in Step 1).

8. Allow cells to grow for an additional 6 days without any selection. After a total of 13 days in culture after the transfection, colonies should range in size from 5 to 15 mm.

9. Harvest the cells by trypsinization. We recommend using cloning cylinders as a method to harvest individual colonies. Two-thirds of cells harvested are transferred to one well of a 24-well tissue culture plate for expansion, and one-third of cells isolated are used for PCR analysis of Cre-loxP-mediated excision of unwanted DNA.

a. Pellet assay cells by centrifugation.

b. Remove supernatant and resuspend cell pellet in $5 \mu \mathrm{L}$ lysis buffer $(40 \mathrm{mM}$ Tris, $\mathrm{pH}$ 8.9; $0.9 \%$ Triton X-100; $0.9 \%$ Nonidet $\mathrm{P}-40 ; 0.4 \mathrm{mg} / \mathrm{mL}$ proteinase $\mathrm{K}$ ) and 
incubate at $65^{\circ} \mathrm{C}$ for $15 \mathrm{~min}$ to lyse the cells, followed by $95^{\circ} \mathrm{C}$ for $10 \mathrm{~min}$ to inactivate the proteinase $\mathrm{K}$.

10. Screen the colonies by PCR to determine which colonies have undergone the Cremediated excision. A PCR screen needs to be designed to flank the unwanted DNA in order to confirm the excision.

11. Expand and cryopreserve positive colonies. SCNT can then be performed to generate fetuses for fibroblast collection for additional genetic manipulations or live pigs with the Cre-excised genotype. 
Table 2. Results of Cre-loxP-Mediated Deletion of a Selectable Marker

\begin{tabular}{ccc}
\hline Transfection Set & $\begin{array}{c}\text { No. of Colonies } \\
\text { Picked }\end{array}$ & $\begin{array}{c}\text { No. of Cre-loxP-Deleted } \\
\text { Colonies (\%) }\end{array}$ \\
\hline Transfection 1 & 24 & $21(87.5 \%)$ \\
Transfection 2 & 23 & $19(82.6 \%)$ \\
Transfection 3 & 10 & $7(70.0 \%)$ \\
Transfection 4 & 21 & $17(81.0 \%)$ \\
Overall & 78 & $64(82.1 \%)$ \\
\hline
\end{tabular}




\section{Summary}

We would like to note that the given protocol demonstrates the addition of a targeted PhiC31 attachment site (attB), followed by the PhiC31-mediated integration of a PhiC31 attachment site (attP) donor vector. We have also given an approach to remove unwanted DNA by the Cre-loxP system using transient expression of Cre for excision. The final contribution is a gene-stacking strategy that has unlimited potential if a dual recombinase attachment system is employed, as described in Figure 1. The gene-stacking system presented is a straightforward method that is unidirectional, site-specific, and enables the sequential insertion of multiple transgenes.

\section{Notes}

1. If assistance with DNA ligations, E. coli transformations, restriction enzyme analysis, or DNA sequencing is needed, we recommend you consult product manuals or protocol literature such as Molecular Cloning: A Laboratory Manual (Sambrook et al., 1989) or Current Protocols in Molecular Biology (Ausubel et al., 2002).

2. For all restriction enzymes and ligation reactions required, we recommend following manufacturer directions; use the protocol given in this chapter as guidance only.

3. The transfection method has been optimized for the ratio of DNA concentration (PhiC31 expression vector:attP donor vector). In addition, we performed a temperature optimization that would allow for the most suitable reaction to occur. We chose to explore varying ratios due to the wide range in ratios that have previously been reported using PhiC31 in mammalian culture (Groth et al., 2000; Thyagarajan et al., 2001; Chalberg et al., 2006). Groman and Suzuki (1962) reported that phages' 
reproduction efficiency varies depending on temperature. In the reported data, phage reproduction is drastically reduced at temperatures above $37^{\circ} \mathrm{C}$. Porcine cell culture is performed at $38.5^{\circ} \mathrm{C}$. Therefore, $\mathrm{PhiC} 31$ expression may not be optimal under normal porcine cell culture conditions. The results from varying ratios and the temperature comparison of $30^{\circ} \mathrm{C}$ and $38.5^{\circ} \mathrm{C}$ are shown in Figure 4.

4. If transfection of larger plates is desired, the amount of each DNA and the transfection reagent should be scaled. We used the amounts of each DNA to ensure a low level of background, which allowed us to efficiently pick well-isolated colonies.

5. For the transfections performed in the experiments demonstrated, we determined that when using FuGENE HD (Promega), 90\% of porcine cells are transfected using reporter DNA (data not shown). Therefore, all experiments performed using PhiC31 have been performed using the transfection reagent FuGENE HD. 


\title{
CHAPTER III
}

\section{THE EFFECT OF DONOR DNA HOMOLOGY LENGTH ON THE OUTCOME OF NUCLEASE-MEDIATED GENE TARGETING}

\begin{abstract}
Gene editing techniques are increasing in their availability and ease of use. These techniques are an attractive alternative to conventional gene targeting methods via homologous recombination due to the ease of use and the efficiency of programmable nucleases. We have previously produced cytidine monophosphate-N-acetylneuraminic acid hydroxylase $(C M A H)$ knockout $(\mathrm{KO})$ pigs in a Minnesota Miniature Pig genetic background. These pigs were generated by using Zinc-Finger Nucleases (ZFNs) in combination with donor DNA containing a total length of homology of 1,600 bp (800 bp homology on each arm). An additional targeted disruption of GGTA1 was desired in the $C M A H$-/- genetic background. We used this opportunity to evaluate the effect of donor DNA homology length on nuclease-mediated gene targeting. Initially we utilized ZFNs as a proof of concept to identify a correlation between the length of donor DNA homology and targeting efficiency by using the $C M A H$ gene and then transitioned to Transcription Activator-Like Effector Nucleases (TALENs) to generate bi-allelic
\end{abstract}


modified GGTA1 cells. Donor DNA was designed to symmetrically flank the predicted cleavage sites in $C M A H$ and GGTA1 for both ZFN and TALEN cleavage sites, respectively. For both genes, the length of total homology ranged from $60-1799$ bp. Donor DNA alone did not result in detectable bi-allelic conversion of GGTA1. As the length of donor DNA increased, the bi-allelic disruption of GGTA1 increased from $0.5 \%$ (TALENs alone, no donor DNA present) to a maximum of 3\% (1,799 bp). Inclusion of homologous donor DNA in TALEN transfections facilitated a higher incidence of biallelically modified cells since bi-allelic disruption was increased in the presence of donor DNA, exogenous templates can affect non-homologous end joining (NHEJ).

\section{Introduction}

Genetic engineering technologies have advanced to a point where imagination and resources are the only limitations. Genetic engineering of cell lines or animal models has traditionally utilized random integration or low-efficiency gene targeting through homologous recombination (HR). As genetic engineering schemes become more elaborate, a need to generate precise modifications is required. Specifically, more precise modifications will be of more interest rather than non-specific mutations. In order to achieve targeted modifications, donor DNA that contains the desired sequence needs to be introduced. HR is a normal cellular mechanism that occurs to repair damaged sequence through a double crossover event with the sister chromatid. The efficiency of gene targeting through HR is relatively inefficient, ranging from $0.5 \%-5.0 \%$ (Mansour

et al., 1988; Hasty \& Bradley, 1993; Rouet et al., 1994; Smih et al., 1995; Jasin, 1996). It 
should be noted that in order for HR to occur, genomic breakage of the target sequence is the rate-limiting factor (Song et al., 1985; Hasty \& Bradley, 1993; 1994; Rouet et al., 1994; Choulika et al., 1995).

The introduction of programmable nucleases, specifically zinc-finger nucleases (ZFNs), transcription activator-like effector nucleases (TALENs), and clustered regularly interspaced short palindromic repeats (CRISPR) associated protein 9 (Cas9) have enabled modification of target genomic sequences. In principal, these tools induce double-strand breaks (DSB) at specific locations in the genome and result in either random mutations through non-homologous end joining (NHEJ) or stimulation of HR through homology directed repair (HDR) (Gaj et al., 2013). In the pig, the different types of nucleases have been effective in generating targeted mutations through NHEJ [ZFNs (Hauschild et al., 2011; Whyte et al., 2011; Yang et al., 2011), TALENs (Carlson et al., 2012; Tan et al., 2013; Lee et al., 2014), CRISPR/Cas9 (Tan et al., 2013; Whitworth et al., 2014)], as well as through HR in the presence of donor DNA (Kwon et al., 2013; Tan et al., 2013; Whitworth et al., 2014).

Pigs are considered a potential resource as organ donors for humans because of their compatible organ size and physiology (Ye et al., 1994; Dai et al., 2002; Lai et al., 2002; Lai \& Prather, 2003). However, pig-to-human xenotransplantation has several immunological barriers to overcome. Rapid rejection of grafted organs is primarily due to hyper acute rejection (HAR) (Sandrin \& McKenzie, 1994; Joziasse \& Oriol, 1999; Galili, 2001). HAR is a response mediated by natural antibody reactivity followed by complement activation and cell lysis. In an attempt to overcome a major xeno-antigen, $\mathrm{N}$-glycolynlneuraminic acid (Neu5Gc), we have produced cytidine monophosphate-N- 
acetylneuraminic acid hydroxylase $(C M A H)$ knockout $(\mathrm{KO})$ pigs in a Minnesota Miniature Pig genetic background (Kwon et al., 2013). Neu5Gc is a sialic acid, which is mediated by $C M A H$. A mutation in the human $C M A H$ gene results in the absence of Neu $5 G c$ in humans. The ablation of a second xeno-antigen gene (alpha 1,3 galactosyltransferase, GGTA1) was desired in the $C M A H$-/- genetic background. CMAH and GGTA1 are expressed on endothelial cells of most mammals, with the exception of humans (Galili et al., 1988; Muchmore et al., 1998; Varki, 2001; Basnet et al., 2010; Tahara et al., 2010). Therefore, these epitopes are a potential target for human endogenous antibodies, and the ablation of these epitopes would not allow for human antibodies, directed to these epitopes, to reject the transplanted organs.

The objective of this project was to generate homozygous knockout cells and evaluate the role of donor DNAs with varying lengths of homology in TALEN-mediated gene targeting. Here, we carried out a series of experiments by using nucleases (ZFNs \& TALENs) to characterize the effect of donor DNA homology length during nucleasemediated gene targeting. As a proof of principle, we used ZFNs as previously reported (Kwon et al., 2013) and determined that a minimum arm length of 35 bp will induce HR. In subsequent experiments to further evaluate the minimum length of homology, we used TALEN-mediated gene targeting. Based upon our ZFN/CMAH observations, we expected to see gene targeting at the same frequency in our TALEN/GGTA1 experiments. Unexpectedly, we did not observe any gene targeting by HR with donor DNA, but instead demonstrated that the addition of donor DNA increases bi-allelic modifications when compared to TALEN-mediated editing in the absence of donor DNA. 


\section{Materials and Methods}

\section{ZFN Design and Construction}

Custom ZFN plasmids were designed and used as described in Kwon et al. (2013).

\section{Production of CMAH Small Donor DNAs}

To identify a minimum length of homology required to induce HR during ZFNmediated targeting, a series of donor DNA with varying lengths of homology were generated. First two oligonucleotides containing short homology were annealed and then PCR was performed to extend the homology (Figure 5). ZFN binding sites were modified and an in-frame stop codon was introduced to the donor DNA: 35 (A), 85 (B), and 125 (C) bp homology on each arm. All oligonucleotides to generate the short donor DNAs are shown in Table 3. 
Table 3. Primer sets used to generate small $C M A H$ donor DNA with minimal homology length in ZFN-mediated gene targeting.

\begin{tabular}{|l|l|}
\hline Primers & Sequences $\left(\mathbf{5}^{\prime} \mathbf{-} \mathbf{3}\right.$ ') \\
\hline $\begin{array}{l}\text { CMAH- } \\
\text { smallF }\end{array}$ & $\begin{array}{l}\text { GGAATGGAAAGCCCAATTCATTAAAACAGAAAGGAAGTAGACACG } \\
\text { AGTCCACGGGCTGGTGAAGGACCTACAACCCAGAATTTACTGCCC }\end{array}$ \\
\hline $\begin{array}{l}\text { CMAH- } \\
\text { smallR }\end{array}$ & $\begin{array}{l}\text { GGGCAGTAAATTCTGGGTTGTAGGTCCTTCACCAGCCCGTGGACTC } \\
\text { GTGTCTACTTCCTTTCTGTTTTAATGAATTGGGCTTTCCATTCC }\end{array}$ \\
\hline $\begin{array}{l}\text { CMAH- } \\
\text { midF }\end{array}$ & $\begin{array}{l}\text { TTTCTGAACAGAGAAGACTAATCCAAACCCTGTCATTCCAGAGGAA } \\
\text { TGGAAAGCCC }\end{array}$ \\
\hline $\begin{array}{l}\text { CMAH- } \\
\text { midR }\end{array}$ & $\begin{array}{l}\text { TACTTGTCTGCTGGGTGGGATTCCACGAAATACCCAGCAAAGGGGC } \\
\text { AGTAAATTCTGGGT }\end{array}$ \\
\hline $\begin{array}{l}\text { CMAH- } \\
\text { longF }\end{array}$ & $\begin{array}{l}\text { GCAAGACTTCTAATCTACTAGAACTTTTGTTTTTCTGTGATTTCTGA } \\
\text { ACAGAG AAGACTA }\end{array}$ \\
\hline $\begin{array}{l}\text { CMAH- } \\
\text { longR }\end{array}$ & $\begin{array}{l}\text { TATTAACTTATGCGTAAACACGTTATATAAAATATCCAGCCATACT } \\
\text { TGTCTGCTGGGTGG }\end{array}$ \\
\hline
\end{tabular}




\section{Transfection of CMAH Donor DNAs and ZFNs}

Transfection conditions were a modification of Ross et al. (2010). For gene targeting, 1 million wild-type porcine fibroblast cells were co-transfected with a pair of ZFN plasmids and donor DNA (600 ng total; 1:1:1 ratio). By using a square wave generator (BTX Electro Cell Manipulator, Harvard Apparatus, Holliston, MA), the cells were electroporated at $490 \mathrm{~V}$ for 3 pulses at 1 millisecond per pulse. ZFNs alone served as a control.

\section{DNA Isolation and Quantitative real-time PCR}

To identify the rate of gene targeting induced by HR, DNA was isolated from the transfected cells after three days. Fifty ng of genomic DNA was used for PCR analysis. Quantitative real-time PCR was performed by using IQ SYBR Green Supermix (Bio-Rad Laboratories). The PCR primers are shown in Table 4. The PCR was performed on a MyiQ single color real-time thermal cycler (Bio-Rad). The program used for amplification included an initial temperature of $94^{\circ} \mathrm{C}$ for 2 minutes followed by 40 cycles of 5 seconds at $94^{\circ} \mathrm{C}, 30$ seconds at $60^{\circ} \mathrm{C}$, and 30 seconds at $72^{\circ} \mathrm{C}$. Real time fluorescence data was collected during the extension time. Differences in gene targeting were compared by ANOVA and $\mathrm{p}<0.05$ was considered significant. Three biological replicates with two technical replicates were applied. 
Table 4. Primer sets used for genotyping $C M A H \mathrm{KO}$ cells and pigs.

\begin{tabular}{|l|l|}
\hline Primers & Sequences $\left(\mathbf{5}^{\prime} \mathbf{-} \mathbf{3}\right.$ ') \\
\hline CMAH-F & AGGAAGTAGACACGAGTCCACG \\
\hline CMAH-R & CATACTCTCTGTTTTCAGGCTGCTTG \\
\hline
\end{tabular}




\section{TALEN Design and Construction}

A single TALEN pair was designed to target exon 4 of the porcine GGTAl locus (NCBI: NM_213810) (Figure 6). TALEN design and construction was completed by using ToolGen, Incorporated (toolgen.com).

Targeting Vector Construction and Production of Small Donor DNAs

A targeting construct was assembled from DNA isolated from female "Minnesota Miniature" porcine fetal fibroblasts (Cell Line: 104824; National Swine Resource and Research Center [NSRRC]). A 2,389 bp GGTAl genomic fragment, which includes most of exon 4, was generated by polymerase chain reaction (PCR) by using specific primers (Forward: 5'-TTCCACCCAGCATCCCTTCCCTCT-3' and Reverse: 5'TGGCCAAAATGGTCCTGCTGGCTC-3') and Q5 DNA polymerase (New England Biolabs, NEB, Ipswich, MA). PCR amplification was repeated for 30 cycles of 10 seconds at $98^{\circ} \mathrm{C}$ for denaturation, 30 seconds at $72^{\circ} \mathrm{C}$ for annealing, and 150 seconds at $72^{\circ} \mathrm{C}$ for extension. The PCR product was cloned into pCR-Blunt II-TOPO (Invitrogen, Grand Island, NY) to produce the plasmid pBB60. Sanger sequencing (University of Missouri DNA Core Facility, Columbia, MO) and restriction enzyme diagnostics confirmed the sequence of the GGTA1 fragment. Reverse PCR was performed to generate donor DNA that would contain a mutated TALEN cut site, stop codons in three

reading frames, and unique restriction enzyme sites for future diagnostics. The PCR was performed on pBB60 by using specific primers (Forward: 5'-

CTCGAGCCTGCAGGCAGGTAATTATGAAAC-3' and Reverse: 5'- 
CTACCCTATCTAGCATTGACAGAACCACTC-3') and the TaKaRa LA system (Takara Bio Inc., Japan). PCR amplification was repeated for 30 cycles of 30 seconds at $94^{\circ} \mathrm{C}$ for denaturation, 30 seconds at $54^{\circ} \mathrm{C}$ for annealing, 180 seconds at $68^{\circ} \mathrm{C}$ and increase by 6 seconds per cycle for extension, and with a final extension for 360 seconds at $72^{\circ} \mathrm{C}$. The PCR product was purified by ethanol precipitation; the $5^{\prime}$ and $3^{\prime}$ ends were phosphorylated (T4 PNK, NEB) and ligated together (T4 Ligase, NEB) prior to E. coli transformation ( $5 \alpha$ Competent, NEB). Sanger sequencing (DNA Core Facility) confirmed the mutated sequence. The targeting and mutated targeting constructs are graphically depicted and sequence differences are represented in Figure 6.

Small donor DNAs with minimal homology sequence (total length of homology: 60, 103, 211, 477, 895, and 1,799 bp) were amplified by PCR (EconoTaq DNA Polymerase, Lucigen, Madison, WI) by using primer sets shown in Table 5. PCR amplification was repeated for 30 cycles of 15 seconds at $94^{\circ} \mathrm{C}$ for denaturation, 15 seconds at $56^{\circ} \mathrm{C}$ for annealing, 30 seconds (short donor DNA: 86 bp, 129 bp, 237 bp, 495 bp) or 120 seconds (long donor DNA: $921 \mathrm{bp}, 1825 \mathrm{bp}$ ) at $72^{\circ} \mathrm{C}$ for extension, and with a final extension for 120 seconds at $72^{\circ} \mathrm{C}$. The PCR product was visualized on a $0.8 \%$ agarose gel, isolated, and purified from agarose by using $\beta$-Agarase I (NEB), followed by ethanol precipitation. 
Table 5. Primer sets used for donor DNA with minimal homology length in the TALEN mediated gene targeting.

\begin{tabular}{|c|c|c|c|c|c|c|}
\hline $\begin{array}{l}\text { Donor } \\
\text { DNA }\end{array}$ & $\begin{array}{l}\text { Forward Primer } \\
\qquad\left(5^{\prime}-3^{\prime}\right)\end{array}$ & $\begin{array}{l}\text { Reverse Primer } \\
\qquad\left(5^{\prime}-3^{\prime}\right)\end{array}$ & $\begin{array}{c}\text { Donor } \\
\text { DNA } \\
\text { Size (bp) }\end{array}$ & $\begin{array}{l}\text { Left Arm } \\
\text { Homology } \\
\text { (bp) }\end{array}$ & $\begin{array}{c}\text { Right Arm } \\
\text { Homology } \\
\text { (bp) }\end{array}$ & $\begin{array}{c}\text { Total } \\
\text { Homology } \\
\text { (bp) }\end{array}$ \\
\hline TALEN 1 & $\begin{array}{l}\text { ATGTCAAAGG } \\
\text { AAGAGTGGTT } \\
\text { CTGTCAATGC }\end{array}$ & $\begin{array}{l}\text { CATCATTTCA } \\
\text { TCATGTTTCA } \\
\text { TAATTACCTG } \\
\text { CCTGC }\end{array}$ & 86 & 30 & 30 & 60 \\
\hline TALEN 2 & $\begin{array}{l}\text { TTCCCAGGAG } \\
\text { AAAATAATGA } \\
\text { ATGTCAAAGG } \\
\text { AAGAGT }\end{array}$ & $\begin{array}{l}\text { AGATTAGAGG } \\
\text { AGACTTTCAT } \\
\text { CAACATCATT } \\
\text { TCA }\end{array}$ & 129 & 50 & 53 & 103 \\
\hline TALEN 3 & $\begin{array}{l}\text { ACCATATTCC } \\
\text { ACTCTGGGTG } \\
\text { T }\end{array}$ & $\begin{array}{l}\text { ACGGTGTCAG } \\
\text { TGAATCCTAC } \\
\text { TT }\end{array}$ & 237 & 102 & 109 & 211 \\
\hline TALEN 4 & $\begin{array}{l}\text { CCCAGACGGC } \\
\text { CCTGTCAGTT } \\
\text { CAT }\end{array}$ & $\begin{array}{l}\text { TGCCGGATCC } \\
\text { TTAAGCCAAA } \\
\text { GAGC }\end{array}$ & 503 & 254 & 223 & 477 \\
\hline TALEN 5 & $\begin{array}{l}\text { TGTGATGCGA } \\
\text { GGTGGGGCAT } \\
\text { CTGA }\end{array}$ & $\begin{array}{l}\text { AGGACAATG } \\
\text { GCAACATGGC } \\
\text { AGGAAGGA }\end{array}$ & 921 & 401 & 494 & 895 \\
\hline TALEN 6 & $\begin{array}{l}\text { TTCCACCCAG } \\
\text { CATCCCTTCC } \\
\text { CTC }\end{array}$ & $\begin{array}{l}\text { AGCTGGAATC } \\
\text { TCCAAGGCAT } \\
\text { CGTAGT }\end{array}$ & 1825 & 896 & 903 & 1799 \\
\hline
\end{tabular}




\section{Preparation of Porcine Fibroblast Cells and Culture Conditions}

Ear tissue was collected and minced from newborn piglets to create ear fibroblast cell lines from female $C M A H \mathrm{KO}$ Minnesota Miniature Pig genetic background (Kwon et al., 2013). The minced tissue was digested in $20 \mathrm{~mL}$ of digestion medium (Dulbecco's modified Eagle's medium containing 2.77 mM glucose, 1.99 mM L-glutamine, $0.5 \mathrm{mM}$ sodium pyruvate (Cellgro, Manassas, VA) supplemented with 200 units/mL collagenase and 25 Kunitz units $/ \mathrm{mL}$ DNaseI) for 5 hours at $38.5^{\circ} \mathrm{C}$. After digestion, ear fibroblast cells were washed and cultured with DMEM, 15\% fetal bovine serum (FBS, Cellgro) with $40 \mu \mathrm{g} / \mathrm{mL}$ gentamicin (Cellgro). After overnight culture, cells were trypsinized and frozen at $-80^{\circ} \mathrm{C}$ in aliquots of FBS with $10 \%$ dimethyl sulfide (DMSO, Sigma) and stored in liquid nitrogen.

\section{Transfection of Donor DNAs and TALENs Plasmids}

Transfection conditions were a modification of Ross et al. (2010) and as previously reported (Beaton \& Wells, 2014). Four replicates of eight transfections were conducted with porcine ear fibroblasts from a female $C M A H \mathrm{KO}$ Minnesota Miniature Pig (Kwon et al., 2013). The fibroblast cells were cultured for 72 hours in complete medium (DMEM and $12 \% \mathrm{FBS}$ ) at $38.5^{\circ} \mathrm{C}$ in $5.5 \% \mathrm{CO}_{2}, 5 \% \mathrm{O}_{2}$, and $89.5 \% \mathrm{~N}_{2}$ balanced humidified air. Fibroblasts were harvested by using trypsin and re-suspended in complete medium at a density of 57,000 cells $/ \mathrm{mL}$. Cells were plated at a density of 28,500 cells $(0.5 \mathrm{~mL}$ of suspension) per well in 8 wells ( 7 treatments and 1 control) of a 24 well plate. Approximately 24 hours post plating of the cells they reached $50-60 \%$ confluency and were ready to be transfected. Left TALEN, Right TALEN, and the donor 
DNA were co-transfected (600 ng total DNA; 1:1:1 ratio) by using FuGENE HD Transfection Reagent (Promega, Madison, WI). Transfected cells were cultured in complete medium for 2 days, passaged and cultured for another 3 days.

\section{Screening and Analysis of Knock-out Cells and Pigs}

Five days after transfection, cells were analyzed by fluorescence-activated cell sorting (FACS). Cells were trypsinized, washed with PBS, and centrifuged. Cells were re-suspended in $1 \mathrm{~mL}$ PBS $+3 \%$ FBS and incubated with $10 \mu \mathrm{g}$ Isolectin-B4-FITC (Sigma) for 1 hour at $4^{\circ} \mathrm{C}$. GGTA1 null cells were counter-selected by using flow cytometry as the $\alpha$-1, 3-galactose (Gal) epitope is recognized by the specific lectin, IB4 (MoFlo XDP, Beckman Coulter; University of Missouri Cell \& Immunobiology Core Facility, Columbia, MO). Three biological replicates were performed for each treatment. Flow sorted cells were pooled and cultured for 7 days. After 7 days the cells were harvested and re-suspended in $30 \mu \mathrm{L}$ of lysis buffer ( $40 \mathrm{mM}$ Tris, $\mathrm{pH} 8.9 ; 0.9 \%$ Triton $\mathrm{X}$ $100 ; 0.9 \%$ Nonidet P-40; $0.4 \mathrm{mg} / \mathrm{mL}$ proteinase K, (Sigma)), incubated at $65^{\circ} \mathrm{C}$ for 15 minutes to disrupt the cells, and then heated to $95^{\circ} \mathrm{C}$ for 10 minutes to inactivate the proteinase K. By using Q5 DNA polymerase (NEB), a single primer set was used for PCR analysis (Table 6). The PCR was designed to amplify porcine GGTA1 sequence located outside of the recombination region homologous with the donor DNA template and resulted in an amplimer of 2,389 bp. PCR amplification was repeated for 30 cycles of 10 seconds at $98^{\circ} \mathrm{C}$ for denaturation, 30 seconds at $72^{\circ} \mathrm{C}$ for annealing, and 150 seconds at $72^{\circ} \mathrm{C}$ for extension. 
One replicate of GGTA1 null cells were sorted and plated at clonal density to later perform analysis on single cell populations. After 10 days, half of the cells were used for genotyping and half were expanded to be cryo-preserved for long-term preservation.

Upon expansion of GGTA1 null cells, the lack of cell surface expression of GGTA1 was determined. Fibroblast cells were washed with PBS, and stained with a 1:500 dilution of $1 \mathrm{mG} / \mathrm{mL}$ Isolectin B4 (IB4)-FITC in PBS for 30 minutes at $4{ }^{\circ} \mathrm{C}$. 
Table 6. Primer sets used for screening and genotyping GGTA1 KO cells and pigs.

\begin{tabular}{|l|l|}
\hline Primers & Sequences $\left(\mathbf{5}^{\prime} \mathbf{-} \mathbf{3}\right.$ ') \\
\hline GGTA1-F & TTCCACCCAGCATCCCTTCCCTCT \\
\hline GGTA1-R & TGGCCAAAATGGTCCTGCTGGCTC \\
\hline
\end{tabular}




\section{Somatic Cell Nuclear Transfer (SCNT)}

For SCNT, sow-derived oocytes were purchased from ART (Madison, WI).

Cumulous oocyte complexes were aspirated from sow ovaries and then shipped overnight in maturation medium (TCM199 with $2.9 \mathrm{mM}$ Hepes, $5 \mathrm{mg} / \mathrm{mL}$ insulin, $10 \mathrm{ng} / \mathrm{mL}$ EGF, $0.5 \mathrm{mg} / \mathrm{mL}$ p-FSH, $0.91 \mathrm{mM}$ pyruvate, $0.5 \mathrm{mM}$ cysteine, $10 \%$ porcine follicular fluid, 25 $\mathrm{ng} / \mathrm{mL}$ gentamicin). Upon arrival, the oocytes were transferred into fresh medium and cultured for additional 20-24 hours. After 40-42 h of maturation cumulus cells were removed from the oocytes by vortexing for $3 \mathrm{~min}$ in the presence of $0.1 \%$ hyaluronidase. The denuded oocytes were manipulated in the maturation medium supplemented with 7.0 $\mu \mathrm{g} / \mathrm{mL}$ cytochalasin B. The polar body along with a portion of the adjacent cytoplasm was removed, and a donor cell was placed in the perivitelline space as described previously (Lai \& Prather, 2003). A combination of two donor cell lines was used. The reconstructed embryos were then fused in a fusion medium ( $0.3 \mathrm{M}$ mannitol, $0.1 \mathrm{mM}$ $\mathrm{CaCl}_{2}, 0.1 \mathrm{mM} \mathrm{MgCl}, 0.5 \mathrm{mM}$ Hepes) by using two DC pulses (1-sec interval) at 1.2 $\mathrm{kV} / \mathrm{cm}$ for $30 \mu \mathrm{sec}$ (by using a BTX Electro Cell Manipulator, Harvard Apparatus, Holliston, MA). After fusion, fused embryos were fully activated with $200 \mathrm{mM}$ thimerosal for $10 \mathrm{~min}$ in the dark followed by $8 \mathrm{mM}$ dithiothreitol for $30 \mathrm{~min}$ (Machaty et al., 1997). Embryos were then incubated in PZM3 (Yoshioka et al., 2002) with $0.5 \mathrm{mM}$ scriptaid, a histone deacetylase inhibitor, for 14-16 hours (Zhao et al., 2009; Zhao et al., 2010). The following day the SCNT embryos were surgically transferred into the ampullary-isthmic junction of a surrogate at 0 or 1 day after observed estrus. 


\section{$R N A$ Isolation and real-time RT-PCR}

Total RNA was extracted from WT-, CMAH KO-, and CMAH/GGTA1 double KO (DKO)-null pig fibroblast by using an RNeasy mini kit (Qiagen, Valencia, CA, USA). Real-time reverse transcriptase polymerase chain reaction (RT-PCR) was conducted by using an ABI ViiA ${ }^{\mathrm{TM}} 7$ system (Applied Biosystems, Foster City, CA, USA) and SYBR Green as the double-stranded DNA-specific fluorescent dye (Bio-Rad, Hercules, CA, USA) (see Table 7 for RT-PCR primer sets). The pig $A C T B$ gene was used as an internal control to normalize the RT-PCR efficiency and to quantify the expression of the genes in WT pig, homozygous $C M A H \mathrm{KO}$, and homozygous $C M A H / G G T A 1$ DKO pig derived mRNA. After normalization with $A C T B$ mRNA, we compared the relative expression of each mRNA in the homozygous $C M A H$ and homozygous $C M A H / G G T A 1$ DKO pigderived genes with those of the controls. We performed RT-PCR on each sample independently and in triplicate. 
Table 7. Primer sets used for detection of sialyltransferases mRNA expression.

\begin{tabular}{|c|c|c|c|c|}
\hline Antigen & Gene & $\begin{array}{l}\text { Forward primer } \\
\qquad\left(5^{\prime}-3^{\prime}\right)\end{array}$ & $\begin{array}{c}\text { Reverse primer } \\
\left(5^{\prime}-3^{\prime}\right)\end{array}$ & $\begin{array}{c}\text { Product } \\
\text { size } \\
\text { (bp) }\end{array}$ \\
\hline \multirow{6}{*}{$\begin{array}{c}\text { H-D } \\
\text { antigen }\end{array}$} & ST3GAL1 & $\begin{array}{l}\text { GCATCCTCTCCGTG } \\
\text { ATCTTC }\end{array}$ & $\begin{array}{l}\text { CAAGATGGTTGTC } \\
\text { ACGTTGG }\end{array}$ & 176 \\
\hline & ST3 GAL 2 & $\begin{array}{l}\text { AACCACCCACCATT } \\
\text { TCATGT }\end{array}$ & $\begin{array}{l}\text { ACTTCACTGGGGC } \\
\text { ATAGGTG }\end{array}$ & 152 \\
\hline & ST3 GAL 3 & $\begin{array}{l}\text { GCTTCAAGTGGCAG } \\
\text { GACTTC }\end{array}$ & $\begin{array}{l}\text { ATGAGGCCATTGT } \\
\text { TGAAAGG }\end{array}$ & 193 \\
\hline & ST3 GAL 4 & $\begin{array}{l}\text { GCCATCACCAGCTA } \\
\text { TTCCAT } \\
\end{array}$ & $\begin{array}{l}\text { GTGGGCAGATTCA } \\
\text { GGGTAGA }\end{array}$ & 219 \\
\hline & ST6 GAL 1 & $\begin{array}{l}\text { TGTGTGACCAGGTG } \\
\text { GATGTT }\end{array}$ & $\begin{array}{l}\text { TCCCAAGCAGGTA } \\
\text { GATGTCC }\end{array}$ & 183 \\
\hline & ST6 GAL 2 & $\begin{array}{l}\text { ACCTGCCATGAAAC } \\
\text { CACACT }\end{array}$ & $\begin{array}{l}\text { GGTCTCCAGGAAG } \\
\text { GAGAAGG }\end{array}$ & 151 \\
\hline \multirow{3}{*}{$\begin{array}{l}\text { Sialyl- } \\
\text { Tn } \\
\text { antigen }\end{array}$} & $\begin{array}{c}\text { ST6 } \\
\text { GALNAC2 } \\
\end{array}$ & $\begin{array}{l}\text { GGCTGGTTCACCAT } \\
\text { GATTCT }\end{array}$ & $\begin{array}{l}\text { AACACGGCCTTCT } \\
\text { CAGTGAT }\end{array}$ & 209 \\
\hline & $\begin{array}{c}\text { ST6 } \\
\text { GALNAC } 3 \\
\end{array}$ & $\begin{array}{l}\text { CTTCGAACTCACTA } \\
\text { TGGATAC } \\
\end{array}$ & $\begin{array}{l}\text { GAGCCAGACTGGA } \\
\text { CTCTGTCCT }\end{array}$ & 467 \\
\hline & $\begin{array}{c}\text { ST6 } \\
\text { GALNAC } 6\end{array}$ & $\begin{array}{l}\text { ATGAGTAGCAACAA } \\
\text { AGAGCAG }\end{array}$ & $\begin{array}{l}\text { CCTGGGGCTTCTG } \\
\text { CATCTTG }\end{array}$ & 478 \\
\hline \multirow{6}{*}{$\begin{array}{l}\text { Tn } \\
\text { antigen }\end{array}$} & GALNT1 & $\begin{array}{l}\text { CTTTCACTCGCTGT } \\
\text { GAACCA }\end{array}$ & $\begin{array}{l}\text { CTCTTCATTACGC } \\
\text { CAGCACA }\end{array}$ & 227 \\
\hline & GALNT2 & $\begin{array}{l}\text { CAGCCTCCCAGTCT } \\
\text { GACTTC }\end{array}$ & $\begin{array}{l}\text { AGCTGGGGGACTG } \\
\text { TTTTCTT }\end{array}$ & 179 \\
\hline & GALNT3 & $\begin{array}{l}\text { TTGGCCTTTGTGTA } \\
\text { AAACCAG }\end{array}$ & $\begin{array}{l}\text { TGCTTCAAGTCAA } \\
\text { GTGGATTTC }\end{array}$ & 239 \\
\hline & GALNT4 & $\begin{array}{l}\text { ATTCCAGTGGCATT } \\
\text { CTGTCC }\end{array}$ & $\begin{array}{l}\text { GACAGCTCGAGGT } \\
\text { TCTCACC }\end{array}$ & 177 \\
\hline & GALNT7 & $\begin{array}{l}\text { TCAGGGTCTGAAAG } \\
\text { GCAGTT }\end{array}$ & $\begin{array}{l}\text { TGTGGCAGTGCTT } \\
\text { CAAAAAG }\end{array}$ & 152 \\
\hline & ACTB & $\begin{array}{l}\text { GAGGGCAGTAGCAT } \\
\text { CGCTTTAGTG }\end{array}$ & $\begin{array}{l}\text { GCACCTCAACCCG } \\
\text { CTCCTAG }\end{array}$ & 179 \\
\hline
\end{tabular}


A)

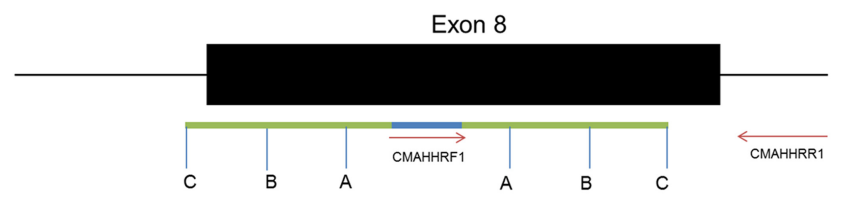

B)
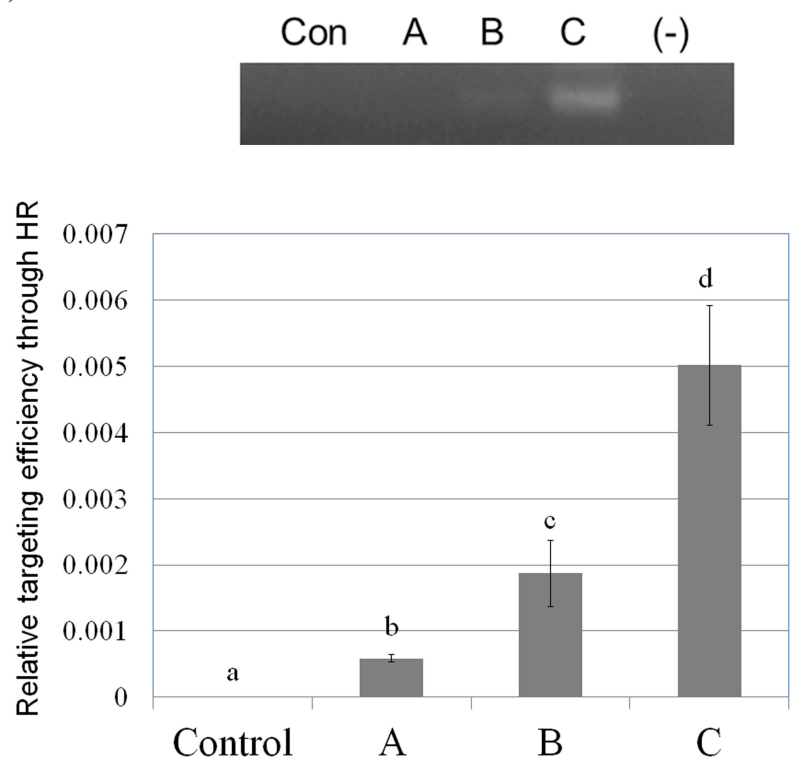

Figure 5. Designed ZFN and comparison of Donor DNA homology length.

A) Schematic design of ZFN-mediated targeting of $C M A H$ by using small donor DNAs. HR junction was amplified by PCR. Green indicates homology region. Blue indicates location of modified ZFN binding site with added in frame termination codon. Three different donors were generated for the study: 35 (A), 85 (B), and 125 (C) bp homology on each arm.

B) Efficiency of gene targeting through HR in ZFN-mediated targeting of $C M A H$. Donor with the longest homology resulted in the highest efficiency of targeting (donor $\mathrm{C}$ ).

Targeting through HR was detected from donor A by using quantitative real-time PCR; however, we could not detect the PCR product on a gel. Different letters indicate statistical difference $(p<0.05)$. 
A)

\section{Wild-Type GGTA1 Exon 4}

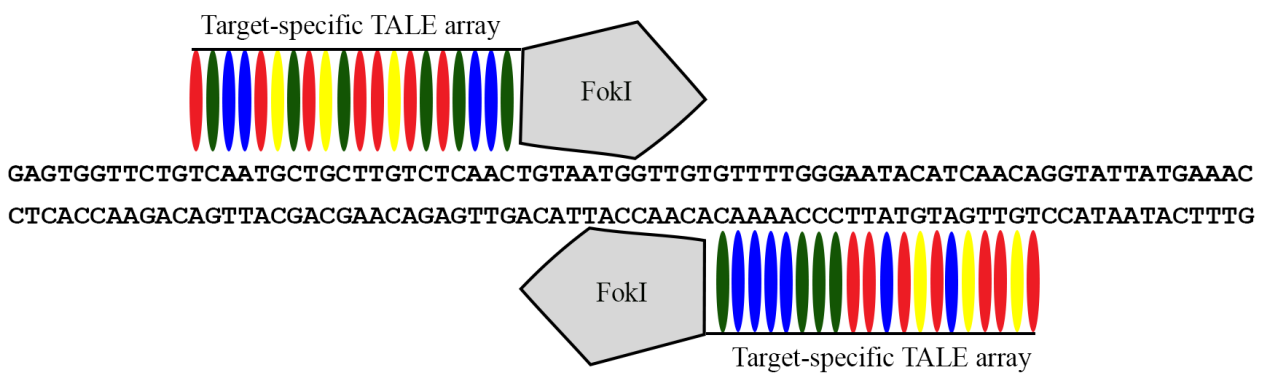

B)

Wild-Type GGTAl Exon 4

GAGTGGTTCTGtcaatgctgcttgtctcaacTGTAATGGTTGTgttttgggaatacatcaacaGGTATTATGAAAC

Mutated GGTA1 Exon 4

GAGTGGTTCTGtcaatgct

gatagggtagctcgagcctgcagg

CaGGTATTATGAAAC

BOLD: Wild-Type Sequence

Blue: TALEN Binding Site

Italicized: Scrambled Sequence 
C)
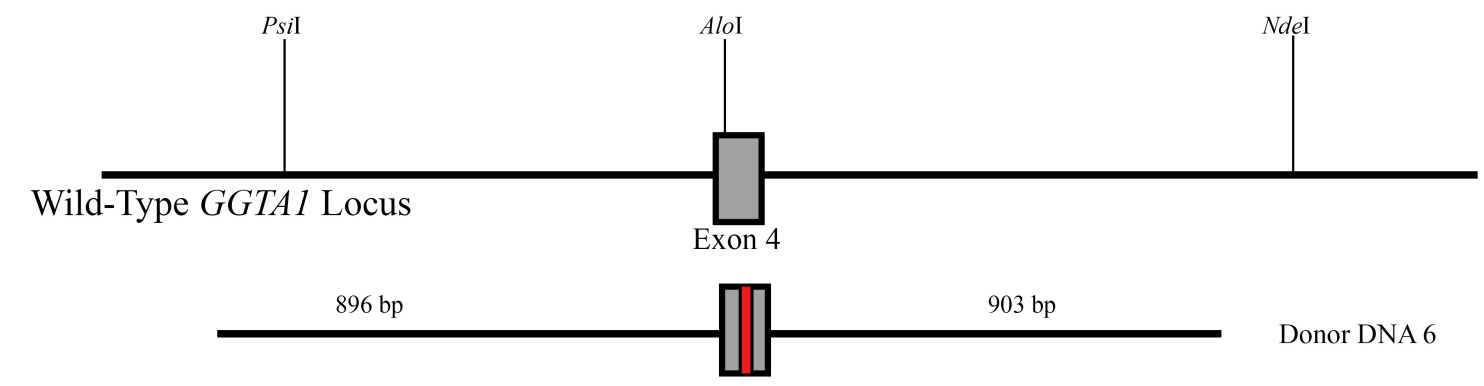

$903 \mathrm{bp}$
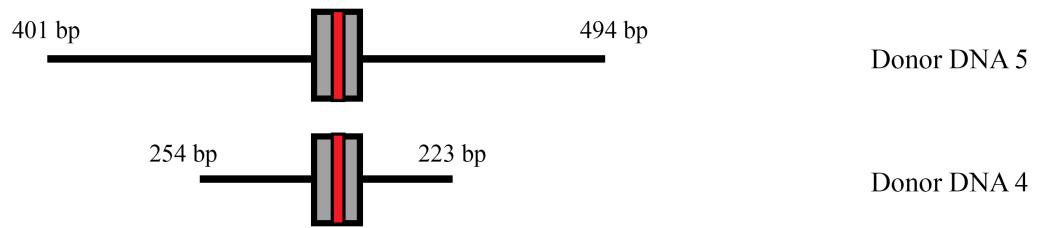

Donor DNA 4

GGTA1 Donor DNA

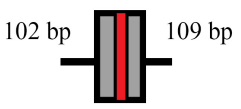

Donor DNA 3

$50 \mathrm{bp}$

53 bp

Donor DNA 2

$30 \mathrm{bp}$

30 bp

Donor DNA 1

Mutated GGTA1 Locus

Figure 6. Designed TALENs and comparison of homology length of Donor DNA. A) Designed TALENs to target porcine GGTA1. The TALENs were designed to recognize $20 \mathrm{bp}$ with a $12 \mathrm{bp}$ spacer between the left and right TALENs. The TALENs are designed to create a double stranded break in exon 4 of GGTA1.

B) Targeted GGTA1 exon 4 sequence and mutated GGTA1 exon 4 donor DNA sequence.

C) Graphical representation of donor DNA with 6 different lengths of homology. 


\section{Results}

\section{Effects of the Homology Length of Donor DNA in ZFN-Mediated Gene Targeting}

The highest targeting efficiency was observed when the donor DNA with $125 \mathrm{bp}$ homology on each arm was used and the efficiency was 10 times higher compared to the donor DNA with 35 bp homology (Figure 5). No recombination event was detected in the negative control as was expected. When the PCR products were examined by gel electrophoresis, we could not detect a visible PCR product from the $35 \mathrm{bp}$ homology group. However the highest intensity of PCR product was detected in the presence of donor DNA with the longest homology (donor C).

\section{Effects of the Homology Length of Donor DNA in TALEN-Mediated Bi-allelic}

\section{Modifications}

To identify the minimal homology length of donor DNA that can induce HR at the targeting locus, a series of DNA fragments of various lengths homologous to GGTA1 exon 4 were generated (Figure 6). Each donor DNA was transiently transfected with TALENs into fibroblast cells that lack functional $C M A H$. Fibroblast cells were recovered 5 days after transfection and analyzed by FACS. Bi-allelic modifications to the GGTA1 gene were analyzed by counter-selection with IB4-FITC. All treatments that included donor DNA resulted in higher amounts of GGTA1-null cells (Figure 7), with the largest quantity of GGTA1-null cells resulting from donor DNA with the longest length of homology. To test if there was a statistical significance across the entire dataset, a pairwise Chi-squared analysis was performed and showed significance at $p<.05$. To test 
between treatment means, count data were analyzed using the Student's T-Test. Based upon our results, all treatments that contained TALEN expression vectors showed significance as compared to donor DNA alone. Additionally, treatments that contained TALEN expression vector DNA and donor DNAs with the lengths associated with donor DNAs 2, 3, and 4 showed a significance of $p<.05$ as compared to TALEN expression vector alone. However, there was not a significant difference between the treatments that contained both donor DNA and TALEN expression vectors. 


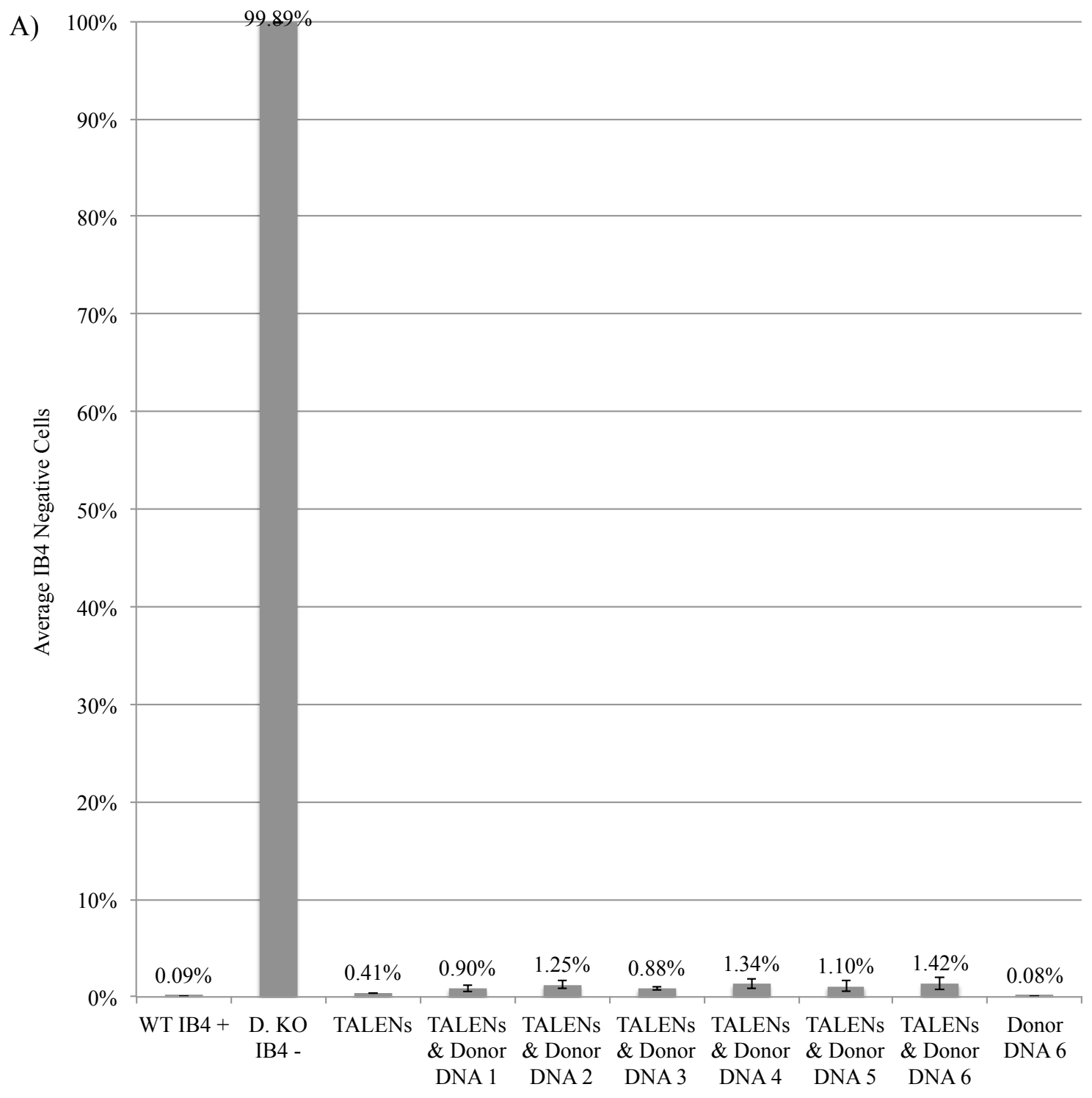




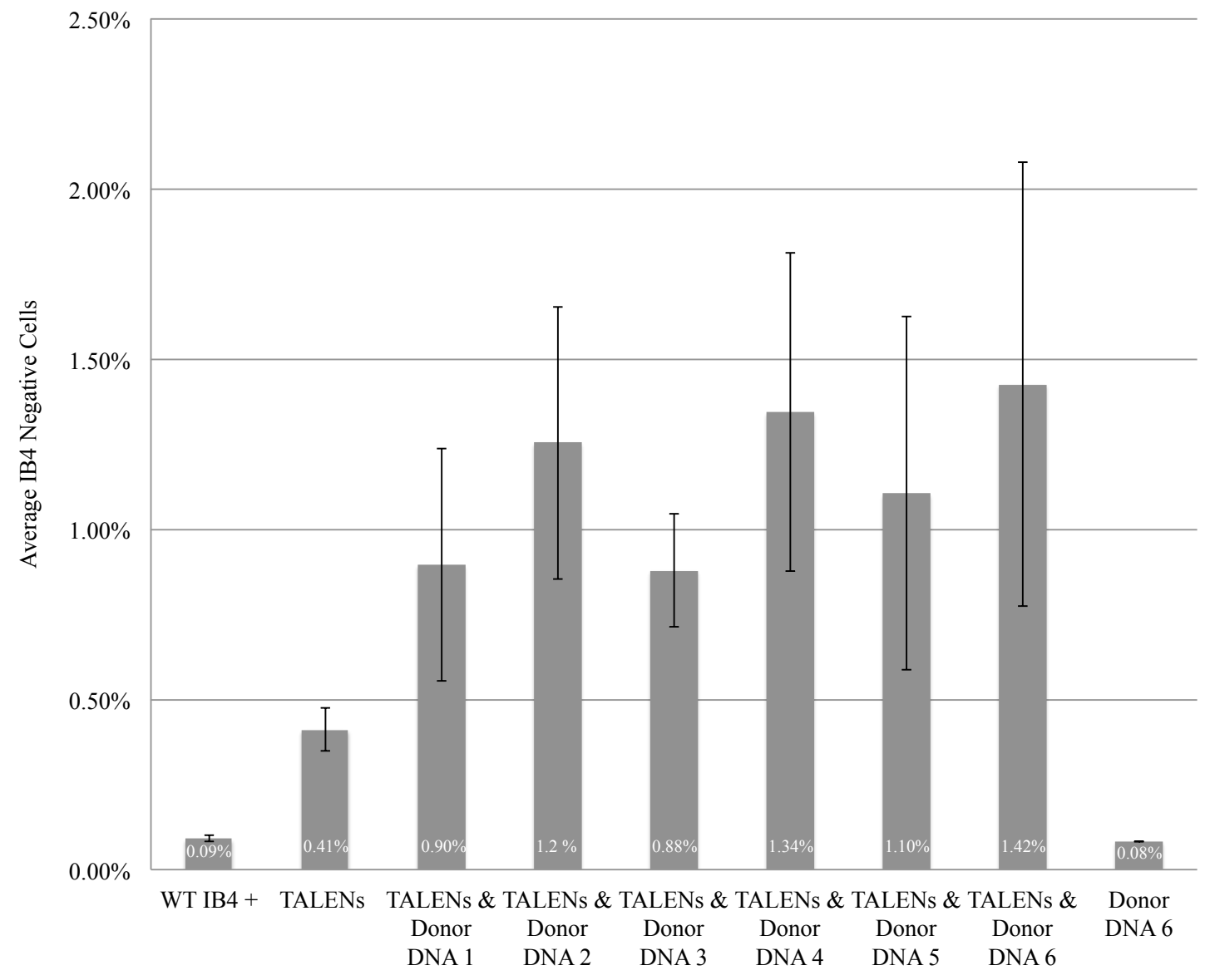

Figure 7. Targeting of GGTA1 locus via TALENs and varying lengths of Donor DNA.

A) Average IB4 negative cells are represented in each column along with the standard error of means (4 replicates). GGTA1 null cells were counter-selected using flow cytometry post TALEN transfection, including controls wild-type Minnesota Miniature (WT IB4 +) cells, homozygous KO GGTA1 (D.KO IB4 -) cells (NSRRC), WT cells transfected with TALENs alone, and WT cells transfected with longest donor DNA (TALEN 6).

B) All treatments compared to WT control, WT control transfected with TALENs alone, and longest donor DNA. 


\section{Disruption of GGTA1 Gene}

When TALENs designed for the GGTA1 gene were introduced into female $C M A H$ null fibroblast cells with donor DNA, GGTA1 null cells were detected. After transfection and sorting of cells that lacked the Gal-epitope, the Gal negative cells were plated at clonal density. DNA was isolated from 66 cell colonies, and then the DNA was used to determine the type of mutations within GGTA1 by PCR (data not shown). Zero colonies showed targeted mutation of the GGTA1 gene via homologous recombination and six colonies showed targeted bi-allelic mutation of the GGTA1 gene via NHEJ with major deletions (395-716 bp). A handful of colonies that did not have major deletions were also sequenced. All contained a single bp deletion near the Right TALEN recognition site.

\section{Production of Bi-Allelic GGTA1 Knock-out Miniature Pigs in a CMAH-null Background}

Upon screening for GGTA1 KO events by both flow cytometry and PCR, three cell colonies were used to produce $C M A H / G G T A 1$ DKO pigs. Two colonies (26 \& 30) that harbored the same homozygous deletions of $395 \mathrm{bp}$ and the colony (22) that harbored a homozygous deletion of $719 \mathrm{bp}$ of GGTA1 were used to produce the $C M A H / G G A T 1$ DKO pigs. A single SCNT was performed, 183 reconstructed embryos were transferred into a single surrogate, and produced 3 piglets (Figure 8). Genotyping from the cloned pigs showed the expected deletions of the GGTA1 and $C M A H$ genes (Figure 8). Two piglets harbored a $395 \mathrm{bp}$ deletion, one piglet had a $716 \mathrm{bp}$ deletion, and for all three piglets, the genotypes were bi-allelic modifications for the respective deletions (Figure 8). 
Since the IB4 lectin from Bandeiraea simplicifolia binds the Gal epitope (Hayes \& Goldstein, 1974), a FITC conjugated IB4 lectin was applied to fibroblasts that were isolated from the tail of the live piglets. In contrast to wild-type cells a fluorescence signal for IB4 could not be detected on cells from any of the three piglets (Figure 8) indicating the lack of Gal-epitope and implying a loss of function. 


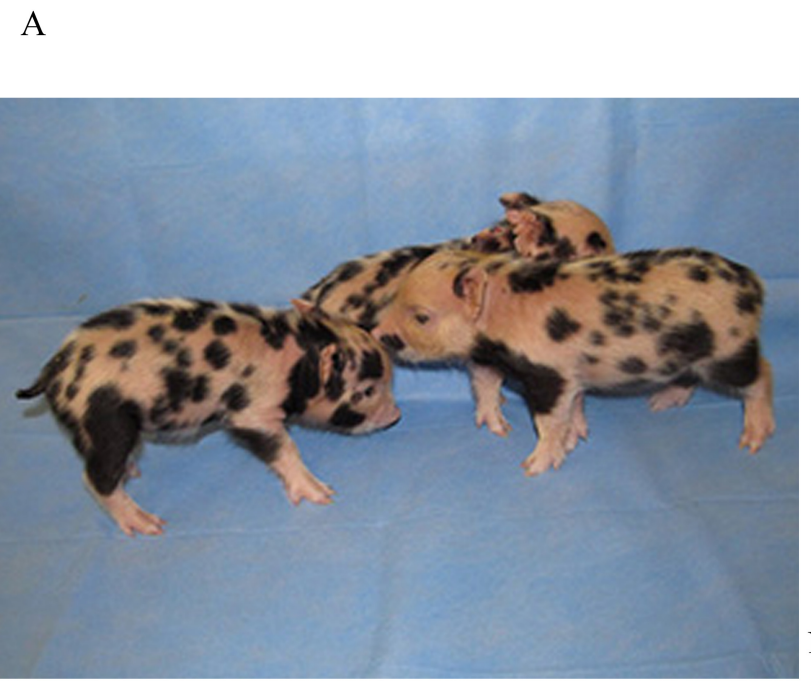

$\mathrm{D}$
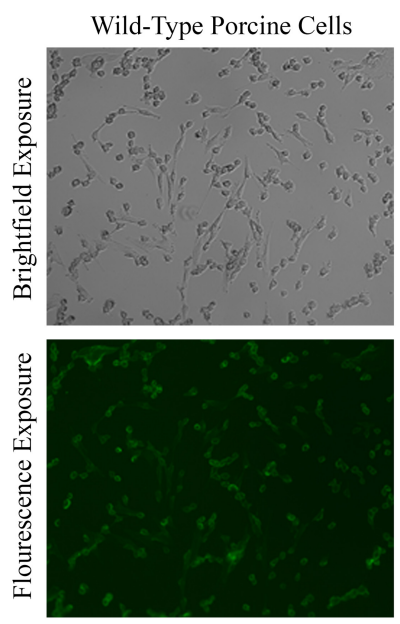

Piglet 71-1 Tail Fibroblasts
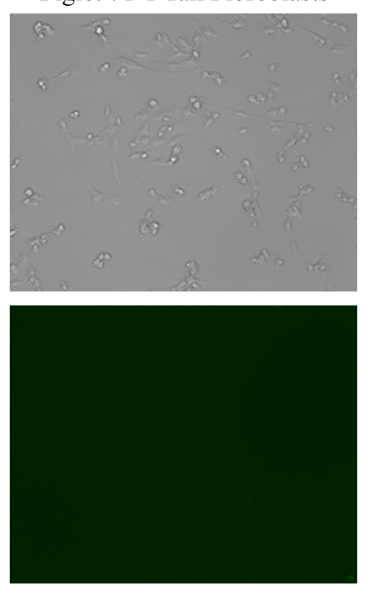

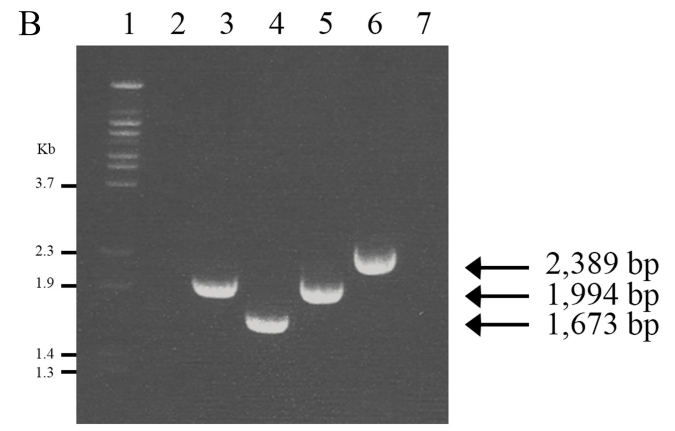

$\mathrm{C}$

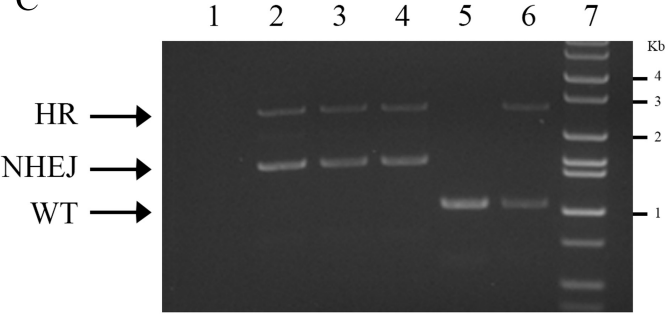

Piglet 71-2 Tail Fibroblasts

Piglet 71-3 Tail Fibroblasts
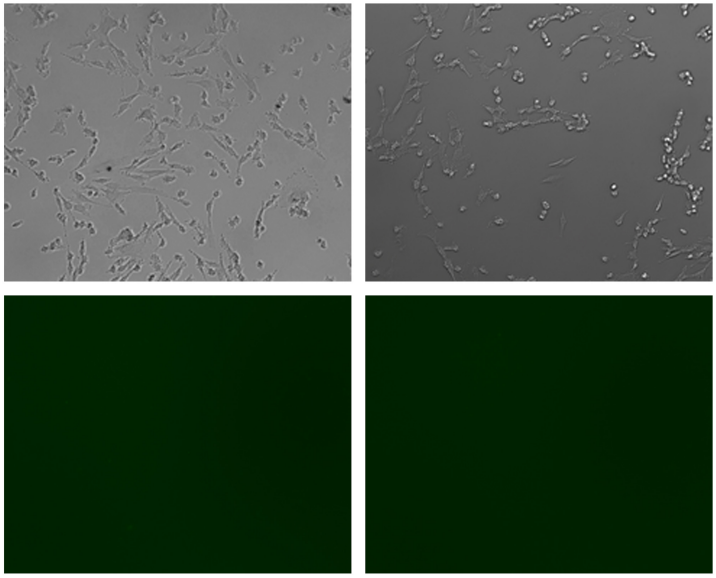

Figure 8. CMAH/GGTA1 DKO Pigs. A) Image of $C M A H / G G T A 1$ DKO pigs. B) Genotyping of DKO Pigs, GGTA1 locus. For genotyping, PCR was performed to verify KO of GGTA1 by amplifying the entire exon 4 junction $(2,389 \mathrm{bp}$ for the endogenous gene). Lane 1: DNA Ladder, Lambda Genome digested with BstEII (NEB), Lane 2: empty lane, Lane 3: Piglet 71-1, Lane 4: Piglet 71-2, Lane 5: Piglet 71-3, Lane 6: Wildtype (WT) control, and Lane 7: $\mathrm{H}_{2} \mathrm{O}$ negative control. PCR products from piglets 71-1 and 71-3 indicate that both alleles have a major deletion of $395 \mathrm{bp}$ (lanes 3 and 5, respectively). PCR product from piglet 71-2 indicates that both alleles have a major deletion of 716 bp (lane 4). C) Genotyping of DKO Pigs, CMAH locus. For genotyping, a PCR was run to verify KO of $C M A H$. A left arm PCR was performed to amplify the left HR junction (1.2 kb for endogenous WT, a $3.2 \mathrm{~kb}$ for $\mathrm{KO}$ by $\mathrm{HR}$, and $1.7 \mathrm{~kb}$ for partial insertion of selectable marker) by using ScS5 and $C M A H \mathrm{R}$ (Kwon et al., 2013). PCR products from biallelic $C M A H \mathrm{KO}$ pigs confirmed one allele was targeted through $\mathrm{HR}$ and the other allele was targeted through NHEJ; lane 1: $\mathrm{H}_{2} \mathrm{O}$ negative 
control, lane 2 - 4: piglets 71-1, 2, \& 3, lane 5: WT control, lane 6: heterozygous targeted $C M A H$ control pig, lane 7: DNA Ladder. D) Cell surface expression of the Gal epitope by using IB4 Lectin-FITC. The WT cells clearly have lectin binding, thus GGTA1 expression. All three $C M A H / G G T A 1$ DKO pigs clearly don't have lectin binding, thus are lacking GGTA1 expression. Cells were imaged at $10 \times$ magnification, with a 5 second exposure. 
Decreased transcript level of H-D and Tn-related Genes in CMAH \& GGTA1 DKO Pig Cells

The Hanganutziu-Deicher antigen (H-D) plays a pivotal role in acute immune rejection of pig xenografts (Ezzelarab et al., 2005; Park et al., 2011; Park et al., 2012). Generally, H-D antigen families are classified as 2 different subfamilies; ST3Gal (ST3Gal1, ST3Gal2, ST3Gal3, ST3Gal4, ST3Gal5, and ST3Gal6) and ST6Gal (ST6Gal1 and ST6Gal2), according to the carbohydrate linkages synthesized (Harduin-Lepers et al., 2005). To normalize the mRNA level of WT-, CMAH biallelic KO-, and $C M A H / G G T A 1$ biallelic DKO-pigs, $A C T B$ mRNA was used as an internal standard. After normalization with ACTB mRNA, ST3GAL1, ST3GAL3, ST3GAL4, ST6GAL1, and ST6GAL2 gene expression in $C M A H / G G T A 1$ biallelic DKO-pigs were significantly down-regulated, whereas ST3GAL2 was up-regulated, compared to those of WT and CMAH biallelic KO pigs, respectively (Figure 9). This observation suggested that down-regulated ST3GAL1, ST3GAL3, ST3GAL4, ST6GAL1, and ST6GAL2 in CMAH/GGTA1 biallelic DKO-pigs potentially should result in decreased Sia $2,3 \mathrm{Gal} \beta 1,3 \mathrm{GalNAc}-\mathrm{R}$, Sia $2,3 \mathrm{Gal} \beta 1,4 \mathrm{GlcNAc-R}$ and Sia $\alpha 2,6 \mathrm{Gal} \beta 1,4 \mathrm{GlcNAc}-\mathrm{R}$ expression, but increased

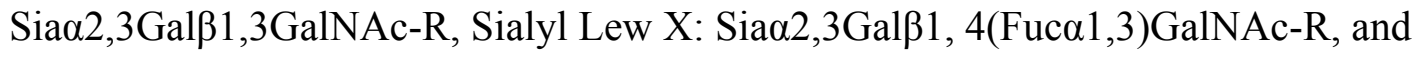
Sia $2,4 \mathrm{Gal} \beta 1,4 \mathrm{GlcNAc}-\mathrm{R}$ expression, respectively, that act as an immune antigen within transplanted recipients. Also, ST6GALNAC3 expression for Sialyl-Tn antigen, GALNT2, GALNT3, GALNT4 and GALNT7 expression for Tn antigen in biallelic CMAH KO pigs were significantly down-regulated compared with $C M A H$ biallelic KO pigs (Figure 9). 
A)

\begin{tabular}{ccccc}
\hline Antigen & Gene & WT & CMAH KO & Double KO \\
\hline & ST3Gal1 & $1.049 \pm 0.048$ & $0.440 \pm 0.020^{* *}$ & $0.035 \pm 0.001^{* * *}$ \\
& ST3Gal2 & $1.031 \pm 0.033$ & $0.150 \pm 0.009^{* * *}$ & $0.302 \pm 0.119^{*}$ \\
H-D antigen & ST3Gal3 & $1.038 \pm 0.037$ & $0.290 \pm 0.012^{* * *}$ & $0.178 \pm 0.005^{* * *}$ \\
& ST3Gal4 & $1.040 \pm 0.035$ & $0.562 \pm 0.037^{* *}$ & $0.311 \pm 0.006^{* * *}$ \\
& ST6Gal1 & $1.046 \pm 0.067$ & $0.336 \pm 0.004^{*}$ & $0.018 \pm 0.001^{* * *}$ \\
& ST6Gal2 & $1.038 \pm 0.053$ & $0.638 \pm 0.055^{*}$ & $0.001 \pm 0.000^{* * *}$ \\
\hline \multirow{4}{*}{ Sialyl Tnantigen } & ST6GalNac2 & $1.087 \pm 0.076$ & $0.604 \pm 0.017^{*}$ & $1.589 \pm 0.115^{*}$ \\
& ST6GalNac3 & $1.079 \pm 0.112$ & $0.074 \pm 0.033^{*}$ & $0.003 \pm 0.002^{*}$ \\
& ST6GalNac6 & $1.048 \pm 0.046$ & $0.196 \pm 0.009^{* * *}$ & $0.234 \pm 0.008^{* * *}$ \\
\hline & GalNT1 & $1.015 \pm 0.026$ & $0.463 \pm 0.022^{* * *}$ & $0.491 \pm 0.007^{* *}$ \\
& GalNT2 & $1.046 \pm 0.066$ & $1.311 \pm 0.031$ & $0.582 \pm 0.094^{*}$ \\
& GalNT3 & $1.042 \pm 0.056$ & $1.413 \pm 0.104$ & $0.249 \pm 0.023^{* *}$ \\
& GalNT4 & $1.052 \pm 0.023$ & $0.621 \pm 0.023^{*}$ & $0.414 \pm 0.018^{* *}$ \\
& GalNT7 & $1.053 \pm 0.039$ & $0.801 \pm 0.039$ & $0.336 \pm 0.026^{*}$ \\
\hline
\end{tabular}

$* \mathbf{P}<0.005, * * \mathbf{P}<0.0001, * * * \mathbf{P}<0.00001$ 
B)

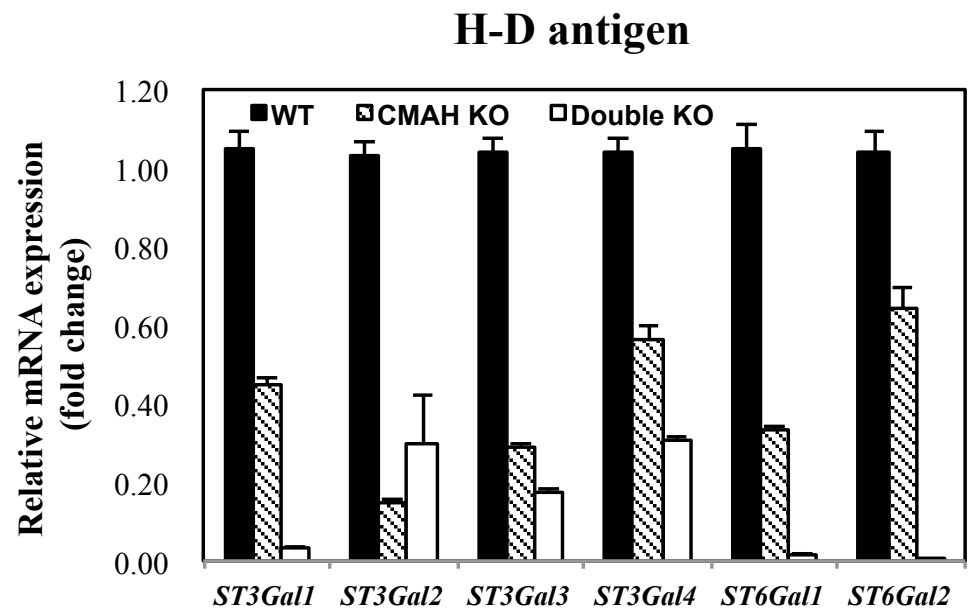

Sialyl Tn antigen

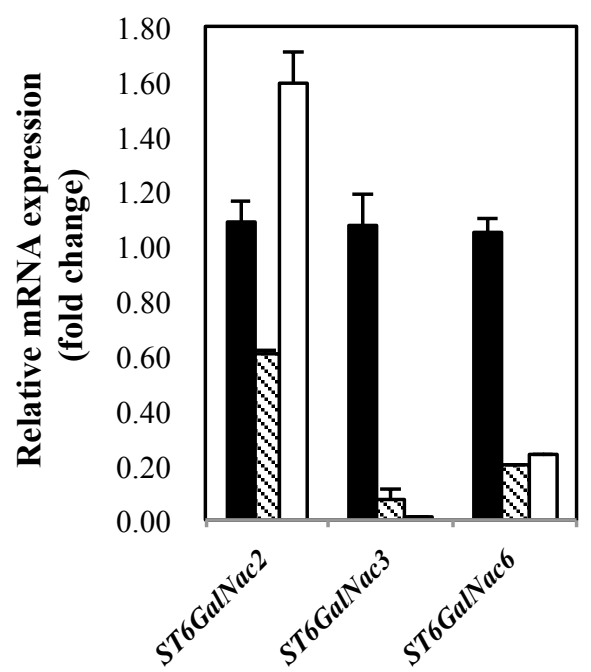

Tn antigen

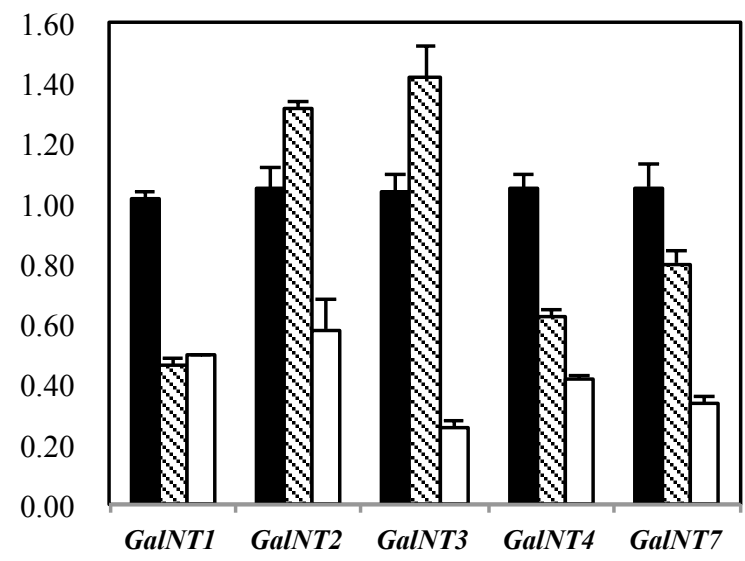

Figure 9. Sialyltransferase gene expression levels in control, biallelic $C M A H \mathrm{KO}$, and biallelic $\boldsymbol{C M A H}$ and $\boldsymbol{G G T A 1}$ DKO pigs. A) Comparison of sialyltransferase gene expression in control-, CMAH KO-, and $C M A H / G G T A 1$ DKO-derived pig fibroblast cells by using real-time RT-PCR. B) Quantification of real-time RT-PCR analysis in control-, $C M A H$ KO-, and $C M A H / G G T A 1$ DKO-pig fibroblast cells. All RT-PCR reactions were conducted in triplicate and normalized with pig actin mRNA. Each of $C M A H \mathrm{KO}-$ and $C M A H / G G T A 1$ DKO-pig relative values is presented as an $\mathrm{n}$-fold expression difference compared to the control pig, which was set as 1 . 


\section{Discussion}

Gene targeting allows precise modifications to be made in cells for the functional analysis for the gene of interest. However, the fairly low efficiency of traditional gene targeting has limited the utility of gene targeting in the study of gene function. The application of custom nucleases has enabled new methods to edit the genomes in a variety of species. To date, three different types of programmable nucleases, ZFNs (Kim et al., 1996), TALENs (Boch et al., 2009), and CRISPR/Cas9 (Jinek et al., 2012) have been used for genome editing. These tools facilitate the induction of DSBs in a targetspecific manner. Upon genomic breakage, cells can repair the damage through one of two major DNA repair systems, NHEJ or HR. If the break is repaired by NHEJ, repaired sequences frequently harbor insertions or deletions. The mechanism of HR enables a precise repair of the genomic break, but provides a much lower frequency (Capecchi, 1989). Traditional gene targeting approaches, which utilize HR machinery in the cell, have used targeting arms in the range of $1-8 \mathrm{~kb}$ in length of homology compared to the target locus (Hasty \& Bradley, 1993). However, successful HR has also been reported using less than $0.5 \mathrm{~kb}$ homologous arms (Hasty, Rivera-Perez, \& Bradley, 1991). In general, the length of contiguous sequence identity is the major determinant of HR efficiency (Waldman \& Liskay, 1988). In addition, Smih et al. (1995) demonstrated that gene targeting through HR could be stimulated by genomic DSBs introduced by a restriction enzyme. Customized nucleases provide a means to generate DSB at specific locations within a genome, thereby increasing the efficiency of gene targeting. Although these nucleases are used in genetic engineering, standards for donor DNA design are not 
yet established. Therefore we wanted to evaluate the effect of donor DNA length and nuclease-mediated gene targeting. Here, we describe the disruption of two genes (CMAH and GGTA1) through ZFN- and TALEN-mediated gene targeting in pigs. Since nucleases are being utilized in the genetic engineering of pigs, an increase in the efficiency of gene targeting will have a major impact for the production of genetically engineered pigs.

The primary goal of the projects was to generate $C M A H / G G T A 1$ DKO cells/pigs utilizing nucleases and the secondary goal was to evaluate the effect of minimum homology length to direct HR after nuclease-mediated DSBs. To illustrate the proof of concept that small repair template (donor DNA) can facilitate HR, we utilized a pair of functional ZFNs (Kwon et al., 2013) in conjunction with three different sizes of donor DNA to facilitate HR. In our initial study, we employed an in vitro HR detection assay to determine the significance of the size of homology arms to the efficiency of HR. We determined the HR frequency by using a PCR method. Overall, we detected recombination events with all lengths of homology arms (as small as 35 bp and as long as $125 \mathrm{bp}) ; 125 \mathrm{bp}$ arms resulted in 10 fold higher efficiency of HR than that of $35 \mathrm{bp}$ (Figure 5). Thus, our ZFN-CMAH results suggest that donor DNA with a minimum of 35 bp of homology is able to successfully facilitate HR during ZFN-mediated gene targeting, but an increase in homology increased the targeting efficiency. We also demonstrated that this strategy can be used to introduce specific mutations rather than just KO's caused by ZFN-mediated NHEJ, but at a much lower frequency.

Given our ability to facilitate HR with small donor DNA in vitro, we chose to investigate the lengths of donor DNA and their effects with TALEN-mediated gene 
targeting of the porcine GGTA1 gene. In an attempt to determine the minimum length of homology utilizing TALEN-mediated gene targeting, we demonstrated that the addition of donor DNA increases the bi-allelic modifications when compared to TALEN-mediated gene targeting without donor DNA. As our primary goal was to identify homozygous GGTA1 KO cells, GGTA1 null cells were counter-selected by using flow cytometry to detect the Gal deficient cells. The introduction of any sized donor DNA resulted in a higher amount of bi-allelic modifications. However, the modifications were point mutations. The normal cellular repair pathway of NHEJ likely introduced these mutations.

When comparing the two methods of nuclease-mediated gene targeting (ZFN vs. TALEN), the differences observed are likely due to: 1) experimental variation; 2) the higher fidelity of the PCR detection methods (ZFN experiment); and/or 3) the donor DNA may have an effect on the NHEJ pathway rather than through the HR repair mechanism (TALEN experiment). In the ZFN/CMAH study we exclusively measured the efficiency of HR, while in the TALEN/GGTAl experiments a lectin-based approach screened for the phenotypic changes of the Gal epitope after biallelic modifications to the GGTA1 gene. Even though our ZFN/CMAH results demonstrated that HR was occurring, HR did not occur and create biallelic modifications in the TALEN/GGTA1 results. However, we did observe an increase in GGTA1-null cells when both donor DNA and TALENs were applied. There are two potential explanations for this. The first is that our study only assessed for bi-allelic modifications of GGAT1 (KO cells); we may have unintentionally created a bias to observe cells that were modified by the NHEJ pathway. The second is that the donor DNA may actually play a role in NHEJ and not just HR. As 
previously reported (Kwon et al., 2013; Whitworth et al., 2014), we have observed an increase in targeting efficiency in the presence of donor DNA, but NHEJ and not HR is observed. A potential explanation is that HR and NHEJ pathways are not independent, but can, or potentially, do act together in the repair process.

The Gal epitope has been identified as the primary target for natural human antibodies, and the successful KO of the GGTAl gene was an important step toward overcoming the major immunological barrier in pig-to-human xenotransplantation (Dai et al., 2002; Lai et al., 2002). The $C M A H$ gene has also been identified as another potential major xeno-antigen (Basnet et al., 2010; Tahara et al., 2010). As previously reported by Kwon et al. (2013), the ablation of the $C M A H$ gene resulted in the reduction of expression of Hanganutziu-Deicher (H-D), Thomsen-Friedenreich (TF), Tn, and sialylTn. It is known that all four gene families play a pivotal role in acute immune rejection of pig xenografts (Ezzelarab et al., 2005). In this study, we were able to demonstrate that the gene expression in most instances was drastically reduced in the $C M A H / G G T A 1$ DKO cells compared to wild-type cells and even further down regulated compared to CMAH null cells.

In conclusion, the methods described in this study allow for an approach to generate $\mathrm{KO}$ cells and pigs with an increased targeting efficiency. The gene editing methods can be applied to other genes as well as other mammalian systems. Additionally, we predict that the utility of the $C M A H / G G T A 1 \mathrm{DKO}$ pigs can be a valuable source for the study of pig-to-human xenotransplantation. 


\title{
CHAPTER IV
}

\section{CRISPR/CAS9-MEDIATED GENE STACKING/GENE TARGETING PRODUCES SWINE WITH HIGH UBIQUITOUS EXPRESSION OF HUMAN CD55 AND HIGH ENDOTHELIAL-SPECIFIC EXPRESSION OF HUMAN CD39}

\begin{abstract}
Genetic engineering facilitates heritable modification of target genomes. Modifications can be site-specific or random. Though inefficient, homologous recombination allows for precise genome modification. Random integration is more efficient but the orientation and location of the introduced DNA is not regulated. Thus, an efficient method for site-specific integration would have utility. Double strand break of the target sequence is often a rate-limiting step of homologous recombination. Geneediting techniques can now be designed to create target-specific cleavage and facilitate the insertion of exogenous DNA through homologous recombination. The specific objective of this project was to utilize the CRISPR/Cas9 system to direct single-copy integration of exogenous DNA into the target site and evaluate the frequency of insertion. To evaluate the feasibility of this strategy, we inserted two transgenes (Hygromycin and hCD39) into a previously modified GGTA1 locus (GGTA1 KO harboring a Neomycin cassette and a $h C D 55$ transgene cassette, GGTA $\left.1^{\mathrm{IRES}-\mathrm{Neo} ; \mathrm{CAG}-h C D 55 /+}\right)$. We observed an
\end{abstract}


increase in gene targeting efficiency from $8.7 \%$ to $37.8 \%$ when using the CRISPR/Cas 9 system over traditional methods. In addition, we inserted four transgenes (Neomycin, Hygromycin, $h C D 39$, and $h C D 55$ ) into wild-type cells to disrupt the GGTA1 locus in a single step. Here, we observed an increase in average gene targeting efficiency from $2.2 \%$ to $40.0 \%$ when using the CRISPR/Cas9 system. These studies demonstrate that the CRISPR/Cas9 system is an efficient method to facilitate the addition of multiple transgenes. The genetically engineered fibroblasts are compatible with somatic cell nuclear transfer as a day 45 fetus and 2 live piglets were generated.

\section{Introduction}

Genetic engineering technologies of swine have advanced to a point where imagination and resources are the only limitations. As the requirement for genetic modifications become more complex, a need to genetically link multiple transgenes has become apparent. In other words, it has become logistically and economically important to ensure that multiple transgenes are inherited together. This consideration is particularly important in regard to maintenance and propagation of genetic lines that harbor multiple genetic modifications. The propagation and maintenance of animals with an increasing number of modifications warrants a large degree of complexity to yield the desired genotype of all modifications.

We have chosen to apply a step-wise strategy that places each new transgene adjacent to the previous transgene(s) such that each modification becomes genetically 
linked to previous modifications. In the end, transmission of the desired genotype in a wild-type cross would result in half the progeny. Upon breeding of two heterozygous/hemizygous animals, one fourth of the progeny would be expected to be homozygous. The genetics follows normal Mendelian inheritance and simple breeding programs can be implemented.

The objective of this project was to develop a strategy that would allow for the sequential addition of multiple transgenes while ensuring the genetic linkage of the transgenes. In this study we utilized the Clustered Regularly Interspaced Short Palindromic Repeats/Cas9 (CRISPR/Cas9) system to facilitate a double strand break and direct integration of multiple genetically linked transgenes at an improved frequency. The ability to "knockin" additional transgenes adjacent to previously targeted genes would result in the end goal of generating transgenic pigs that have multiple transgenes that are genetically linked.

Gene targeting by homologous recombination (HR) allows for precise modifications to the target genome (Capecchi, 1989). In cells, HR a natural cellular process used to repair DNA double-strand breaks (DSBs). It has also been shown that target genome breakage is the rate-limiting step in HR (Song et al., 1985; Hasty \& Bradley, 1993; 1994; Rouet et al., 1994; Choulika et al., 1995). The CRISPR/Cas9 system includes a nuclease guided by a short RNA that pairs with the target DNA. Once paired, the Cas9 enzyme cleaves both strands of DNA creating a DSB (Jinek et al., 2012). The DSB can be repaired by non-homologous end joining (NHEJ) to generate random mutations or can be repaired using exogenous template DNA by HR. 
These studies were designed to facilitate animal models for pig-to-human xenotransplantation, as multiple modifications are likely required to overcome immunological barriers (Cooper et al., 2012). Due to the lack of viable human donor organs, the possibility of utilizing animal tissues/organs has been considered a possible solution. Pig organs are seen as a potential resource for xenotransplantation as pigs are anatomically and physiologically similar to humans (Cooper et al., 1991; Sachs, 1994; Cooper et al., 2002; Cooper, 2012). A major xenoantigen responsible for tissue rejection is the alpha 1,3-linked terminal galactose (Gal) epitope (Galili et al., 1988; Cooper et al., 1993). Humans have preformed antibodies against the Gal epitope, which initiates hyperacute rejection (HAR) of porcine cells that are naturally abundant in the epitope (Lambrigts et al., 1998). Thus, the absence of Gal expression appears to be one of the elements essential for successful xenotransplantation. The alpha 1,3galactosyltransferase (GGTAl) gene encodes the enzyme responsible for deposition of the Gal epitope (Galili et al., 1988; Cooper et al., 1993). Several groups have demonstrated the ability to disrupt the GGTA1 gene (Denning et al., 2001; Dai et al., 2002; Harrison et al., 2002; Lai et al., 2002; Jin et al., 2003; Takahagi et al., 2005). However, the absence of the Gal epitope is not the only element essential for xenotransplantation. Additional genes regulating immune function are likely required in conjunction to the disruption of the GGTA1 gene (Ramsoondar et al., 2003; Fujimura et al., 2004; Diaz-Roman et al., 2006).

In an attempt to generate a multi-transgenic xenotransplantation pig, we have developed a strategy that combines gene stacking with gene targeting such that a series of transgenes can be placed within the disrupted GGTAl locus. To produce such pigs, we 
previously targeted the GGTAl locus through homologous recombination with a targeting vector that contains a floxed neomycin selectable marker $\left(\mathrm{Neo}^{\mathrm{R}}\right)$, a transgene that codes for the human protein $C D 55$, and a PhiC31 attB site (Figure 11) (Beaton et al., 2013). To facilitate the addition of subsequent transgenes in a sequential manner, we chose to use a gene-stacking system that utilizes the CRISPR/Cas9 system to generate a double strand break in the genomic DNA to increase the efficiency of homology directed repair of a gene targeting vector (Figure 11). In the first set of experiments, we chose to repurpose the unique PhiC31 att $\mathrm{B}$ as a target sequence for the CRISPR/Cas9 system and in the presence of a targeting vector we were able to achieve targeted insertion of two additional genes (Hygromycin and $h C D 39$ ). Further, we implemented a supplementary strategy that employs the CRISPR/Cas9 system to simultaneously insert four exogenous genes (Neomycin, Hygromycin, $h C D 55, h C D 39$ ) into the GGTA1 locus (Figure 12). In addition to the insertion capabilities of our targeted insertion strategies, we have engineered the use of an excision-favoring recombinase system, Cre/loxP, to remove DNA that has become superfluous after integration. 


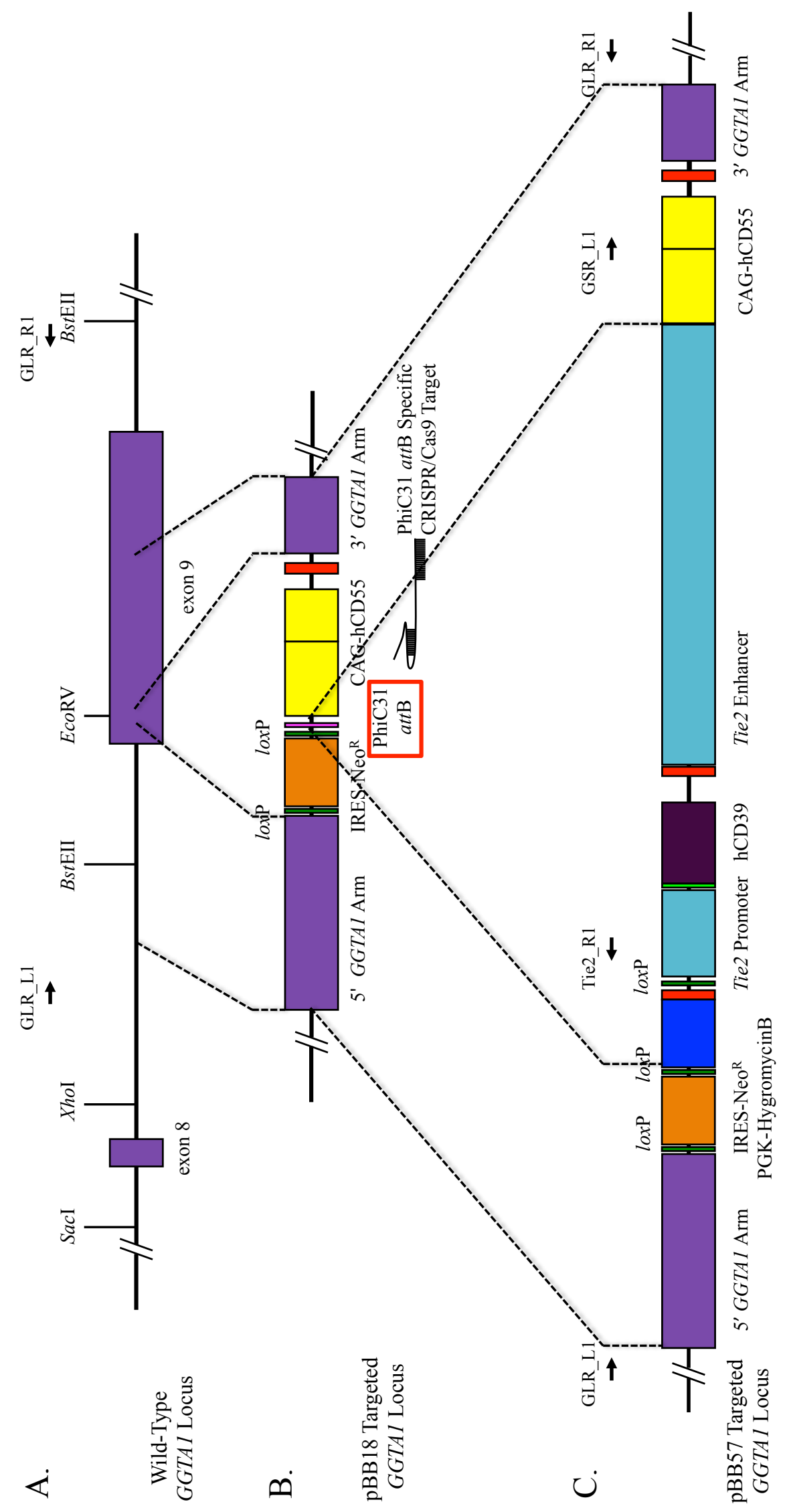


Figure 10. Graphical representation of PhiC31 attB specific CRISPR/Cas9mediated gene targeting. A.) Top diagram illustrates wild-type GGTA1 locus. B.) The middle diagram illustrates a previously targeted GGTA1 locus. C.) The lower diagram illustrates a pBB57-targeted allele after the PhiC31 attB CRISPR sgRNA facilitated the targeted insertion of pBB57. The homologous sequence in the pBB57-targeting vector was used to promote homologous recombination (5' homologous arm: 5' GGTA1, IRES$\mathrm{Neo}^{\mathrm{R}}$ and 3' homologous arm: CAG- $h C D 55,3^{\prime}$ GGTAl). Short arrows along with their respective names; indicate the position of the primers used for the PCR assays. The PCR assays were designed to amplify only targeting events. 


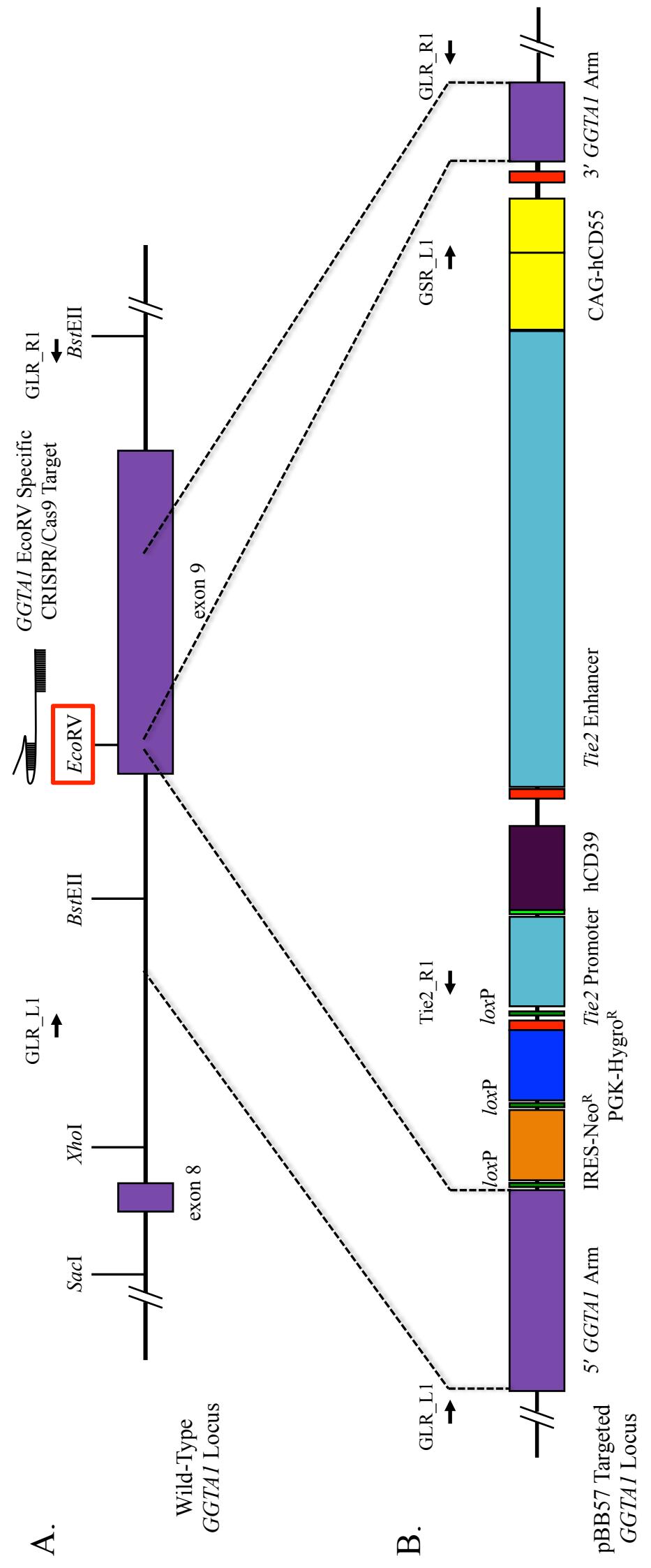


Figure 11. Graphical representation of GGTA1 EcoRV specific CRISPR/Cas9mediated gene targeting. A.) Top diagram illustrates wild-type GGTA1 locus. B.) The lower diagram illustrates a pBB57-targeted allele after the GGTA1 EcoRV CRISPR sgRNA facilitated the targeted insertion of pBB57. The homologous sequence in the pBB57-targeting vector was used to promote homologous recombination (5' homologous arm: 5' GGTA1 and the 3' homologous arm: 3' GGTA1). Short arrows along with their respective names; indicate the position of the primers used for the PCR assays. The PCR assays were designed to amplify only targeting events. 


\section{Materials And Methods}

All restriction enzymes used were sourced from New England Biolabs (NEB) unless otherwise noted.

\section{Targeting Vector Construction}

A single targeting construct, pBB57, was assembled from several intermediate plasmids. The pBB57 targeting vector included several components: 1) a 6,641 bp GGTA1 genomic fragment (5' Arm: 4,822 bp; 3' Arm: 1,819 bp); 2) a mammalian codon optimized neomycin resistance $\left(\mathrm{Neo}^{\mathrm{R}}\right)$ cassette, where expression stems from a promoter trap of the porcine GGTAl gene through the use of an internal ribosome entry site (IRES), flanked by lox $\mathrm{P}$ sites; 3 ) a hygromycin resistance $\left(\operatorname{Hygro}^{\mathrm{R}}\right)$ cassette, flanked by lox $\mathrm{P}$ sites; 4) an R4 Phage attachment B (attB) site; 5) a human CD39 (hCD39) cassette with endothelial specific expression, where expression is driven by a murine Tie 2 promoter and Tie2 enhancer element; and 6) a human CD55 (hCD55) cassette with ubiquitous expression, where expression is driven by the CAG promoter (Figures 11 and 12).

Previously, a targeting vector (pBB13) was generated with a 6,641 bp GGTA1 genomic fragment and a 5,740 bp loxP-IRES-mNeo ${ }^{\mathrm{R}}$-loxP-CAG/hCD55-PhiC1 attBSV40 poly (A) cassette inserted into the unique EcoRV site in exon 9 of GGTA1 (Beaton et al., 2013). A series of modifications were made to pBB13, a multiple cloning region was added and the PhiC31 att $\mathrm{B}$ site was removed and inserted between the second lox $\mathrm{P}$ site and the CAG promoter, the resulting plasmid was named pBB18 (2014). The utility of relocating the att $\mathrm{B}$ site will be advantageous to future additions of transgenes and the 
ability to remove superfluous DNA, i.e. selectable markers or E. coli backbone components, without disrupting or destroying previously added transgenes.

The $\operatorname{Hygro}^{\mathrm{R}}$ cassette, $\mathrm{R} 4$ att $\mathrm{B}$ site, and an endothelial specific $h C D 39$ transgene cassette were sourced from commercial and lab-constructed plasmids. The $h C D 39$ was isolated from cDNA Clone: LIFESEQ2862692 (Open Biosystems, Catalog Number: IHS1380-212907370, Accession: NM_001776). A small intron, 81 bp, was amplified from porcine $C D 163$ using the primer pair $\mathrm{CD} 163$ intronL 5' GAAAATGacGcGTcCTGCAGgtgagaatcagtgaccaacctatgaa and CD163 intronR 5' ccaggcGAATTcACCACTCCetgcaaagaggaaataaaac. The small intron was digested with $M l u \mathrm{I}$ and $E c o$ RI and directionally cloned into the unique $M l u \mathrm{I}$ and $E c o$ RI sites in clone LIFESEQ2862692, generating plasmid pBB30. To provide endothelial cell-specific expression of $h C D 39$, the $h C D 39$ and $C D 163$ intron were added to a plasmid containing the murine Tie 2 promoter $(2.1 \mathrm{~kb})$ and regulatory region $(10.4 \mathrm{~kb})$, as previously defined (Schlaeger et al., 1997). A 2,601 bp Sbfl/XbaI fragment, containing the $C D 163$ intron and $h C D 39 \mathrm{cDNA}$, were isolated from pBB30 and directionally cloned into a previously modified Tie2 promoter/Tie2 enhancer plasmid (Suvorava \& Kojda, 2009; Whyte et al., 2011) (a generous gift of G. Kojda für Pharmakologie und Klinische Pharmakologie, Heinrich-Heine-Universität, Dusseldorf, Germany) at the compatible Sbfl/NheI sites, producing the plasmid pBB31. For the addition of the R4 attB site and the Hygro ${ }^{\mathrm{R}}$ cassette, a 15,465 bp AbsI/NotI fragment harboring the $h C D 39$ transgene cassette was isolated from pBB31 and directionally cloned into pBB53 (Beaton \& Wells, 2014) at the compatible $A b s \mathrm{I} /$ NotI sites, producing the plasmid pBB55. A 17,615 bp Sbfl fragment from pBB55 was cloned into pBB18's Sbfl site to generate pBB57. The final resulting 
plasmid was 33,355 bp in total size. The targeting vector was linearized using $B s t \mathrm{BI}$ prior to transfection.

Design and Construction of CRISPR/gRNA Expression Vectors

For the CRISPR/Cas9 system, target guide sequences for single guide RNAs (sgRNA) were designed to precede the Streptococcus pyogenes protospacer adjacent motif (PAM) as previously described (Jinek et al., 2012; Mali et al., 2013). Guide sequences were evaluated for RNA structure (Zuker, 2003) and potential off-target cleavage effects using Sus scrofa (pig) NCBI Nucleotide BLAST (https://blast.ncbi.nlm.nih.gov/Blast.cgi?PAGE_TYPE=BlastSearch\&BLAST_SPEC=O GP_9823_10718). The sequences of the sgRNAs were designed to regions of the engineered PhiC31 attB site and to the EcoRV region in exon 9 of GGTA1.

To target PhiC31 attB, three sgRNAs were designed. PhiC31 attB \# 1 (pBB67) and PhiC31 attB \# 2 (pBB68) sgRNAs are on the antisense strand. The PhiC31 att B \# 3 (pBB69) sgRNA is on the sense strand. The PhiC31 attB sgRNA sequences, including the PAM sequence are: PhiC31 attB \# 1 (pBB67) 5'TCGCGCCCGGGGAGCCCAAGGG-3', PhiC31 attB \# 2 (pBB68) 5'GTACAAGTCGACTTCGCGCCCGG-3', PhiC31 attB \# 3 (pBB69) 5'-

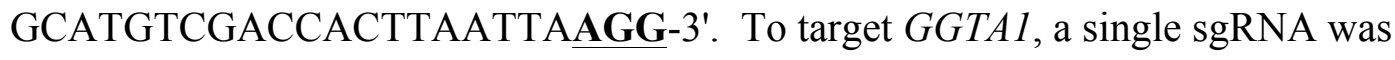
designed to target the sense strand. The GGTA1 sgRNA sequence is 5'ATCTGCAAATACATACTTCATGG-3'. For each target sgRNA, following the Zhang laboratory protocol (http://www.genome-engineering.org/crispr/wpcontent/uploads/2014/05/CRISPR-Reagent-Description-Rev20140509.pdf) a pair of 
oligonucleotides (Table 8) were annealed and cloned into pX330 (Addgene plasmid \#42230) (Cong et al., 2013). The pX330 vector is a vector that contains two expression cassettes, a human codon-optimized Streptococcus pyogenes Cas9 and a chimeric sgRNA. The resulting expression vectors were named pBB67, pBB68, pBB69, and pBB71. pBB67 - 69 are specific to PhiC31 att $\mathrm{B}$ and $\mathrm{pBB} 71$ is specific to GGTA1. 
Table 8. Designed sgRNAs. Forward and Reverse primers were annealed following the Zhang protocol.

\begin{tabular}{|l|l|}
\hline \multicolumn{1}{|c|}{ sgRNA Primers } & Sequence $\left(5^{\prime}-3{ }^{\prime}\right)$ \\
\hline Forward - PhiC31 attB \# 1 (pBB67) & caccgTCGCGCCCGGGGAGCCCAA \\
\hline Reverse - PhiC31 attB \# 1 (pBB67) & aaacTTGGGCTCCCCGGGCGCGAc \\
\hline Forward - PhiC31 attB \# 2 (pBB68) & caccGTACAAGTCGACTTCGCGCC \\
\hline Reverse - PhiC31 attB \# 2 (pBB68) & aaacGGCGCGAAGTCGACTTGTAC \\
\hline Forward - PhiC31 attB \# 3 (pBB69) & caccGCATGTCGACCACTTAATTA \\
\hline Reverse - PhiC31 attB \# 3 (pBB69) & aaacTAATTAAGTGGTCGACATGC \\
\hline Forward - GGTA1 E9 (pBB71) & caccgATCTGCAAATACATACTTCA \\
\hline Reverse - GGTA1 E9 (pBB71) & aaacTGAAGTATGTATTTGCAGATc \\
\hline
\end{tabular}




\section{Preparation of Porcine Fibroblast Cells and Culture Conditions}

For the CRISPR/Cas9-mediated gene stacking/targeted insertion experiments, tail tissue was collected and minced from a male piglet (NSRRC:0037, National Swine Resource and Research Center, University of Missouri), GGTA1 ${ }^{\text {IRES-Neo; CAG-hCD55/+ }}$ Minnesota Miniature Pig genetic background (Beaton et al., 2013). The minced tissue was washed and cultured in complete medium (Dulbecco's modified Eagle's medium (DMEM) containing $2.77 \mathrm{mM}$ glucose, $1.99 \mathrm{mM} \mathrm{L-glutamine,} \mathrm{and} 0.5 \mathrm{mM}$ sodium pyruvate (Cellgro, Manassas, VA), supplemented with $1 \mathrm{mM}$ L-alanyl-L-glutamine (Cellgro) and $15 \%$ fetal bovine serum (FBS) (HyClone), at $38.5^{\circ} \mathrm{C}$ in $5.5 \% \mathrm{CO}_{2}, 5 \% \mathrm{O}_{2}$, and $89.5 \% \mathrm{~N}_{2}$ balanced humidified air. After two passages, cultured cells were harvested and frozen at $-80^{\circ} \mathrm{C}$ in aliquots of $90 \%$ FBS with $10 \%$ dimethyl sulfide (DMSO, Sigma) and stored in liquid nitrogen.

For the CRISPR/Cas9-mediated gene targeting experiments, wild-type male and female fetal fibroblast cell lines of the Minnesota Miniature Pig genetic background (NSRRC:0005) were established from day 35 and day 45 fetal collections. Fetuses were collected into individual $50 \mathrm{~mL}$ conical bottom centrifuge tubes. The fetuses were washed twice in Dulbecco's PBS (Invitrogen) to remove excess debris, once in $70 \%$ ethanol to disinfect, and once more in Dulbecco's PBS to remove excess ethanol. The head and viscera were removed; the remaining tissue was minced and cultured in complete medium. After a single passage, the cultured cells were harvested and frozen at $-80^{\circ} \mathrm{C}$ in aliquots of $90 \% \mathrm{FBS}$ with $10 \% \mathrm{DMSO}$ and stored in liquid nitrogen. Four male and three female lines were established and used in the experiments. 
Transfection of Targeting Vector and PhiC31/attB CRISPR Expression Vectors

Transfection conditions were as previously reported (Beaton \& Wells, 2014). As there is not an optimized protocol to perform homology directed targeting in porcine somatic cells, three series of transfections were conducted. To evaluate the molecular ratio of Donor DNA to sgRNA/Cas9 expression vector, varying amounts of Donor DNA and sgRNA/Cas9 expression vectors were tested. The transfections were performed in male passage three porcine ear and tail fibroblasts, GGTA1 $1^{\mathrm{IRES}-\mathrm{Neo} \text {; PhiC31 attB; CAG- } h C D 55 /+}$ (NSRRC:0037). The fibroblast cells were cultured for 72 hours and grown to $70-90 \%$ confluency in complete medium at $38.5^{\circ} \mathrm{C}$ in $5.5 \% \mathrm{CO}_{2}, 5 \% \mathrm{O}_{2}$, and $89.5 \% \mathrm{~N}_{2}$ balanced humidified air. Fibroblasts were harvested by trypsinization and were re-suspended at a density of $1 \times 10^{6}$ cells $/ \mathrm{mL}$ in a modified electroporation media (25\% OptiMEM (Invitrogen) $+75 \%$ buffered $\mathrm{KCl}$ (Sigma, St. Louis, MO; 135mM KCl, $15 \mathrm{mM}$ Tris, 11.3 mM BES, 3.7 mM PIPES, $\mathrm{pH} 7.3)$. Two hundred $\mu \mathrm{L}$ of the cell suspension $(200,00$ cells) and DNA BstBI linearized targeting vector DNA, pBB57; supercoiled sgRNA/Cas9 expression vectors - pBB67, pBB68, pBB69) were placed in a $2 \mathrm{mM}$ electroporation cuvette and the cells were electroporated by using 250 volts X 3 pulses for 1 millisecond/pulse by using a square wave generator (BTX Electro-cell Manipulator 200, San Diego, CA). Electroporated cells were cultured in complete medium in twenty $100 \mathrm{~mm}$ tissue culture plates $(\sim 10,000$ cells/plate). Twenty-four hours after culture, cells were administered Hygromycin B (300mg/L, Invitrogen) and cultured for 13 more days. Hygro $^{\mathrm{R}}$ colonies were then harvested by using cloning cylinders and screened by PCR. 
Transfection of Targeting Vector and GGTA1 CRISPR Expression Vectors

Based upon the results for the gene stacking/targeting into the GGTA1

PhiC31attB site, we chose to explore the possibility to target the GGTA1 gene by adding all four transgenes $\left(\mathrm{Neo}^{\mathrm{R}}\right.$, Hygro $^{\mathrm{R}}, h C D 39$, and $\left.h C D 55\right)$ into the GGTAl locus. In addition, based upon our results that an increasing amount of sgRNA/Cas 9 expression vector yielded higher targeting (Figure 13), we chose to further explore the ratios of donor DNA to sgRNA/Cas9 expression vector. The same transfection methods are used as described above. For this set of experiments, nine series of transfections were performed by using various ratios of donor DNA (pBB57) to a sgRNA/Cas9 vector (pBB71), which targets exon 9 of GGTA1, in male and female wild-type fetal fibroblast cells of the Minnesota Miniature pig genetic background.

\section{Screening and Analysis of Knock-out Cells and Pigs}

Thirteen days after selection, G418 resistant $\left(\mathrm{G} 418^{\mathrm{R}}\right)$ or Hygromycin B resistant $\left(\right.$ HygroB $\left.^{\mathrm{R}}\right)$ colonies were harvested by using cloning cylinders and screened by PCR. Two thirds of harvested cells were transferred to a single well of a 24-well tissue culture plate for expansion under the same $\mathrm{G} 418^{\mathrm{R}} / \operatorname{HygroB}^{\mathrm{R}}$ medium and one third of cells isolated were used for PCR analysis of targeted clones. Approximately 1,000 cells (1/3 of a colony) were re-suspended in $5 \mu \mathrm{L}$ of a lysis buffer (40mM Tris, $\mathrm{pH} 8.9 ; 0.9 \%$

Triton X-100; 0.9\% Nonidet P-40; $0.4 \mathrm{mg} / \mathrm{mL}$ proteinase $\mathrm{K}$, (Sigma)), incubated at $65^{\circ} \mathrm{C}$ for 15 minutes to disrupt the cells, and then heated to $95^{\circ} \mathrm{C}$ for 10 minutes to inactivate the proteinase $\mathrm{K}$. 
Three primer sets were used for PCR analysis by using the TaKaRa LA system (Takara Bio Inc., Japan) and are illustrated in Figures 11 and 12. The first primer pair flanked the upstream (5') homology arm and resulted in a PCR product of $11.2 \mathrm{~kb}$ from a targeted locus. One $\mu \mathrm{l}$ of cell lysate was used as template in a $25 \mu \mathrm{l}$ reaction volume with the following parameters: $94^{\circ} \mathrm{C}$ for 1 minute, followed by 30 cycles of 30 seconds at $94^{\circ} \mathrm{C}, 30$ seconds at $62^{\circ} \mathrm{C}$, and 6.5 minutes increasing 13 seconds/cycle at $68^{\circ} \mathrm{C}$, with a final extension of 5 minutes at $72^{\circ} \mathrm{C}$. The upstream assay primers were: GLR_L1 5'GGAGAGGAGAATGGTGTCACAGGGCCA-3' and Tie2_R1 5'AACTTTGCGACTTCCCGCTCGCATGG-3'. The second primer pair flanked the downstream (3') homology arm and produced a band of $3.8 \mathrm{~kb}$ from a targeted locus. One $\mu 1$ of cell lysate was used as template in a $25 \mu$ l reaction volume with the following parameters: $94^{\circ} \mathrm{C}$ for 1 minute, followed by 30 cycles of 30 seconds at $94^{\circ} \mathrm{C}, 30$ seconds at $62^{\circ} \mathrm{C}$, and 2.5 minutes increasing 5 seconds $/$ cycle at $68^{\circ} \mathrm{C}$, with a final extension of 5 minutes at $72^{\circ} \mathrm{C}$. The downstream assay primers were: GSR_L1 5'AGTGCCGTCCAGGTTACAGAAGAGAACC-3' and GLR_R1 5'GAGTAGGAGGCCCAGGGAAACAGTAGAG-3'. The third primer pair (previously described, GLR_L1 and GLR_R1) was used to evaluate the native GGTA1 locus, if there was a modification to both GGTA1 allele then the long range PCR assay would not be as predicted. The primer pair flanks the upstream (5') and downstream (3') homology arms of the targeting vector. The resulting PCR product would only generate a wild-type PCR product of $7.2 \mathrm{~kb}$. One $\mu \mathrm{l}$ of cell lysate was used as template in a $25 \mu 1$ reaction volume with the following parameters: $94^{\circ} \mathrm{C}$ for 1 minute, followed by 30 cycles of 30 seconds at $94^{\circ} \mathrm{C}, 30$ seconds at $62^{\circ} \mathrm{C}$, and 6.25 minutes increasing 15 seconds $/$ cycle at $68^{\circ} \mathrm{C}$, with a 
final extension of 13 minutes at $72^{\circ} \mathrm{C}$. For later use in SCNT, positive colonies were expanded and upon confluency were frozen at $-80{ }^{\circ} \mathrm{C}$ in aliquots of FBS with $10 \%$ DMSO and transitioned into liquid nitrogen for long-term preservation.

\section{Cre/loxP-Mediated Excision of Selectable Markers}

The genes encoding the selectable markers were introduced into the genome to aid in the selection process by isolate cells that contain the desired stacked/targeted genotype. For the addition of future modifications, selectable markers may be required to aid in the isolation of those modifications. Therefore, the removal of the selectable marker allows recycling of selectable markers for future modifications. Not only did we want to remove the selectable markers, but we wanted to eliminate a cloning step by performing more than one modification prior to somatic cell nuclear transfer (SCNT). In the normal cloning process, a cloned animal or fetus is generated with a particular modification and then additional modifications are applied to the cells from the cloned animal. Our strategy implements multiple modifications prior to SCNT. Once we have isolated a cell population that contains the desired modifications $\left(\mathrm{Neo}^{\mathrm{R}}\right.$, $\mathrm{Hygro}^{\mathrm{R}}, h C D 39$, and $h C D 55)$, then the removal of the selectable markers $\left(\mathrm{Neo}^{\mathrm{R}}\right.$ and $\left.\mathrm{Hygro}^{\mathrm{R}}\right)$ will be facilitated by the Cre/loxP system.

To remove the selectable markers, 3 - 7 days prior to SCNT cells were transiently transfected with a Cre expression vector, pCAG:Cre-GFP (Addgene plasmid 13776;(Matsuda \& Cepko, 2007)). The lipid-based transfection protocol and conditions used were as previously described (Beaton \& Wells, 2014). In a 24 well plate, $\sim 15,000-$ 20,000 cells were transfected with 750 ng pCAG:Cre-GFP and $2 \mu \mathrm{L}$ FuGENE HD 
(Promega, Madison, WI). The cells were transfected in complete medium, as described above, for 48 hours. After 48 hours, the cells were cultured in fresh complete medium to either be cyro-preserved or used for SCNT. Evaluation of Cre-mediated excision was determined on live piglets, we expected $\sim 80 \%$ of the cells used for SCNT to have undergone Cre-excision (Beaton \& Wells, 2014).

\section{Somatic Cell Nuclear Transfer (SCNT)}

For SCNT, sow-derived oocytes were purchased from ART (Madison, WI). Cumulous oocyte complexes were aspirated from sow ovaries and then shipped overnight in maturation medium (TCM199 with $2.9 \mathrm{mM}$ Hepes, $5 \mathrm{mg} / \mathrm{mL}$ insulin, $10 \mathrm{ng} / \mathrm{mL}$ EGF, $0.5 \mathrm{mg} / \mathrm{mL}$ p-FSH, $0.91 \mathrm{mM}$ pyruvate, $0.5 \mathrm{mM}$ cysteine, $10 \%$ porcine follicular fluid, 25 $\mathrm{ng} / \mathrm{mL}$ gentamicin). Upon arrival, the oocytes were transferred into fresh medium and cultured for additional $20-24$ hours. After a total of $40-42$ hours of maturation, cumulus cells were removed from the oocytes by vortexing for $3 \mathrm{~min}$ in the presence of $0.1 \%$ hyaluronidase. The denuded oocytes were manipulated in manipulation medium that consisted of Hepes-buffered TCM-199, 0.3\% BSA, and $7.5 \mu \mathrm{g} / \mathrm{ml}$ of cytochalasin B (CB). The polar body along with a portion of the adjacent cytoplasm was removed, and a donor cell was placed in the perivitelline space as previously described (Lai \& Prather, 2003). The reconstructed embryos were then fused and activated in fusion medium $(0.3$ M mannitol, $0.1 \mathrm{mM} \mathrm{CaCl}_{2}, 0.1 \mathrm{mM} \mathrm{MgCl}_{2}, 0.5 \mathrm{mM}$ Hepes) by using two DC pulses (1sec interval) at $1.2 \mathrm{kV} / \mathrm{cm}$ for $30 \mu \mathrm{sec}$ (by using a BTX Electro Cell Manipulator, Harvard Apparatus, Holliston, MA). Embryos were then incubated in PZM3 (Yoshioka et al., 2002), for $14-16$ hours. The next day, the SCNT embryos were surgically 
transferred into the ampullary-isthmic junction of a surrogate at 0 or 1 day after observed estrus. The surrogates were checked for pregnancy by ultrasound examination around day 30. The cloned fetus was collected on day 45 of gestation. The cloned piglets were delivered by cesarean section on day 116 or 117 of gestation.

RNA Isolation, Reverse Transcriptase, and PCR Analysis of hCD39 Expression RNA was extracted from transgenic (pBB57 targeted into GGTA1) and wild-type piglets. Total RNA was isolated from xenotransplantation significant organs (heart, liver, lung, kidney, pancreas) and unrelated tissues (tail, spleen, and umbilical) by using STAT60 RNA extraction reagent (Tel-Test, Inc., Friendswood, TX). The extracted RNAs were treated with RNase-Free DNase (Qiagen, Valencia, CA) at room temperature according to the manufacturer's recommendations. The DNA-free RNA samples were quantified and analyzed for quality. Two micrograms of RNA from each sample were reverse transcribed by using an oligo-dT primer and PrimeScript ${ }^{\mathrm{TM}}$ Reverse Transcriptase (TaKaRa, Japan) at $42^{\circ} \mathrm{C}$ for 1 hour.

Oligonucleotides for PCR on the cDNA were designed to span the engineered intron (Figure 16), hCD39_5' UTR_L1: 5'-TCGCAAAGTTGTGAGTTGTTG-3' and hCD39_R3: 5'-AAGCCAAGGATGGCTAGGAT-3'. Oligonucleotides were also designed for a control gene in swine, GAPDH (glyceraldehyde 3-phosphate dehydrogenase), GAPDH_L1: 5'-GCAAAGTGGACATTGTCGCCATCA-3' and GAPDH_R1: 5'-AGCTTCCCATTCTCAGCCTTGACT-3'. PCR was performed by using a mixture of AmpliTaq Gold ${ }^{\circledR} 360$ DNA Polymerase system (Applied Biosystems, CA) and $0.5 \mu \mathrm{L}$ of cDNA. The PCR parameters were: $94^{\circ} \mathrm{C}$ for 2 minutes, followed by 
40 cycles of 15 seconds at $94^{\circ} \mathrm{C}, 30$ seconds at $60^{\circ} \mathrm{C}$, and 1 minute at $72^{\circ} \mathrm{C}$, with a final extension of 1 minute at $72^{\circ} \mathrm{C}$.

\section{Characterization of hCD55 and hCD39 Ectopic Expression}

Xenotransplantation significant organs (heart, kidney, liver, lung, and pancreas) from transgenic piglets and diagnostic tissues (tail and umbilical) from transgenic and wild-type piglets were harvested and frozen in tissue freezing media (American MasterTech, CA). Immunohistochemistry was carried out following general immunohistochemistry procedures on 5-micron thick sections fixed with ice-cold acetone. The tissue sections were reacted with primary mouse monoclonal antibodies against human CD55 (Clone: IA10, BD Biosciences) and human CD39 (Clone: BU61, Ancell).

\section{Results}

\section{CRISPR/Cas9-Mediated Gene Stacking/Knock-in into PhiC31 attB}

A series of experiments were performed to evaluate the efficiency of the CRISPR/Cas9 system by targeted insertion into a PhiC31 attB site. The PhiC31 attB site was previously inserted into one allele of the GGTAl gene and now served as a unique sequence that $\operatorname{sgRNAs}$ were designed to target. The first experiment was to evaluate the

effects on targeting efficiency if a single sgRNA or a combination of three sgRNAs was used in the presence of a targeting vector (pBB57). When targeting vector DNA (pBB57) was kept constant and the sgRNA vector was kept constant, all four treatments 
(pBB67 sgRNA, pBB68 sgRNA, pBB69 sgRNA, and all three sgRNAs) resulted in an increase of targeting at the PhiC31 location compared to targeting vector alone (Figure 13). In particular, any treatment that included the pBB67 sgRNA resulted in the highest targeting efficiency. Thus, the subsequent set of experiments utilized only the pBB67 sgRNA vector. The second and third experiments were designed to evaluate and determine the optimum ratio/amount of donor targeting vector DNA and Cas9/sgRNA DNA. If the total amount of DNA transfected was kept constant (a total of $3.5 \mu \mathrm{g}$ ), but the ratios of targeting vector DNA to Cas9/sgRNA DNA were changed (1:0, 5:1, 3:1, 1:1, $1: 3,1: 5)$, the targeting efficiency increased in the presence of higher amounts of Cas9/sgRNA DNA (Figure 13). This observation led to the conclusion that higher amounts of Cas9/sgRNA DNA facilitate an increase in targeting. To further evaluate this observation, we kept the targeting vector DNA constant $(2.0 \mu \mathrm{g})$ and increased the amount of Cas9/sgRNA DNA, thus increasing the ratio of the two DNAs (1:0, 5:1, 3:1, $1: 1,1: 3,1: 5,1: 10)$. The combined results demonstrate a higher targeting efficiency in the presence of more Cas9/sgRNA DNA and a constant amount of targeting vector DNA (Figure 13). 
A)

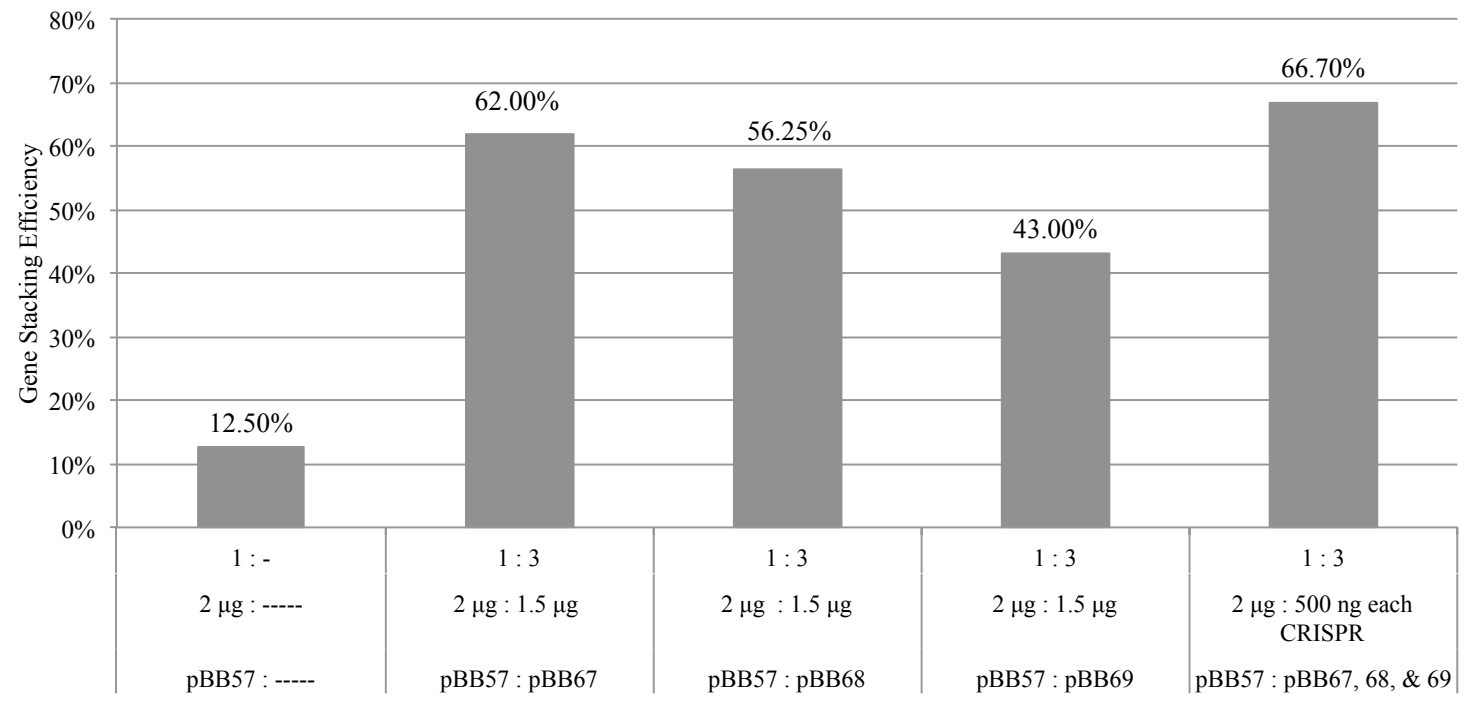

B)

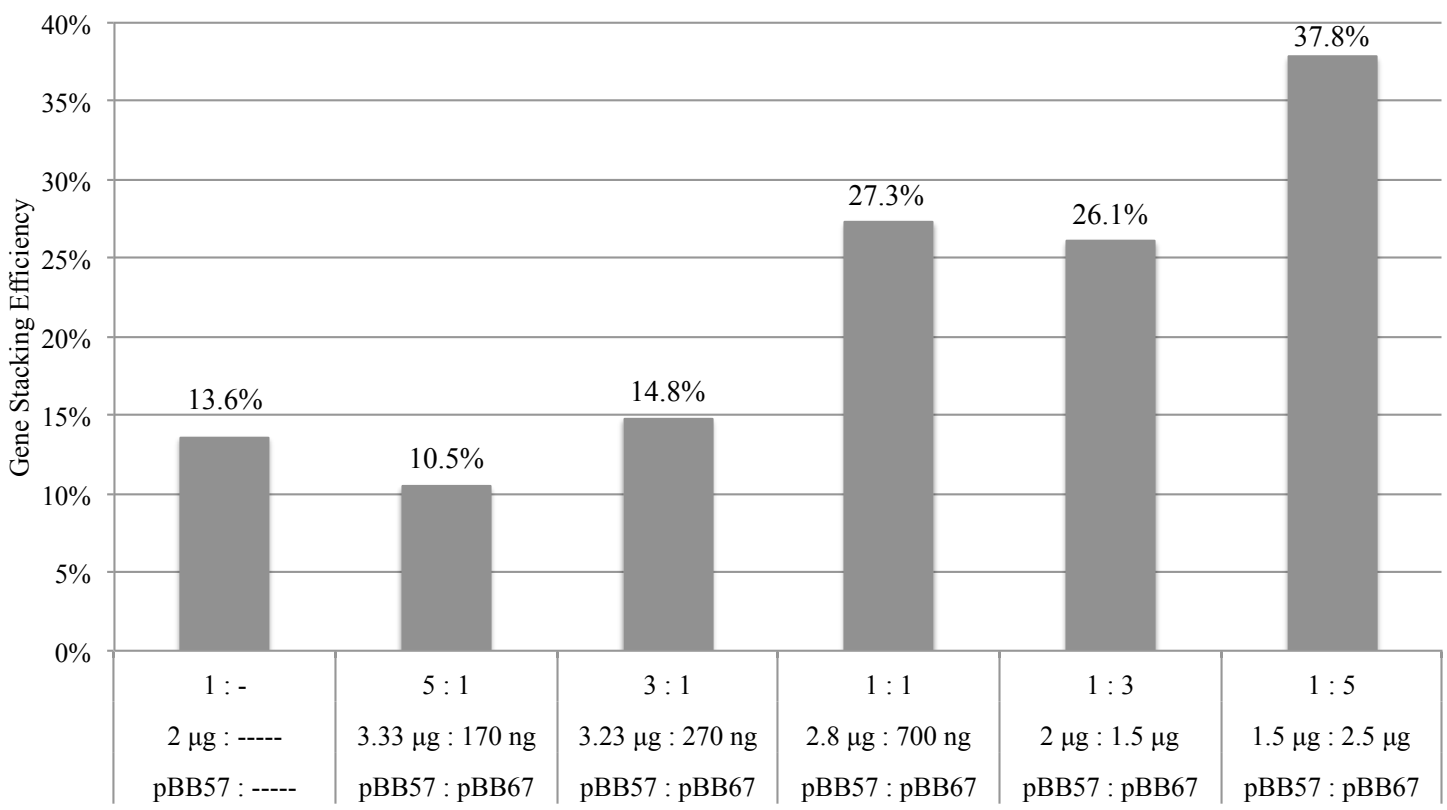


C)

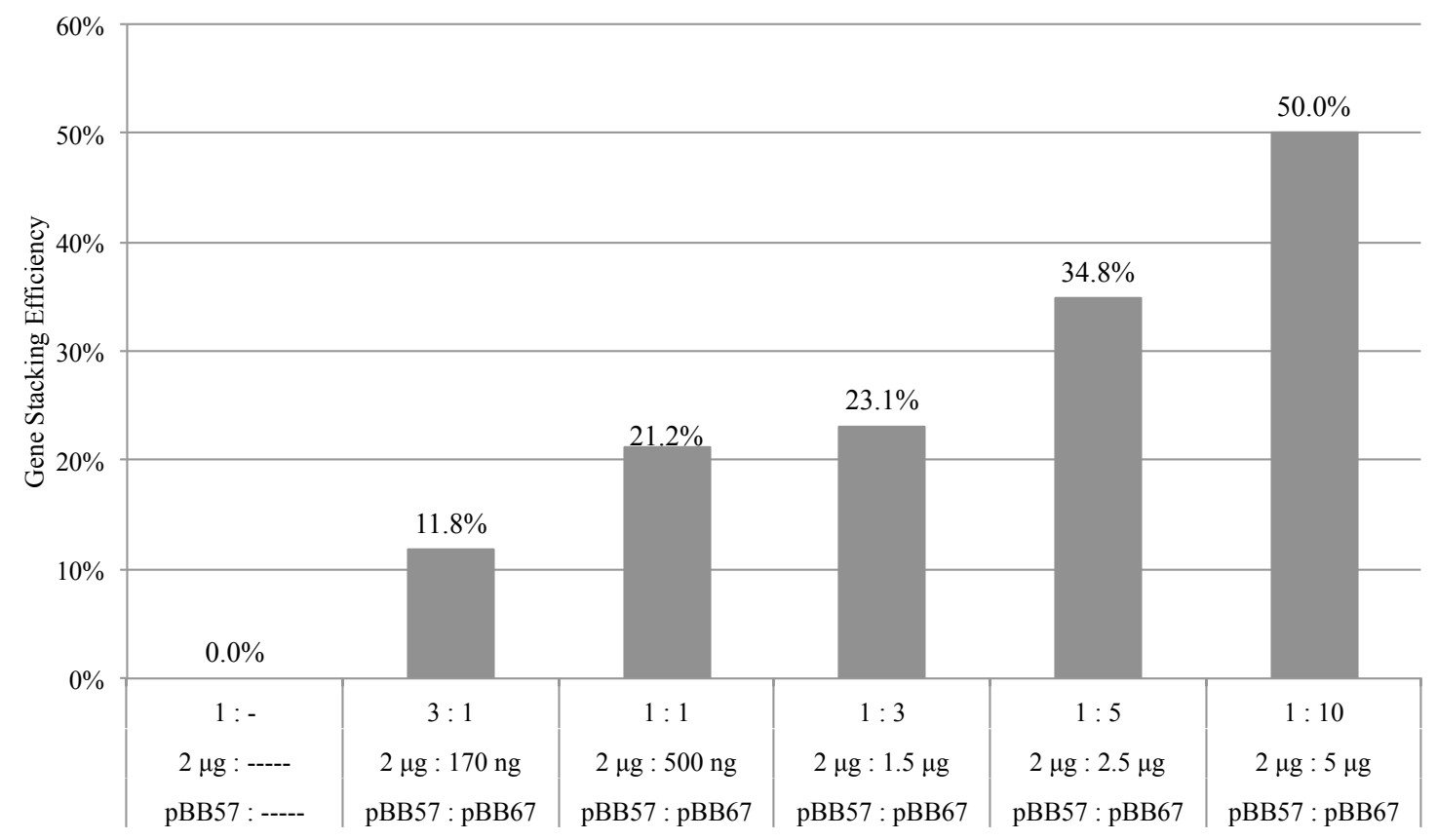

Figure 12. CRISPR/Cas9-Mediated Gene Stacking/Targeting into the unique PhiC31 attB previously targeted into the $G G T A 1$ locus.

A) Gene targeting the PhiC31 attB site located within the GGTA1 locus, testing different sgRNAs. The total application of DNA introduced was kept constant, $3.5 \mu \mathrm{g}$.

B) Gene targeting the PhiC31 attB site with a single Cas9/sgRNA (pBB67 sgRNA) where the total amount of DNA being transfected was constant, but the ratios of targeting vector DNA to sgRNA DNA was varied.

C) Gene targeting the PhiC31 attB site with a single sgRNA (pBB67 sgRNA) where the targeting vector DNA was kept constant, but the amounts of sgRNA DNA were varied to create different ratios of targeting vector DNA to sgRNA DNA.

**In all panels, the data represents the percentage of gene targeting/integration at the target PhiC31 attB location. Varying ratios of targeting vector DNA to Cas $9 / \mathrm{sgRNA}$ expression vector was calculated per molecule. 


\section{CRISPR/Cas9-Mediated Gene Targeting into GGTA1}

To further optimize CRISPR/Cas9-mediated gene targeting and attempt to knockin 4 transgenes into a single locus in one step, various ratios of targeting vector to Cas9/sgRNA expression vector were transfected into wild-type porcine fibroblast cells. A single Cas9/sgRNA expression vector, pBB71, that specifically targets exon 9 of GGTAl was used at varying concentrations of DNA in combination with a targeting vector, pBB57. The targeting vector DNA was constant throughout the experiment, with different amounts of Cas9/sgRNA DNA to yield the following ratios; 1:0 (no Cas9/sgRNA control to compare to baseline targeting efficiencies), 3:1, 1:1, 1:3, 1:5, 1:10, and 1:20. The results from a total of 63 transfections ( 9 replicates) demonstrate that the addition of a Cas9/sgRNA expression in the target region of the targeting vector aids in CRISPR/Cas9-mediated gene targeting (Figure 14). To test if there was a statistical significance across the entire dataset, a pairwise Chi-squared analysis was performed and showed significance at $p=0.001$. To test between treatment means, count data were analyzed by using the Student's T-Test. Based upon our gene targeting results, a ratio of 1:3 - 1:10 would be an optimum ratio range for targeting vector DNA to Cas $9 / \mathrm{sgRNA}$ expression vector DNA. 


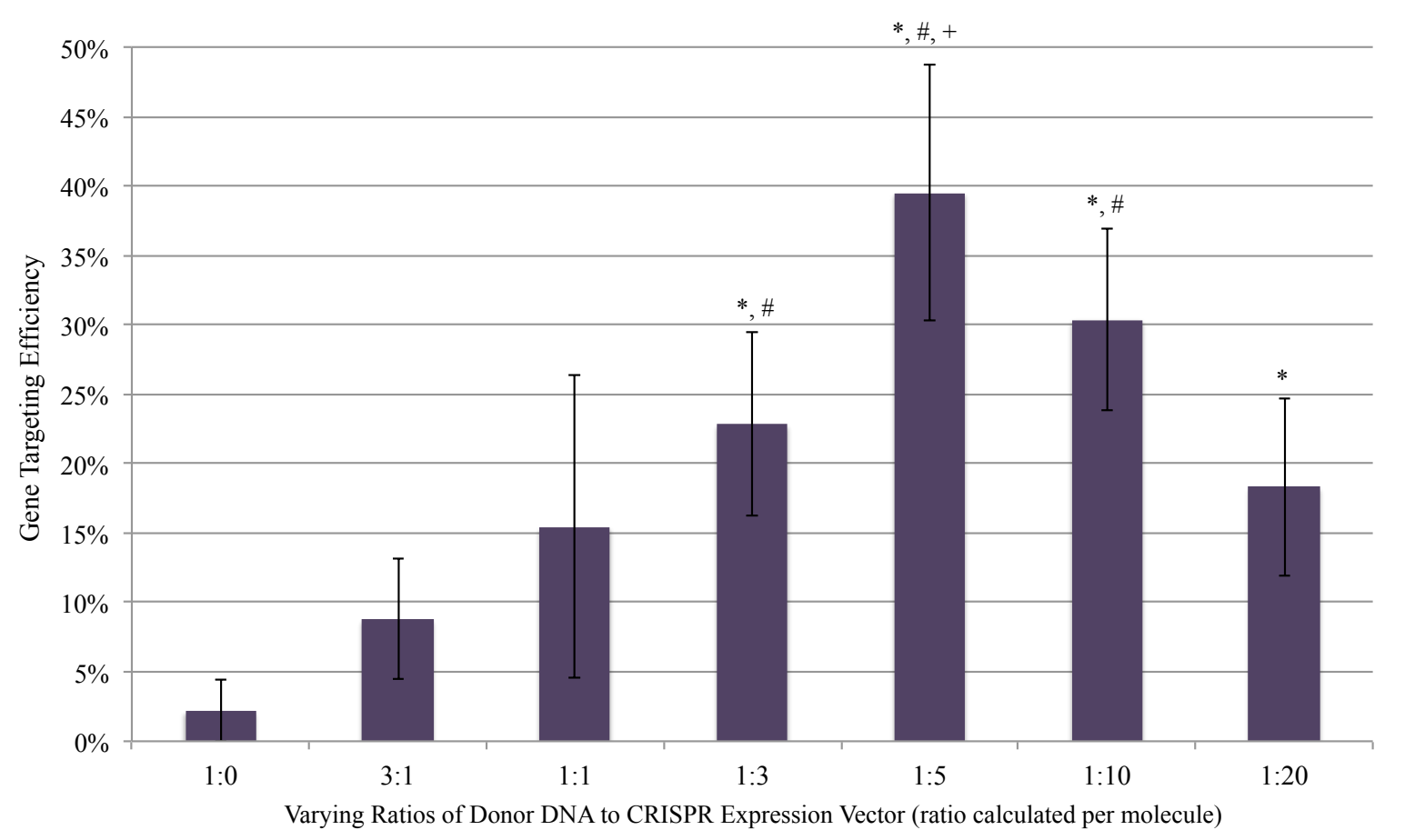

Figure 13. CRISPR/Cas9-Mediated Gene Targeting the unique the EcoRV site on exon 9 of the $G G T A 1$ locus.

Gene targeting GGTA1 with a single Cas9/sgRNA expression vector (pBB71) where the targeting vector DNA was kept constant and the amounts of Cas9/sgRNA DNA were varied to create different ratios of targeting vector DNA to sgRNA DNA. The data represents the gene targeting efficiency. Varying ratios of targeting vector DNA to Cas9/sgRNA expression vector was calculated per molecule.

Student T-test $p<0.05$. * Significance was found when count data was compared to 1:0 ratio. \# Significance was found when count data was compared to 3:1 ratio. + Significance was found when count data was compared to 1:20 ratio. 
Production of Gene-Stacked / Gene-Targeted Fetus and Targeted Pigs Through SCNT

To confirm that the gene-stacked colonies could generate live offspring via SCNT, a pool of cells from different clones were used in three rounds of SCNT (Table 9). One of the three recipients became pregnant; the pregnancy was terminated at day 45 to collect fetuses, a single fetus was recovered.

To confirm that the gene-targeted colonies could generate live offspring via SCNT, a pool of cells from different male and female clones were used in 6 rounds of SCNT (Table 10). Prior to SCNT, the cells were transiently transfected with the Cre recombinase to cre-excise the selectable markers, as they will not be desired for future use and we were attempting to perform more than one modification prior to SCNT (1gene targeting, 2-excise selectable marker). Four of the six recipients became pregnant and the piglets were delivered by cesarean section (c-section) at day 116 of gestation, with the exception of 1 pregnancy that was terminated by c-section at gestation day 137 . Of the four pregnancies, two pregnancies each contained a single piglet for a total of two live piglets (Figure 15). The other two pregnancies resulted in 3 stillborn piglets (Table 10). The two live piglets, male: 6-1 and female: $11-1$, were confirmed to contain the transgene cargo at the GGTA1 locus (Figure 15). As mentioned above, the cells used were transiently transfected with the Cre recombinase, and both piglets had undergone some form of Cre-mediated excision of either one (6-1) or both selectable markers excised (11-1) (Figure 15). Piglet 11-1 was null at the GGTA1 locus, this was due to one allele being targeted by the targeting vector and the other allele was modified by NHEJ. Piglet 11-1 died one-hour post c-section and piglet 6-1 was euthanized at 14 days of age. Tissues from both piglets were collected for further analysis of transgene expression. 
Table 9. Cloned fetus produced following SCNT on gene-stacked cells.

\begin{tabular}{cccccc}
\hline $\begin{array}{c}\text { Nuclear } \\
\text { Transfer }\end{array}$ & $\begin{array}{c}\text { Number of Reconstructed } \\
\text { Embryos Transferred }\end{array}$ & $\begin{array}{c}\text { Surrogate } \\
\text { Number }\end{array}$ & Outcome & $\begin{array}{c}\text { Number } \\
\text { Born Alive }\end{array}$ & $\begin{array}{c}\text { Additional } \\
\text { Comments }\end{array}$ \\
\hline NT1 & 199 & O049 & Return & N/A & N/A \\
NT2 & 193 & W200853 & Open & N/A & N/A \\
NT3 & 188 & W200852 & Pregnant & 0 & $\begin{array}{c}\text { day 45 fetus } \\
\text { collected }\end{array}$ \\
\hline
\end{tabular}


Table 10. Cloned piglets produced following SCNT on gene-targeted cells.

\begin{tabular}{cccccc}
\hline $\begin{array}{c}\text { Nuclear } \\
\text { Transfer }\end{array}$ & $\begin{array}{c}\text { Number of Reconstructed } \\
\text { Embryos Transferred }\end{array}$ & $\begin{array}{c}\text { Surrogate } \\
\text { Number }\end{array}$ & Outcome & $\begin{array}{c}\text { Number } \\
\text { Born Alive }\end{array}$ & $\begin{array}{c}\text { Additional } \\
\text { Comments }\end{array}$ \\
\hline NT1 & 222 & O231 & Pregnant & 0 & $\begin{array}{c}1 \text { stillborn } \\
\text { delivered }\end{array}$ \\
NT2 & 144 & O204 & Pregnant & 1 & $\begin{array}{c}\text { Euthanized: } \\
\text { Age 14 days }\end{array}$ \\
NT3 & 214 & O244 & Return & N/A & N/A \\
NT4 & 210 & O240 & Pregnant & 1 & $\begin{array}{c}\text { Died: } \\
\text { Age 1 hour }\end{array}$ \\
NT5 & 208 & W200077 & Pregnant & 0 & $\begin{array}{c}\text { p stillborn } \\
\text { piglets; day }\end{array}$ \\
& 163 & & & & 137 c-section \\
NT6 & & O344 & Return & N/A & N/A \\
\hline
\end{tabular}


A)

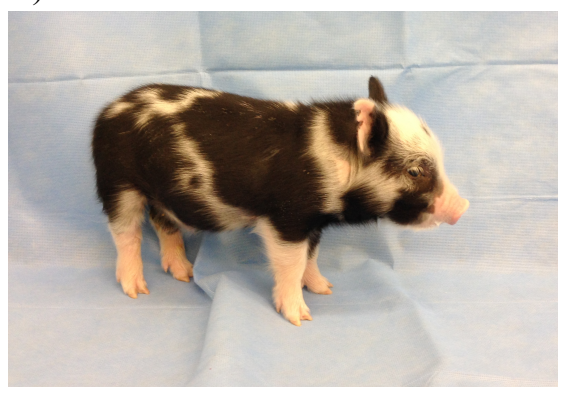

B)

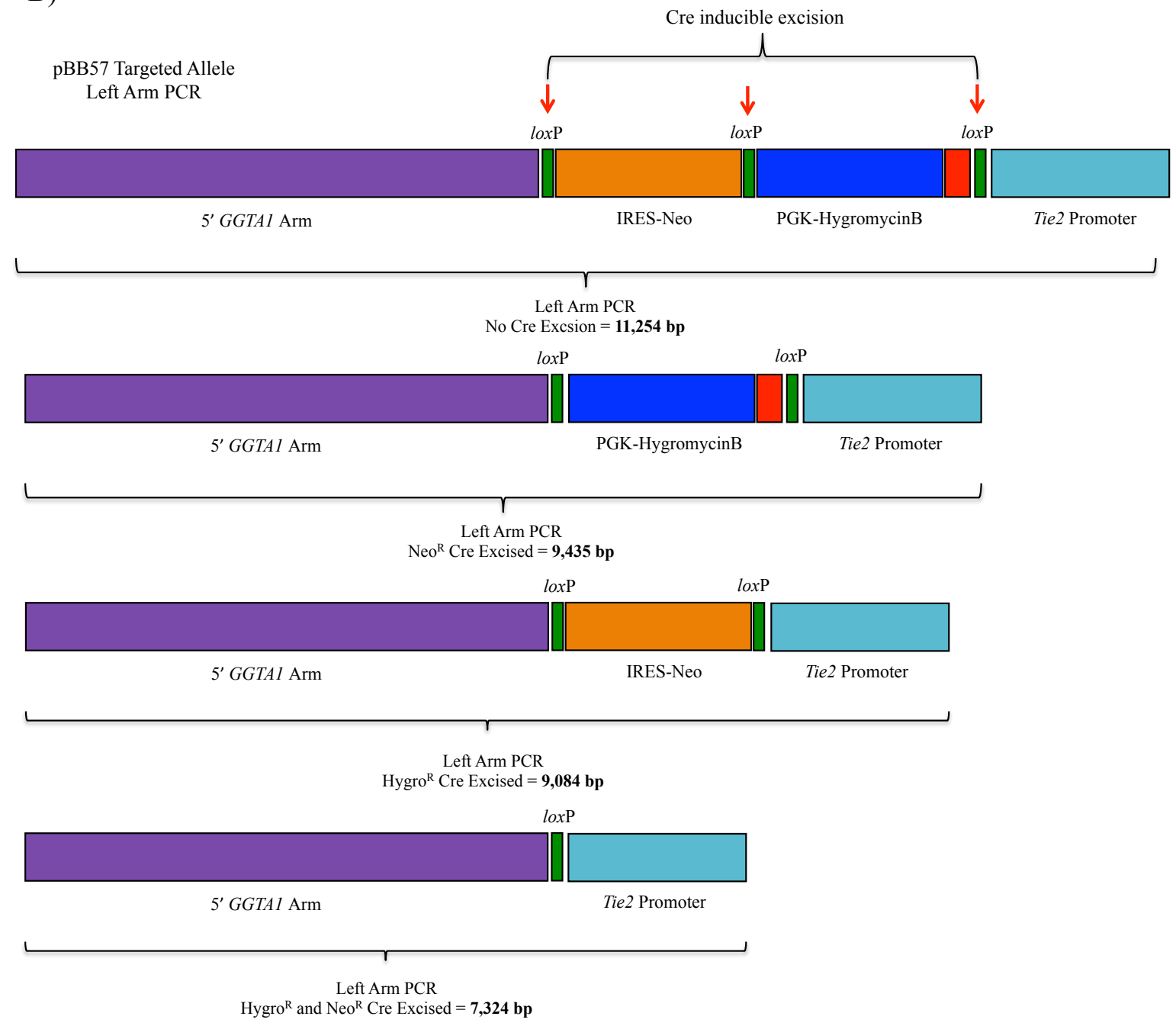


C)

Long Range and Upstream Assay

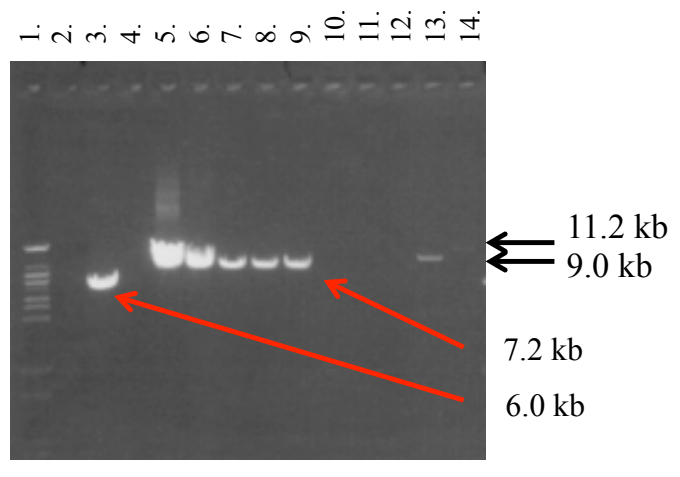

Downstream Assay

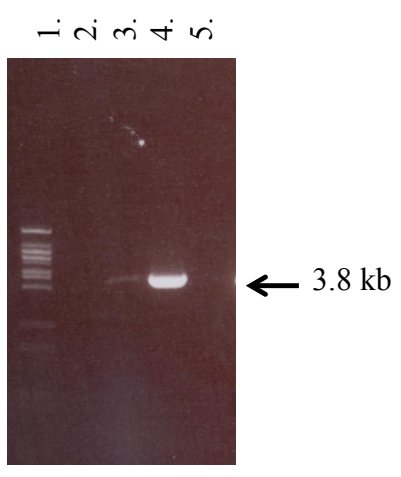

Figure 14. GGTA1 ${ }^{\mathrm{IRES}-\mathrm{Neo} \text {; PGK-Hygro; CAG-hCD55; Tie2-hCD39/+ }}$ Pigs.

A) Image of piglet 6-1 at 10 days of age, born August 11, 2014.

B) Graphical representation of the Upstream PCR Assay. The top image is a representation of the PCR product at a pBB57-targeted allele. The following images are representations of the PCR product if one of the three possible cre-mediated excision events occurred.

C) Genotyping of pigs. For genotyping, a PCR was performed to verify gene targeting by an upstream, long range, and downstream PCR. PCR results from piglets 6-1 and 111 demonstrate that one allele is targeted. In piglet 11-1, the second allele was confirmed to have a major deletion in the GGTAl locus, thus this animal is homozygous $\mathrm{KO}$ for $G G T A 1$, but hemizygous for $h C D 39$ and $h C D 55$. Long Range (Lanes $3-8$ ) and Upstream Assay (Lanes 9-14) - Lane 1: DNA Ladder, Lambda Genome digested with BstEII, Lane 2: empty lane, Lanes 3 and 9: Piglet 11-1, Lanes 4 and 10: $\mathrm{H}_{2} \mathrm{O}$ negative control, Lanes 5 and 11: Wild-type control, Lanes 6 and 12: pBB18 targeted positive control, Lanes 7 and 13: Piglet 6-1, Lanes 8 and 14: positive control pBB57 fetus. Downstream Assay - Lane 1: DNA Ladder, Lambda Genome digested with BstEII, Lane 2: $\mathrm{H}_{2} \mathrm{O}$ negative control, Lane 3: Piglet 6-1, Lane 4: Piglet 11-1, Lane 5: Wild-type control. 
Transcript Expression of hCD39 in GGTA1 Targeted Pig Tissues

Human CD39 mRNA expression, as determined by PCR of cDNA, was evident in all tissues examined in transgenic animals (Figure 16). The controls (wild-type pig cDNA, no template control, and transgenic animal tail DNA) demonstrated that samples were appropriately negative for the presence/contamination of genomic DNA for both human $C D 39$ and swine $G A P D H$.

Immunohistochemistry - Cell Surface Expression of hCD39 and hCD55 in GGTA1 Targeted Pig Organs

As expected, negative control images of both tail and umbilical did not show staining for either human $C D 39$ or human $C D 55$ (Figure $17 \mathrm{~A}, \mathrm{~B}, \mathrm{E}$, and F). Fixed tissues from piglet 6-1 and 11-1 displayed robust-ubiquitous human CD55 expression that was associated with cell membranes (images of tissues from animal 11-1 are shown in Figure 17: C, D, G, H, I, J, K, L, M, N, O, P). In addition, fixed tissues from piglet 111 displayed endothelial-specific expression for human $C D 39$ and all other cell types did not appear to express $C D 39$. Together with the result of transcription for human $C D 39$ expression, these results demonstrate that the transgenes are properly expressed in the desired cell type. 
A)

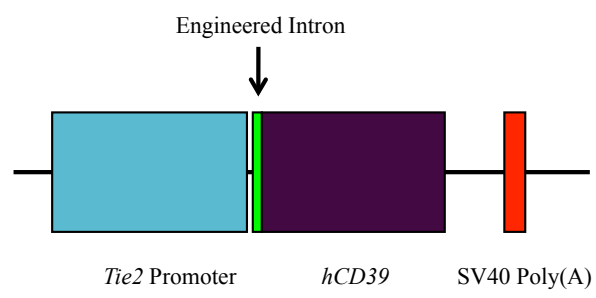

B)

cDNA - transgenic $h C D 39$

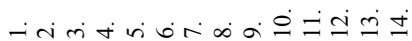

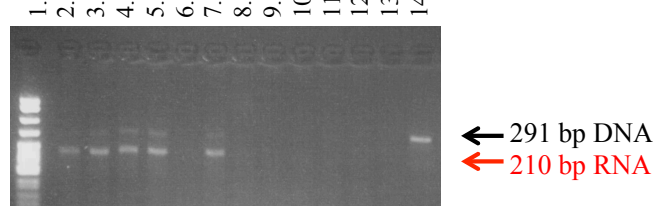

5. UTR Primer hCD39 Primer

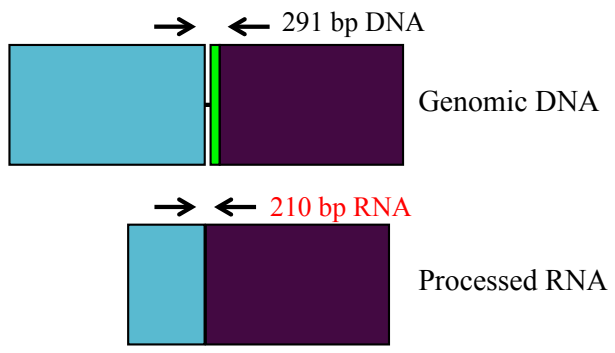

cDNA - porcine GAPDH

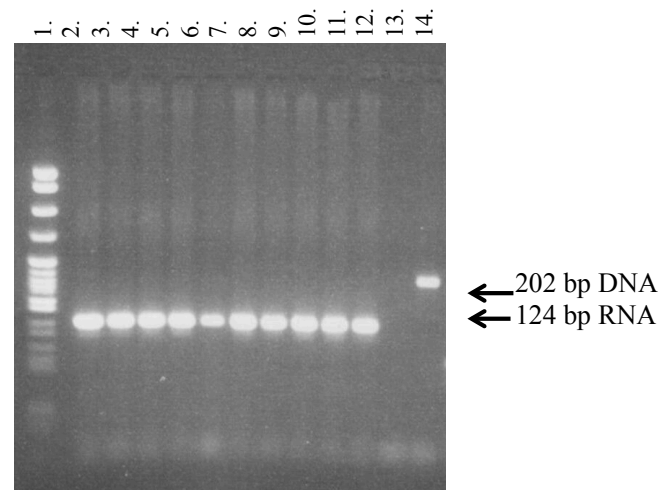

Figure 15. Reverse Transcriptase PCR Analysis of Tie2-hCD39 Transgene Expression.

A) Graphical representation of the location of the PCR. Predicted size of PCR product for both genomic DNA and processed RNA after splicing of engineered intron.

B) Primers are specific to 5'UTR of Tie2 promoter sequence and $h C D 39$ and show noncross reactivity with wild-type porcine cDNA. Piglets 6-1 and 11-1 were determined to express the Tie2-hCD39 transgene in all tissues examined. Lane 1: DNA Ladder, pBR digested with MspI (NEB), Lane 2: Transgenic 6-1 Heart cDNA, Lane 3: Transgenic 6-1 Liver cDNA, Lane 4: Transgenic 6-1 Lung cDNA, Lane 5: Transgenic 6-1 Kidney cDNA, Lane 6: Transgenic 6-1 Pancreas cDNA, Lane 7: Transgenic 6-1 Spleen cDNA, Lane 8: Wild-type Liver cDNA, Lane 9: Wild-type Lung cDNA, Lane 10: Wild-type Kidney cDNA, Lane 11: Wild-type Pancreas cDNA, Lane 12: Wild-type Heart cDNA, Lane 13: $\mathrm{H}_{2} \mathrm{O}$ negative control, and Lane 14: Transgenic 6-1 Genomic DNA. 


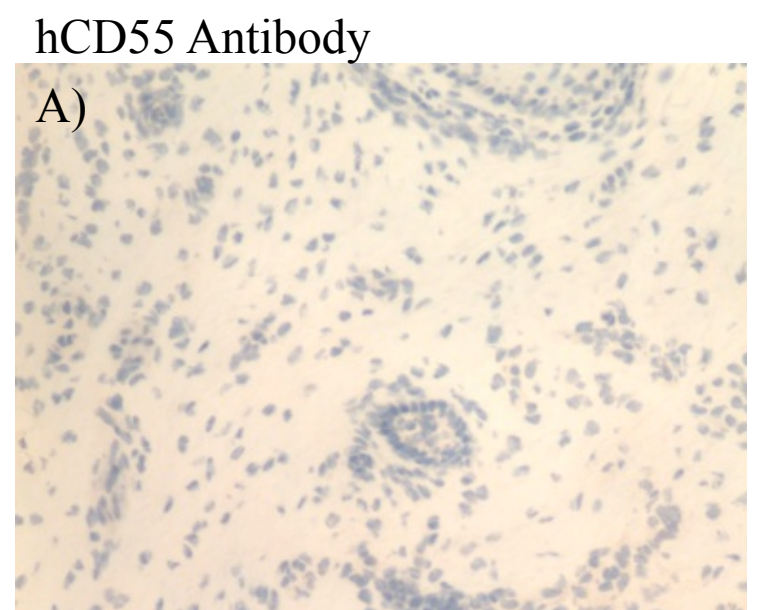

Wild-type Tail

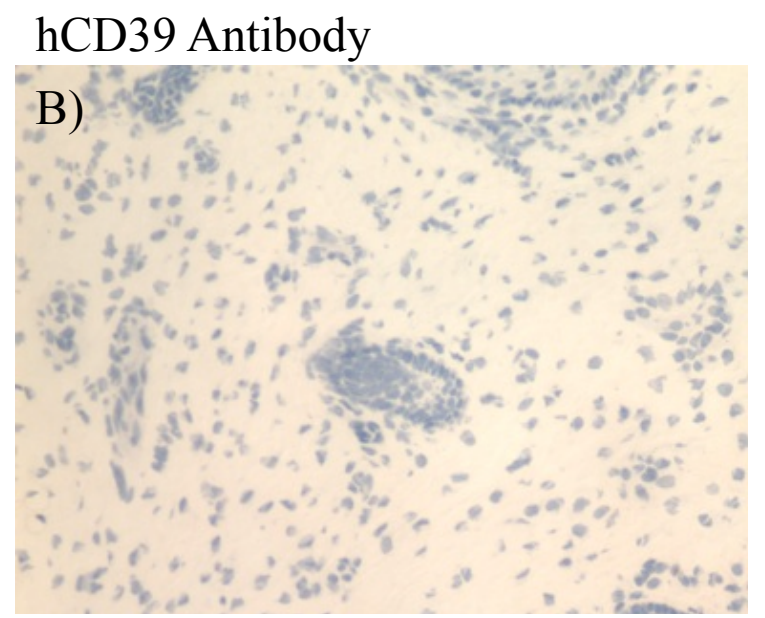

Wild-type Tail

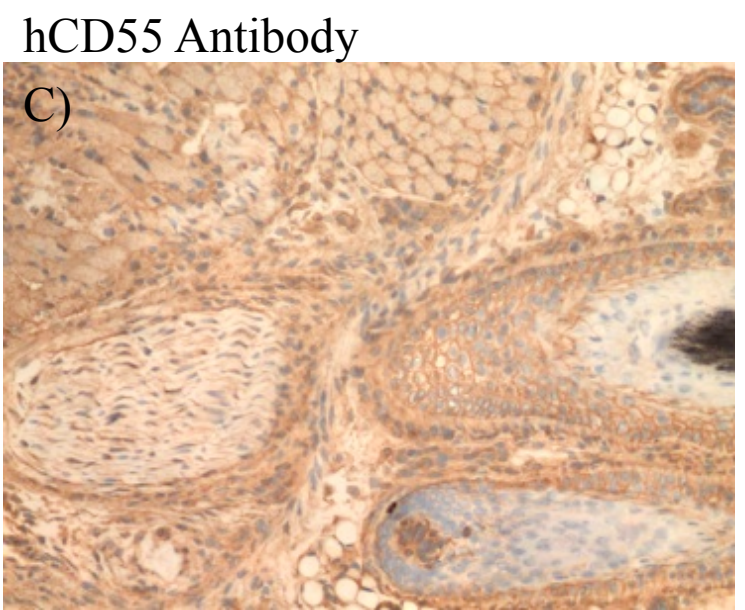

Transgenic Tail

hCD39 Antibody

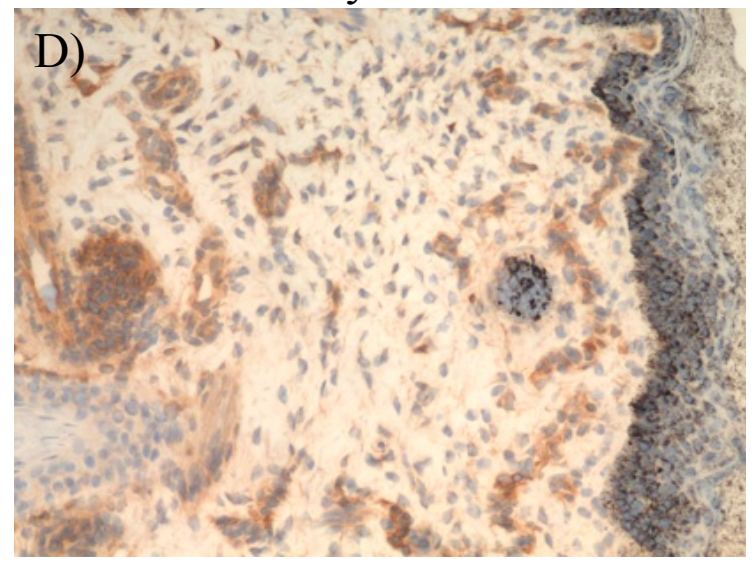

Transgenic Tail 


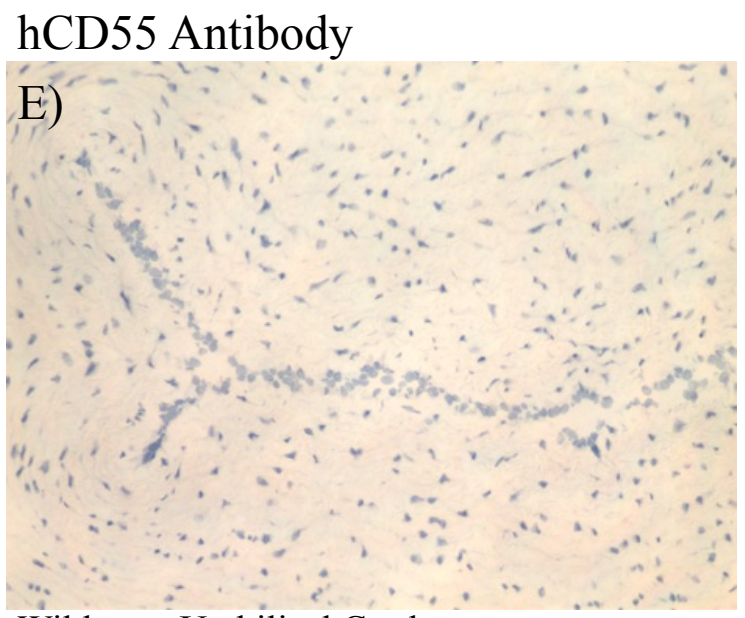

Wild-type Umbilical Cord

\section{hCD39 Antibody}

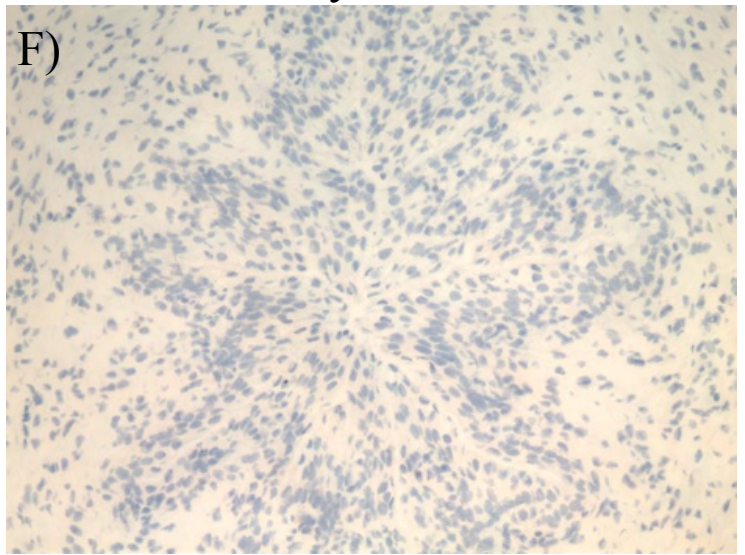

Wild-type Umbilical Cord

\section{hCD55 Antibody}

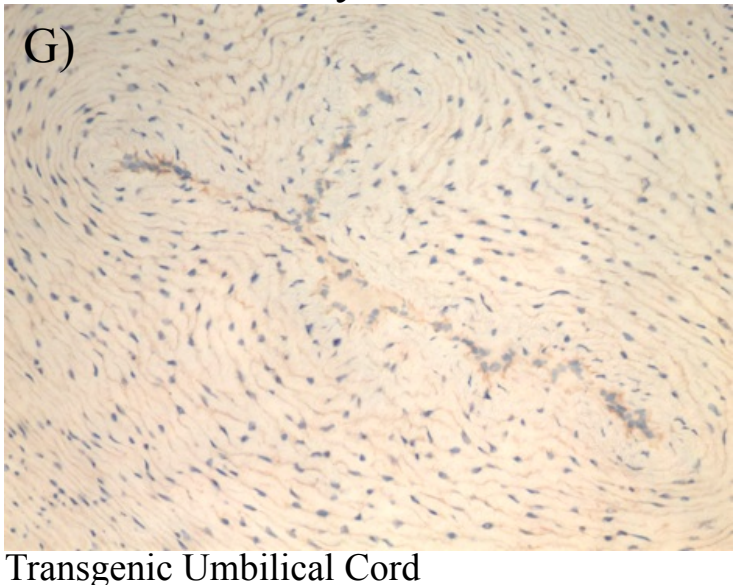

hCD39 Antibody

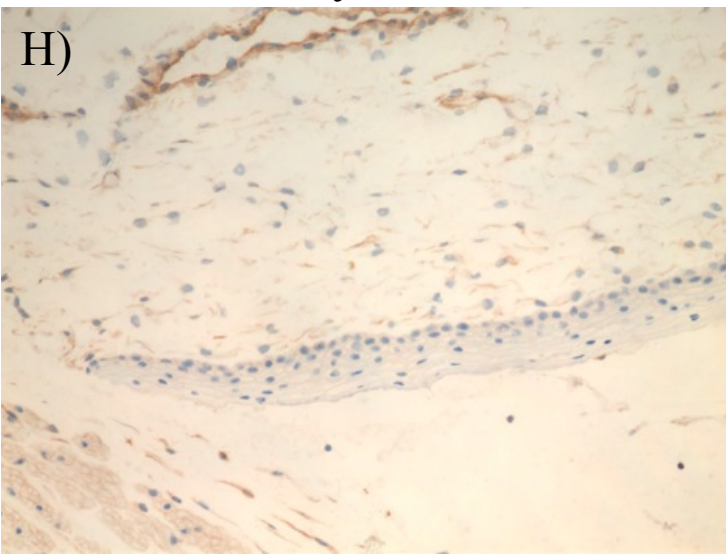

Transgenic Umbilical Cord 


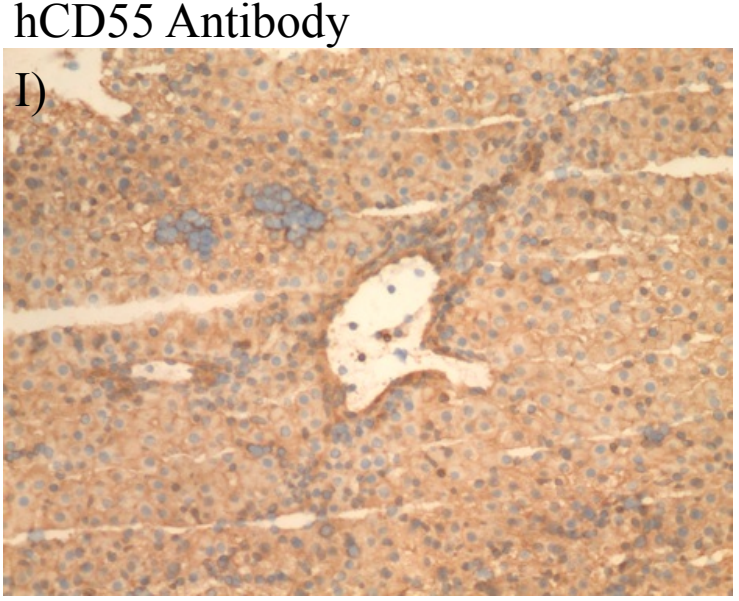

Transgenic Liver

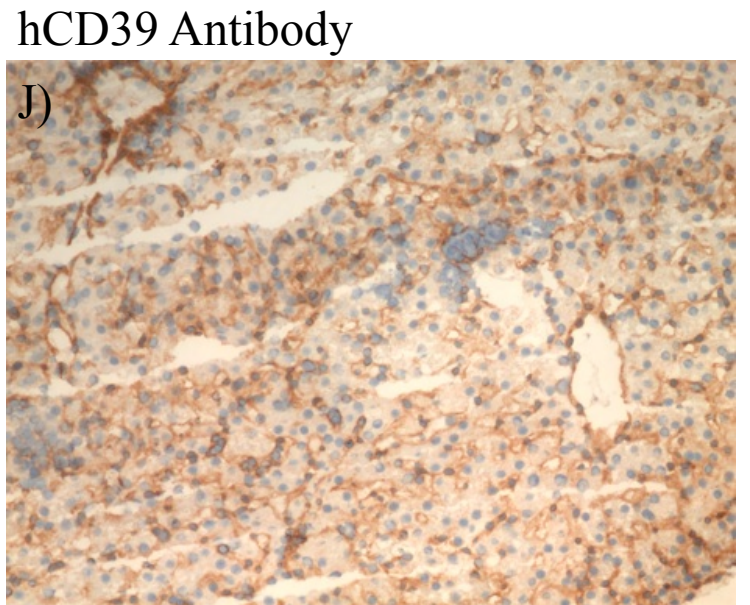

Transgenic Liver

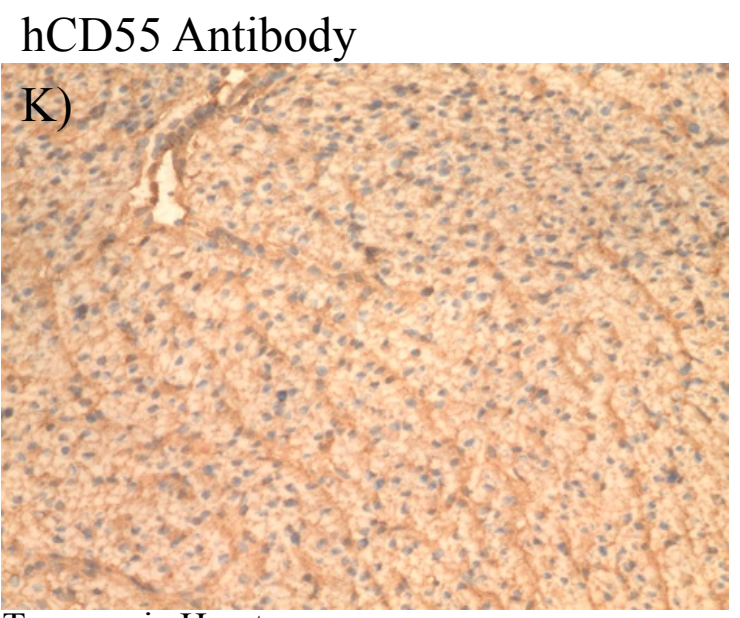

Transgenic Heart

\section{hCD39 Antibody}

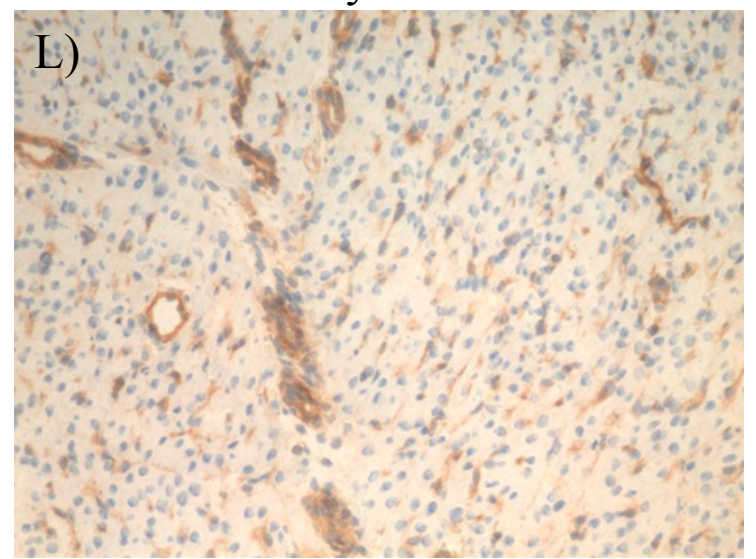

Transgenic Heart 


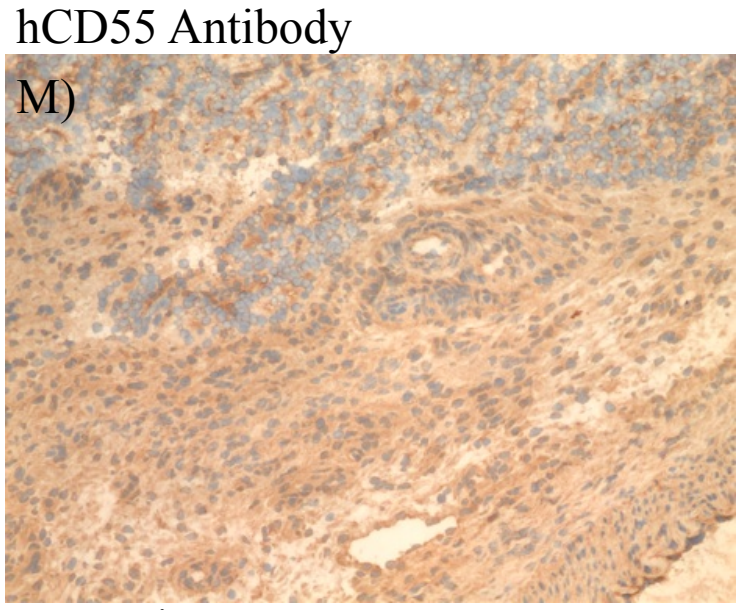

Transgenic Pancreas

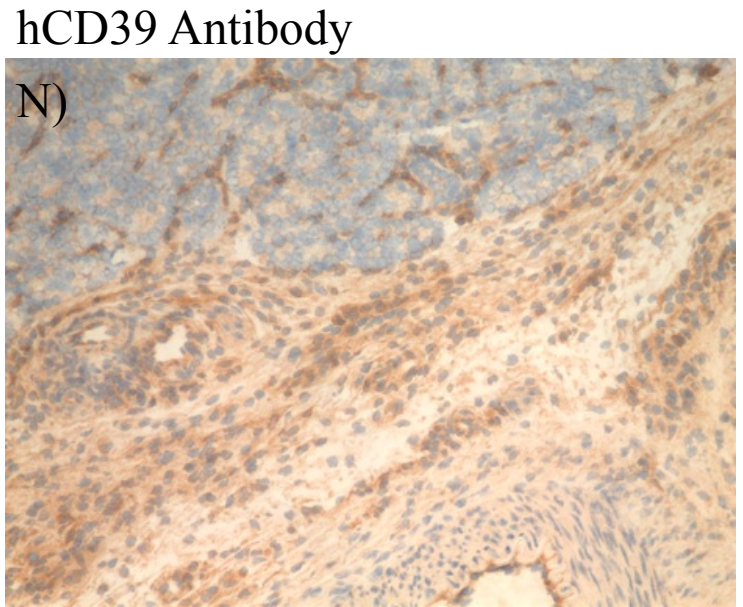

Transgenic Pancreas

\section{hCD55 Antibody}

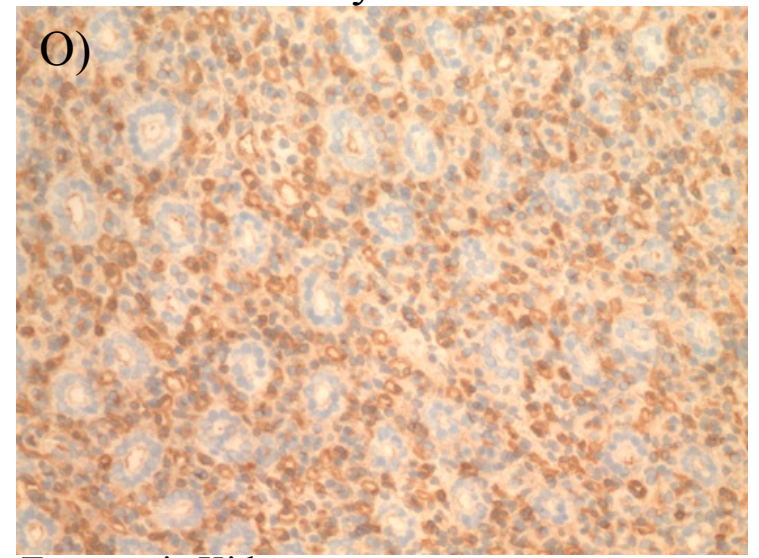

Transgenic Kidney

\section{hCD39 Antibody}

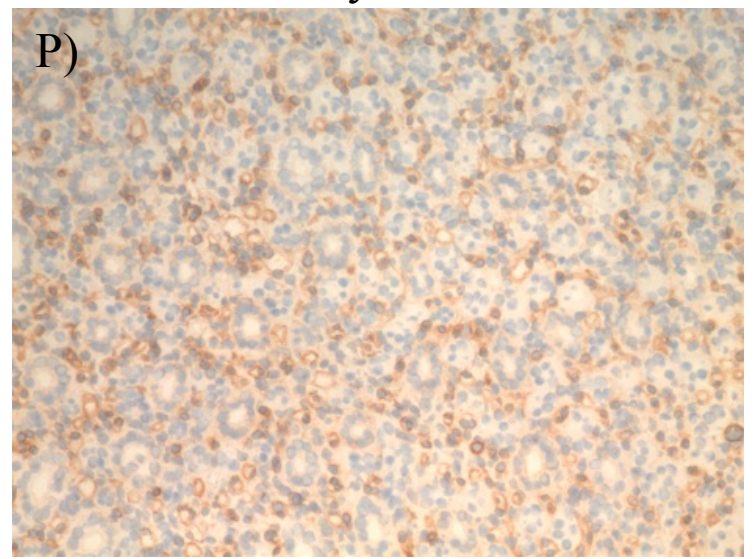

Transgenic Kidney

Figure 16. Representative immunohistochemistry analysis of human CD55 and human CD39 expression.

Immunohistochemistry of wild-type pig tail and umbilical (used as a negative control); transgenic GGTA1 $1^{C A G-h C D 55 ; \text { Tie2-hCD39/+ }}$ pig (11-1) heart, kidney, liver, lung, pancreas, tail, and umbilical tissues were stained against an anti-Human CD55 antibody and an antiHuman CD39 antibody. Panel A, B, C, and D: Tail Tissue; Panel E, F, G, and H:

Umbilical Tissue; Panel I and J: Liver Tissue; Panel K and L: Heart Tissue; Panel M and $\mathrm{N}$ : Pancreas Tissue; Panel $\mathrm{O}$ and P: Kidney Tissue. The transgenic (GGTA1 ${ }^{\mathrm{CAG}-h C D 55 ; \text { Tiez- }}$ ${ }_{h C D 39 /+}$ ) pig shows diffuse-ubiquitous human $C D 55$ expression and endothelial specific expression of human $C D 39$ on all transgenic tissues with no expression on wild-type tissues. 


\section{Discussion}

Recent advances in genetic engineering technologies, including ZFNs, TALENs, and the CRISPR/Cas9 system, enable precise gene targeting including gene $\mathrm{KO}$ and targeted insertion in several organisms, including the pig (Whitworth et al., 2014; Zhou et al., 2015). Through two novel genetic engineering strategies, we have shown that it is possible to efficiently link multiple genes/modifications $\left(\mathrm{Neo}^{\mathrm{R}}\right.$ cassette, Hygro $^{\mathrm{R}}$ cassette, $h C D 39, h C D 55$, and GGTA1 KO) by sequentially stacking additional transgenes into a previously targeted allele, as well as by targeted insertion of multiple transgenes $\left(\mathrm{Neo}^{\mathrm{R}}\right.$ cassette, Hygro ${ }^{\mathrm{R}}$ cassette, $h C D 39$, and $\left.h C D 55\right)$ into a single locus (GGTA1). This strategy would guarantee the co-inheritance of multiple genetic modifications.

We chose to take advantage of DNA repair mechanisms (i.e., HR by using a targeting vector) in conjunction with induced target breakage in the genome to facilitate an increase in HR. As a proof-of-principle, we elected to evaluate transgene linking to a disrupted locus within the context of xenotransplantation. In order for pig-to-human xenotransplantation to be successful, it has become evident amongst the xenotransplantation community that in addition to GGTA1 KO, additional transgenes involving suppression of human immune function are going to be required (Cooper et al., 2002; Cooper et al., 2012). In addition, the ability to have such transgenes genetically linked could be extremely useful in building a multi-transgenic xenotransplantation pig.

To facilitate precise modifications, the use of HR has had a tremendous impact on genetic engineering strategies (Mansour et al., 1988; Capecchi, 1989; Hasty, RiveraPerez, \& Bradley, 1991; Hasty \& Bradley, 1993; Fiering et al., 1995; Smih et al., 1995; Nagy \& Rossant, 1996; Whyte et al., 2011). It was demonstrated 20 years ago that gene 
targeting could be stimulated by a genomic DSB introduced by a restriction enzyme (Rouet et al., 1994; Smih et al., 1995). More recently, the CRISPR/Cas9 system, a programmable RNA guided DNA endonuclease, has emerged as an easy-to-use and efficient method for inducing site-specific DNA cleavage (Jinek et al., 2012). Due to the high efficiency of the CRISPR/Cas9 system and the enhancement of HR post target DSB, we wanted to evaluate the efficiency of gene targeting to stack additional transgenes next to previously targeted transgenes.

Since experimental parameters have not been defined for CRISPR/Cas9-mediated gene targeting, we chose to evaluate the ratios of DNA (targeting vector DNA and CRISPR/Cas9 expression vector). We were able to identify an effect in the ratio of targeting vector DNA to CRISPR/Cas9 expression vector DNA and that in the presence of more CRISPR/Cas9 expression vector DNA, the higher the gene targeting efficiency (Figure 13). The average efficiencies of CRISPR/Cas9 to mediate targeted insertion of two additional transgenes increased from $8.7 \%$ (only targeting vector DNA) to $37.0 \%$ of the colonies screened. Based upon the initial success of targeted insertion of two transgenes into a previously targeted allele, we chose to evaluate the efficiencies of inserting four transgenes into a targeted site through CRISPR/Cas9-mediated gene targeting (Figure 14). We were able to demonstrate that the CRISPR/Cas9 system can efficiently target the porcine GGTA1 locus and insert four independent, functional transgenes. The cells that contained all four modifications were used for SCNT and live pigs were generated to evaluate the expression of $h C D 39$ and $h C D 55$.

The resulting pigs had ubiquitous, non-variegated expression of $h C D 55$ transgene and endothelial cell-specific expression of $h C D 39$. $h C D 55$ has been proposed as a key 
transgene to inhibit the human complement cascade, thus combating hyper acute rejection (Cozzi et al., 1997; Diaz-Roman et al., 2006; Lee et al., 2011). To aid in coagulation and blood clotting during transplants, an anti-thrombotic transgene would be useful. CD39 is an important regulator of platelet function, and $h C D 39$ transgenic mice have demonstrated impaired platelet aggregation and prolonged bleeding times (Dwyer et al., 2004). This antithrombotic phenotype would be valuable for the prevention of undesirable coagulation and blood clotting during transplants. It should also be noted, that both $h C D 55$ and $h C D 39$ expression was comparable in all tissues examined.

Work performed by several groups has shown the murine ROSA26 locus to be a safe harbor for generalized transgene expression (Friedrich \& Soriano, 1991; Soriano, 1999; Awatramani et al., 2001). Based upon the given results of the proper expression of multiple transgenes and previous demonstration that GGTA1 null pigs are normal (Phelps et al., 2003; Kolber-Simonds et al., 2004; Takahagi et al., 2005), we propose that the porcine GGTA1 locus is a safe-harbor in the porcine genome for transgenes.

In summary, gene targeted (both gene stacked and gene targeting) pigs can be efficiently produced by using the CRISPR/Cas9 system with a targeting vector. This gene-targeting strategy provides a convenient and efficient approach to generate genetically engineered pigs, yet easily applicable to other species. In regards to xenotransplantation, our study showed that multiple genes with various gene expression patterns could be expressed appropriately, while remaining genetically linked together. Future work would include the production of homozygous GGTA1 KO pigs that would contain two copies of both $h C D 39$ and $h C D 55$ (one copy on each targeted allele). Once 
these pigs are generated, further characterization and potential xeno-related utility of the multi-transgenic xeno-pig would need to be evaluated. 


\section{CHAPTER V}

\section{SUMMARY AND CONCLUSIONS}

The ability to precisely modify the genome has and will continue to have profound effects in the fields of agriculture and human medicine. The current protocols used are effective, but additional enhancements in the efficiencies are desirable. In particular, any added efficiency to modify the genomes in livestock species will have a profound impact. This is due in large part to the expenses related to husbandry of large animals in comparison to that of small animals. The aim of this dissertation was to develop an efficient system to precisely modify the pig genome and to develop a system that would link multiple modifications, either gene $\mathrm{KO}$ or the addition of transgenes. There were three main topics that were evaluated: 1) Phic31 system in pigs, 2) effect of donor DNA length in nuclease-mediated gene targeting, and 3) CRISPR/Cas9-mediated gene stacking and gene targeting.

Due to the success of the PhiC31 system in other species, we initially evaluated the PhiC31 system as an efficient method to sequentially add and/or stack transgenes in the pig. We were able to demonstrate that, upon optimization, transient PhiC31 expression is possible in pig cells. We additionally demonstrated that PhiC31-mediated 
gene stacking is possible with small $(5.0 \mathrm{~kb})$ and large $(19.7 \mathrm{~kb})$ att $\mathrm{P}$ vectors. However, the efficiencies were not as predicted based upon results in other species. The rate of stable PhiC31-mediated integrations ranged from $1.3-5.0 \%$ of evaluated colonies. These efficiencies are comparable to current gene targeting efficiencies. Thus we chose to investigate nuclease-mediated gene targeting.

In gene targeting, it is known that a genomic DSB is a rate-limiting factor. Customized nucleases provide a means to generate DSB at specific locations to a genome, thereby increasing the efficiency of gene targeting. Even though these nucleases are currently used in genetic engineering strategies, the standards for donor DNA design in conjunction with the nucleases have not yet been established. Therefore we wanted to evaluate the effect of donor DNA length on nuclease-mediated gene targeting. We described the disruption of two genes (CMAH and GGTA1) through ZFN- and TALENmediated gene targeting in pigs, respectively. As a proof of principle, in vitro we used ZFNs and determined that a minimum homologous arm length of $35 \mathrm{bp}$ will induce HR. In subsequent experiments to determine the minimum length of homology, we used TALEN-mediated gene targeting. Based upon our ZFN/CMAH observations, we expected to see gene targeting at some frequency in our TALEN/GGTA1 experiments. Unexpectedly, we did not observe any gene targeting by HR with donor DNA, but instead demonstrated that the addition of donor DNA increases bi-allelic modifications when compared to TALEN-mediated editing in the absence of donor DNA.

Given the recent success of the CRISPR/Cas9 system and its ability to create genomic DSB, we wanted to evaluate its ability to stack multiple transgenes into a predetermined location through gene targeting. In summary, gene-targeted (both gene 
stacked and gene targeting) pigs can efficiently be produced by using the CRISPR/Cas9 system with a targeting vector. Overall, we demonstrated that efficiencies can increase from $\sim 5 \%$ in the presence of donor DNA, up to $\sim 50 \%$ by using the CRISPR/Cas9 system in the presence of donor DNA. This gene-targeting strategy provides a convenient and efficient approach to generate genetically engineered pigs. In regards to xenotransplantation, our study showed that multiple genes with various gene expression patterns could be expressed appropriately, while remaining genetically linked together. Future work would include the production of homozygous GGTAl KO pigs that would contain two copies of both $h C D 39$ and $h C D 55$ (one copy on each targeted allele). Once these pigs are generated, further characterization and potential xeno-related utility of the multi-transgenic xeno-pig would need to be evaluated.

In conclusion, we have demonstrated several methods to manipulate the swine genome and the collective data described within this dissertation could affect the strategies researchers use to implement their genetic engineering schemes. 


\section{BIBLIOGRAPHY}

Abuin, A., \& Bradley, A. (1996). Recycling selectable markers in mouse embryonic stem cells. Mol Cell Biol, 16(4), 1851-1856.

Andrews, B. J., Proteau, G. A., Beatty, L. G., \& Sadowski, P. D. (1985). The FLP recombinase of the 2 micron circle DNA of yeast: interaction with its target sequences. Cell, 40(4), 795-803.

Ausubel, F. M., Brent, R., Kingston, R. E., Moore, D. D., Seidman, J. G., \& Smith, J. A. (2002). Short protocols in molecular biology: a compendium of methods from current protocols in molecular biology 5th ed: New York: Wiley.

Awatramani, R., Soriano, P., Mai, J. J., \& Dymecki, S. (2001). An Flp indicator mouse expressing alkaline phosphatase from the ROSA26 locus. Nature genetics, 29(3), 257-259. doi: 10.1038/ng1101-257

Baguisi, A., Behboodi, E., Melican, D. T., Pollock, J. S., Destrempes, M. M., Cammuso, C., Williams, J. L., Nims, S. D., Porter, C. A., Midura, P., Palacios, M. J., Ayres, S. L., Denniston, R. S., Hayes, M. L., Ziomek, C. A., Meade, H. M., Godke, R. A., Gavin, W. G., Overstrom, E. W., \& Echelard, Y. (1999). Production of goats by somatic cell nuclear transfer. Nat Biotechnol, 17(5), 456-461. doi: 10.1038/8632

Basnet, N. B., Ide, K., Tahara, H., Tanaka, Y., \& Ohdan, H. (2010). Deficiency of Nglycolylneuraminic acid and Galalpha1-3Galbeta1-4GlcNAc epitopes in xenogeneic cells attenuates cytotoxicity of human natural antibodies. Xenotransplantation, 17(6), 440-448. doi: 10.1111/j.1399-3089.2010.00610.x

Beaton, B. P., Mao, J., Murphy, C. N., Samuel, M. S., Prather, R. S., \& Wells, K. D. (2013). Use of single stranded targeting DNA or negative selection does not further increase the efficiency of a GGTA1 promoter trap. J Mol Cloning Genet Recomb, 2(1). doi: 10.4172/2325-9787.1000101

Beaton, B. P., \& Wells, K. D. (2014). Compound Transgenics: Recombinase-Mediated Gene Stacking. In C. A. Pinkert (Ed.), Transgenic Animal Technology: A Laboratory Handbook $3 e$ (3 ed., pp. 565-578). Waltham, MA: Elsevier.

Beelman, C. A., \& Parker, R. (1995). Degradation of mRNA in eukaryotes. Cell, 81(2), 179-183. 
Bertoni, C., Jarrahian, S., Wheeler, T. M., Li, Y., Olivares, E. C., Calos, M. P., \& Rando, T. A. (2006). Enhancement of plasmid-mediated gene therapy for muscular dystrophy by directed plasmid integration. Proceedings of the National Academy of Sciences of the United States of America, 103(2), 419-424. doi: 10.1073/pnas.0504505102

Boch, J., Scholze, H., Schornack, S., Landgraf, A., Hahn, S., Kay, S., Lahaye, T., Nickstadt, A., \& Bonas, U. (2009). Breaking the code of DNA binding specificity of TAL-type III effectors. Science, 326(5959), 1509-1512. doi: 10.1126/science. 1178811

Bonifer, C., Huber, M. C., Jagle, U., Faust, N., \& Sippel, A. E. (1996). Prerequisites for tissue specific and position independent expression of a gene locus in transgenic mice. J Mol Med (Berl), 74(11), 663-671.

Bradley, A., Evans, M., Kaufman, M. H., \& Robertson, E. (1984). Formation of germline chimaeras from embryo-derived teratocarcinoma cell lines. Nature, 309(5965), 255-256.

Brinster, R. L., Allen, J. M., Behringer, R. R., Gelinas, R. E., \& Palmiter, R. D. (1988). Introns increase transcriptional efficiency in transgenic mice. Proceedings of the National Academy of Sciences of the United States of America, 85(3), 836-840.

Brinster, R. L., Braun, R. E., Lo, D., Avarbock, M. R., Oram, F., \& Palmiter, R. D. (1989). Targeted correction of a major histocompatibility class II E alpha gene by DNA microinjected into mouse eggs. Proceedings of the National Academy of Sciences of the United States of America, 86(18), 7087-7091.

Campbell, K. H., McWhir, J., Ritchie, W. A., \& Wilmut, I. (1996). Sheep cloned by nuclear transfer from a cultured cell line. Nature, 380(6569), 64-66. doi: $10.1038 / 380064 \mathrm{a} 0$

Capecchi, M. R. (1989). Altering the genome by homologous recombination. Science, 244(4910), 1288-1292.

Carlson, D. F., Tan, W., Lillico, S. G., Stverakova, D., Proudfoot, C., Christian, M., Voytas, D. F., Long, C. R., Whitelaw, C. B., \& Fahrenkrug, S. C. (2012). Efficient TALEN-mediated gene knockout in livestock. Proceedings of the National Academy of Sciences of the United States of America, 109(43), 1738217387. doi: 10.1073/pnas.1211446109 
Chalberg, T. W., Portlock, J. L., Olivares, E. C., Thyagarajan, B., Kirby, P. J., Hillman, R. T., Hoelters, J., \& Calos, M. P. (2006). Integration specificity of phage phiC31 integrase in the human genome. Journal of molecular biology, 357(1), 28-48. doi: 10.1016/j.jmb.2005.11.098

Chang, Y. F., Imam, J. S., \& Wilkinson, M. F. (2007). The nonsense-mediated decay RNA surveillance pathway. Annu Rev Biochem, 76, 51-74. doi:

10.1146/annurev.biochem.76.050106.093909

Chkheidze, A. N., Lyakhov, D. L., Makeyev, A. V., Morales, J., Kong, J., \& Liebhaber, S. A. (1999). Assembly of the alpha-globin mRNA stability complex reflects binary interaction between the pyrimidine-rich 3' untranslated region determinant and poly(C) binding protein alphaCP. Mol Cell Biol, 19(7), 4572-4581.

Choulika, A., Perrin, A., Dujon, B., \& Nicolas, J. F. (1995). Induction of homologous recombination in mammalian chromosomes by using the I-SceI system of Saccharomyces cerevisiae. Mol Cell Biol, 15(4), 1968-1973.

Cibelli, J. B., Stice, S. L., Golueke, P. J., Kane, J. J., Jerry, J., Blackwell, C., Ponce de Leon, F. A., \& Robl, J. M. (1998). Cloned transgenic calves produced from nonquiescent fetal fibroblasts. Science, 280(5367), 1256-1258.

Clark, A. J., Bissinger, P., Bullock, D. W., Damak, S., Wallace, R., Whitelaw, C. B., \& Yull, F. (1994). Chromosomal position effects and the modulation of transgene expression. Reprod Fertil Dev, 6(5), 589-598.

Clark, A. J., \& Margulies, A. D. (1965). Isolation and Characterization of Recombination-Deficient Mutants of Escherichia Coli K12. Proceedings of the National Academy of Sciences of the United States of America, 53, 451-459.

Cong, L., Ran, F. A., Cox, D., Lin, S., Barretto, R., Habib, N., Hsu, P. D., Wu, X., Jiang, W., Marraffini, L. A., \& Zhang, F. (2013). Multiplex genome engineering using CRISPR/Cas systems. Science, 339(6121), 819-823. doi: 10.1126/science. 1231143

Cooper, D., Ye, Y., Rolf Jr, L., \& Zuhdi, N. (1991). The pig as potential organ donor for man Xenotransplantation (pp. 481-500): Springer.

Cooper, D. K. (2012). A brief history of cross-species organ transplantation. Proc (Bayl Univ Med Cent), 25(1), 49-57. 
Cooper, D. K., Ekser, B., Burlak, C., Ezzelarab, M., Hara, H., Paris, L., Tector, A. J., Phelps, C., Azimzadeh, A. M., Ayares, D., Robson, S. C., \& Pierson, R. N., 3rd. (2012). Clinical lung xenotransplantation--what donor genetic modifications may be necessary? Xenotransplantation, 19(3), 144-158. doi: 10.1111/j.13993089.2012.00708.x

Cooper, D. K., Gollackner, B., \& Sachs, D. H. (2002). Will the pig solve the transplantation backlog? Annu Rev Med, 53, 133-147. doi: 10.1146/annurev.med.53.082901.103900

Cooper, D. K., Good, A. H., Koren, E., Oriol, R., Malcolm, A. J., Ippolito, R. M., Neethling, F. A., Ye, Y., Romano, E., \& Zuhdi, N. (1993). Identification of alphagalactosyl and other carbohydrate epitopes that are bound by human anti-pig antibodies: relevance to discordant xenografting in man. Transpl Immunol, 1(3), 198-205.

Cozzi, E., Tucker, A. W., Langford, G. A., Pino-Chavez, G., Wright, L., O'Connell, M. J., Young, V. J., Lancaster, R., McLaughlin, M., Hunt, K., Bordin, M. C., \& White, D. J. (1997). Characterization of pigs transgenic for human decay-accelerating factor. Transplantation, 64(10), 1383-1392.

Dai, Y., Vaught, T. D., Boone, J., Chen, S. H., Phelps, C. J., Ball, S., Monahan, J. A., Jobst, P. M., McCreath, K. J., Lamborn, A. E., Cowell-Lucero, J. L., Wells, K. D., Colman, A., Polejaeva, I. A., \& Ayares, D. L. (2002). Targeted disruption of the alpha1,3-galactosyltransferase gene in cloned pigs. Nat Biotechnol, 20(3), 251255. doi: 10.1038/nbt0302-251

Denning, C., Burl, S., Ainslie, A., Bracken, J., Dinnyes, A., Fletcher, J., King, T., Ritchie, M., Ritchie, W. A., Rollo, M., de Sousa, P., Travers, A., Wilmut, I., \& Clark, A. J. (2001). Deletion of the alpha(1,3)galactosyl transferase (GGTA1) gene and the prion protein (PrP) gene in sheep. Nat Biotechnol, 19(6), 559-562. doi: $10.1038 / 89313$

Diaz-Roman, T. M., Manez, R., Lopez-Pelaez, E., Centeno, A., Moscoso, I., Pertegaz, S., \& Domenech, N. (2006). Human DAF on pig cells protects against human and non-human primate sera cytotoxicity mediated by exogenous or endogenous complement, as determined by flow cytometry. Transpl Immunol, 16(2), 125-130. doi: 10.1016/j.trim.2006.03.008 
Doetschman, T., Maeda, N., \& Smithies, O. (1988). Targeted mutation of the Hprt gene in mouse embryonic stem cells. Proceedings of the National Academy of Sciences of the United States of America, 85(22), 8583-8587.

Dwyer, K. M., Robson, S. C., Nandurkar, H. H., Campbell, D. J., Gock, H., MurraySegal, L. J., Fisicaro, N., Mysore, T. B., Kaczmarek, E., Cowan, P. J., \& d'Apice, A. J. (2004). Thromboregulatory manifestations in human CD39 transgenic mice and the implications for thrombotic disease and transplantation. The Journal of clinical investigation, 113(10), 1440-1446. doi: 10.1172/JCI19560

Dyerberg, J., \& Bang, H. O. (1979). Haemostatic function and platelet polyunsaturated fatty acids in Eskimos. Lancet, 2(8140), 433-435.

Evans, M. J., \& Kaufman, M. H. (1981). Establishment in culture of pluripotential cells from mouse embryos. Nature, 292(5819), 154-156.

Ezzelarab, M., Ayares, D., \& Cooper, D. K. (2005). Carbohydrates in xenotransplantation. Immunol Cell Biol, 83(4), 396-404. doi: 10.1111/j.1440-1711.2005.01344.x

Fiering, S., Epner, E., Robinson, K., Zhuang, Y., Telling, A., Hu, M., Martin, D. I., Enver, T., Ley, T. J., \& Groudine, M. (1995). Targeted deletion of 5'HS2 of the murine beta-globin LCR reveals that it is not essential for proper regulation of the betaglobin locus. Genes Dev, 9(18), 2203-2213.

Fish, M. P., Groth, A. C., Calos, M. P., \& Nusse, R. (2007). Creating transgenic Drosophila by microinjecting the site-specific phiC31 integrase mRNA and a transgene-containing donor plasmid. Nat Protoc, 2(10), 2325-2331. doi: $10.1038 /$ nprot.2007.328

Folger, K. R., Wong, E. A., Wahl, G., \& Capecchi, M. R. (1982). Patterns of integration of DNA microinjected into cultured mammalian cells: evidence for homologous recombination between injected plasmid DNA molecules. Mol Cell Biol, 2(11), 1372-1387.

Friedrich, G., \& Soriano, P. (1991). Promoter traps in embryonic stem cells: a genetic screen to identify and mutate developmental genes in mice. Genes Dev, 5(9), 1513-1523.

Fujimura, T., Kurome, M., Murakami, H., Takahagi, Y., Matsunami, K., Shimanuki, S., Suzuki, K., Miyagawa, S., Shirakura, R., Shigehisa, T., \& Nagashima, H. (2004). 
Cloning of the transgenic pigs expressing human decay accelerating factor and Nacetylglucosaminyltransferase III. Cloning Stem Cells, 6(3), 294-301. doi:

10.1089/clo.2004.6.294

Gaj, T., Gersbach, C. A., \& Barbas, C. F., 3rd. (2013). ZFN, TALEN, and CRISPR/Casbased methods for genome engineering. Trends Biotechnol, 31(7), 397-405. doi: 10.1016/j.tibtech.2013.04.004

Galili, U. (2001). The alpha-Gal epitope (Galalpha1-3Galbeta1-4GlcNAc-R) in xenotransplantation. Biochimie, 83(7), 557-563.

Galili, U., Shohet, S. B., Kobrin, E., Stults, C. L., \& Macher, B. A. (1988). Man, apes, and Old World monkeys differ from other mammals in the expression of alphagalactosyl epitopes on nucleated cells. The Journal of biological chemistry, 263(33), 17755-17762.

Garrick, D., Fiering, S., Martin, D. I., \& Whitelaw, E. (1998). Repeat-induced gene silencing in mammals. Nature genetics, 18(1), 56-59. doi: 10.1038/ng0198-56

Godwin, A. R., Bollag, R. J., Christie, D. M., \& Liskay, R. M. (1994). Spontaneous and restriction enzyme-induced chromosomal recombination in mammalian cells. Proceedings of the National Academy of Sciences of the United States of America, 91(26), 12554-12558.

Gordon, J. W., \& Ruddle, F. H. (1981). Integration and stable germ line transmission of genes injected into mouse pronuclei. Science, 214(4526), 1244-1246.

Groman, N. B., \& Suzuki, G. (1962). Temperature and lambda phage reproduction. $J$ Bacteriol, 84, 431-437.

Groth, A. C., Fish, M., Nusse, R., \& Calos, M. P. (2004). Construction of transgenic Drosophila by using the site-specific integrase from phage phiC31. Genetics, 166(4), 1775-1782.

Groth, A. C., Olivares, E. C., Thyagarajan, B., \& Calos, M. P. (2000). A phage integrase directs efficient site-specific integration in human cells. Proceedings of the National Academy of Sciences of the United States of America, 97(11), 5995-6000. doi: 10.1073/pnas.090527097 
Grubb, B. R., \& Boucher, R. C. (1999). Pathophysiology of gene-targeted mouse models for cystic fibrosis. Physiol Rev, 79(1 Suppl), S193-214.

Hammer, R. E., Pursel, V. G., Rexroad, C. E., Jr., Wall, R. J., Bolt, D. J., Ebert, K. M., Palmiter, R. D., \& Brinster, R. L. (1985). Production of transgenic rabbits, sheep and pigs by microinjection. Nature, 315(6021), 680-683.

Harduin-Lepers, A., Mollicone, R., Delannoy, P., \& Oriol, R. (2005). The animal sialyltransferases and sialyltransferase-related genes: a phylogenetic approach. Glycobiology, 15(8), 805-817. doi: 10.1093/glycob/cwi063

Harrison, S. J., Guidolin, A., Faast, R., Crocker, L. A., Giannakis, C., D'Apice, A. J., Nottle, M. B., \& Lyons, I. (2002). Efficient generation of alpha(1,3) galactosyltransferase knockout porcine fetal fibroblasts for nuclear transfer. Transgenic Res, 11(2), 143-150.

Hasty, P., \& Bradley, A. (1993). Gene targeting vectors for mammalian cells. In A. L. Joyner (Ed.), Gene targeting: a practical approach: Oxford.

Hasty, P., Rivera-Perez, J., \& Bradley, A. (1991). The length of homology required for gene targeting in embryonic stem cells. Mol Cell Biol, 11(11), 5586-5591.

Hasty, P., Rivera-Perez, J., Chang, C., \& Bradley, A. (1991). Target frequency and integration pattern for insertion and replacement vectors in embryonic stem cells. Mol Cell Biol, 11(9), 4509-4517.

Hauschild, J., Petersen, B., Santiago, Y., Queisser, A.-L., Carnwath, J. W., Lucas-Hahn, A., Zhang, L., Meng, X., Gregory, P. D., \& Schwinzer, R. (2011). Efficient generation of a biallelic knockout in pigs using zinc-finger nucleases. Proceedings of the National Academy of Sciences, 108(29), 12013-12017.

Hayes, C. E., \& Goldstein, I. J. (1974). An $\alpha$-d-Galactosyl-binding Lectin from Bandeirae simplicifolia Seeds ISOLATION BY AFFINITY CHROMATOGRAPHY AND CHARACTERIZATION. Journal of Biological Chemistry, 249(6), 1904-1914.

Heyer, W. D., Ehmsen, K. T., \& Liu, J. (2010). Regulation of homologous recombination in eukaryotes. Annu Rev Genet, 44, 113-139. doi: 10.1146/annurev-genet-051710150955 
Jasin, M. (1996). Genetic manipulation of genomes with rare-cutting endonucleases. Trends Genet, 12(6), 224-228.

Jasin, M., \& Berg, P. (1988). Homologous integration in mammalian cells without target gene selection. Genes Dev, 2(11), 1353-1363.

Jin, D. I., Lee, S. H., Choi, J. H., Lee, J. S., Lee, J. E., Park, K. W., \& Seo, J. S. (2003). Targeting efficiency of a-1,3-galactosyl transferase gene in pig fetal fibroblast cells. Exp Mol Med, 35(6), 572-577. doi: 10.1038/emm.2003.75

Jinek, M., Chylinski, K., Fonfara, I., Hauer, M., Doudna, J. A., \& Charpentier, E. (2012). A programmable dual-RNA-guided DNA endonuclease in adaptive bacterial immunity. Science, 337(6096), 816-821. doi: 10.1126/science.1225829

Joziasse, D. H., \& Oriol, R. (1999). Xenotransplantation: the importance of the Galalpha1,3Gal epitope in hyperacute vascular rejection. Biochim Biophys Acta, 1455(2-3), 403-418.

Keravala, A., \& Calos, M. P. (2008). Site-specific chromosomal integration mediated by phiC31 integrase. Methods in molecular biology, 435, 165-173. doi: 10.1007/9781-59745-232-8_12

Kim, A. I., Ghosh, P., Aaron, M. A., Bibb, L. A., Jain, S., \& Hatfull, G. F. (2003). Mycobacteriophage Bxb1 integrates into the Mycobacterium smegmatis groEL1 gene. Mol Microbiol, 50(2), 463-473.

Kim, Y. G., Cha, J., \& Chandrasegaran, S. (1996). Hybrid restriction enzymes: zinc finger fusions to Fok I cleavage domain. Proceedings of the National Academy of Sciences of the United States of America, 93(3), 1156-1160.

Kinsella, J. E., Lokesh, B., \& Stone, R. A. (1990). Dietary n-3 polyunsaturated fatty acids and amelioration of cardiovascular disease: possible mechanisms. Am J Clin Nutr, $52(1), 1-28$.

Knirsch, L., \& Clerch, L. B. (2000). A region in the 3' UTR of MnSOD RNA enhances translation of a heterologous RNA. Biochemical and biophysical research communications, 272(1), 164-168. doi: 10.1006/bbrc.2000.2754 
Kolber-Simonds, D., Lai, L., Watt, S. R., Denaro, M., Arn, S., Augenstein, M. L., Betthauser, J., Carter, D. B., Greenstein, J. L., Hao, Y., Im, G. S., Liu, Z., Mell, G. D., Murphy, C. N., Park, K. W., Rieke, A., Ryan, D. J., Sachs, D. H., Forsberg, E. J., Prather, R. S., \& Hawley, R. J. (2004). Production of alpha-1,3galactosyltransferase null pigs by means of nuclear transfer with fibroblasts bearing loss of heterozygosity mutations. Proceedings of the National Academy of Sciences of the United States of America, 101(19), 7335-7340. doi: 10.1073/pnas.0307819101

Kwon, D. N., Lee, K., Kang, M. J., Choi, Y. J., Park, C., Whyte, J. J., Brown, A. N., Kim, J. H., Samuel, M., Mao, J., Park, K. W., Murphy, C. N., Prather, R. S., \& Kim, J. H. (2013). Production of biallelic CMP-Neu5Ac hydroxylase knock-out pigs. Sci Rep, 3, 1981. doi: 10.1038/srep01981

Lai, L., Kang, J. X., Li, R., Wang, J., Witt, W. T., Yong, H. Y., Hao, Y., Wax, D. M., Murphy, C. N., Rieke, A., Samuel, M., Linville, M. L., Korte, S. W., Evans, R. W., Starzl, T. E., Prather, R. S., \& Dai, Y. (2006). Generation of cloned transgenic pigs rich in omega-3 fatty acids. Nat Biotechnol, 24(4), 435-436. doi: $10.1038 /$ nbt1 198

Lai, L., Kolber-Simonds, D., Park, K. W., Cheong, H. T., Greenstein, J. L., Im, G. S., Samuel, M., Bonk, A., Rieke, A., Day, B. N., Murphy, C. N., Carter, D. B., Hawley, R. J., \& Prather, R. S. (2002). Production of alpha-1,3galactosyltransferase knockout pigs by nuclear transfer cloning. Science, 295(5557), 1089-1092. doi: 10.1126/science. 1068228

Lai, L., \& Prather, R. S. (2003). Production of cloned pigs by using somatic cells as donors. Cloning \& Stem Cells, 5(4), 233-241.

Lambrigts, D., Sachs, D. H., \& Cooper, D. K. (1998). Discordant organ xenotransplantation in primates: world experience and current status. Transplantation, 66(5), 547-561.

Lee, H. J., Lee, B. C., Kim, Y. H., Paik, N. W., \& Rho, H. M. (2011). Characterization of transgenic pigs that express human decay accelerating factor and cell membranetethered human tissue factor pathway inhibitor. Reprod Domest Anim, 46(2), 325332. doi: 10.1111/j.1439-0531.2010.01670.x

Lee, K., Kwon, D. N., Ezashi, T., Choi, Y. J., Park, C., Ericsson, A. C., Brown, A. N., Samuel, M. S., Park, K. W., Walters, E. M., Kim, D. Y., Kim, J. H., Franklin, C. L., Murphy, C. N., Roberts, R. M., Prather, R. S., \& Kim, J. H. (2014). 
Engraftment of human iPS cells and allogeneic porcine cells into pigs with inactivated RAG2 and accompanying severe combined immunodeficiency. Proceedings of the National Academy of Sciences of the United States of America, 111(20), 7260-7265. doi: 10.1073/pnas.1406376111

Macejak, D. G., \& Sarnow, P. (1991). Internal initiation of translation mediated by the 5' leader of a cellular mRNA. Nature, 353(6339), 90-94. doi: 10.1038/353090a0

Machaty, Z., Wang, W. H., Day, B. N., \& Prather, R. S. (1997). Complete activation of porcine oocytes induced by the sulfhydryl reagent, thimerosal. Biology of reproduction, 57(5), 1123-1127.

Magram, J., \& Bishop, J. M. (1991). Dominant male sterility in mice caused by insertion of a transgene. Proceedings of the National Academy of Sciences of the United States of America, 88(22), 10327-10331.

Mali, P., Yang, L., Esvelt, K. M., Aach, J., Guell, M., DiCarlo, J. E., Norville, J. E., \& Church, G. M. (2013). RNA-guided human genome engineering via Cas9. Science, 339(6121), 823-826. doi: 10.1126/science.1232033

Mansour, S. L., Thomas, K. R., \& Capecchi, M. R. (1988). Disruption of the protooncogene int-2 in mouse embryo-derived stem cells: a general strategy for targeting mutations to non-selectable genes. Nature, 336(6197), 348-352. doi: $10.1038 / 336348 \mathrm{a} 0$

Martin, G. R. (1981). Isolation of a pluripotent cell line from early mouse embryos cultured in medium conditioned by teratocarcinoma stem cells. Proceedings of the National Academy of Sciences of the United States of America, 78(12), 7634-7638.

Matsuda, T., \& Cepko, C. L. (2007). Controlled expression of transgenes introduced by in vivo electroporation. Proceedings of the National Academy of Sciences of the United States of America, 104(3), 1027-1032. doi: 10.1073/pnas.0610155104

Matsuura, M., Noguchi, T., Yamaguchi, D., Aida, T., Asayama, M., Takahashi, H., \& Shirai, M. (1996). The sre gene (ORF469) encodes a site-specific recombinase responsible for integration of the R4 phage genome. J Bacteriol, 178(11), 33743376.

Mc, C. M., \& Tribe, D. E. (1954). The baby pig as a laboratory animal. The Journal of physiology, 124(3), 52P. 
McCreath, K. J., Howcroft, J., Campbell, K. H., Colman, A., Schnieke, A. E., \& Kind, A. J. (2000). Production of gene-targeted sheep by nuclear transfer from cultured somatic cells. Nature, 405(6790), 1066-1069. doi: 10.1038/35016604

Mediavilla, J., Jain, S., Kriakov, J., Ford, M. E., Duda, R. L., Jacobs, W. R., Jr., Hendrix, R. W., \& Hatfull, G. F. (2000). Genome organization and characterization of mycobacteriophage Bxb1. Mol Microbiol, 38(5), 955-970.

Meyers, E. N., Lewandoski, M., \& Martin, G. R. (1998). An Fgf8 mutant allelic series generated by Cre- and Flp-mediated recombination. Nature genetics, 18(2), 136141. doi: $10.1038 / \mathrm{ng} 0298-136$

Muchmore, E. A., Diaz, S., \& Varki, A. (1998). A structural difference between the cell surfaces of humans and the great apes. Am J Phys Anthropol, 107(2), 187-198. doi: 10.1002/(SICI)1096-8644(199810)107:2<187::AID-AJPA5>3.0.CO;2-S

Nagy, A. (2000). Cre recombinase: the universal reagent for genome tailoring. Genesis, 26(2), 99-109.

Nagy, A., Moens, C., Ivanyi, E., Pawling, J., Gertsenstein, M., Hadjantonakis, A. K., Pirity, M., \& Rossant, J. (1998). Dissecting the role of N-myc in development using a single targeting vector to generate a series of alleles. Curr Biol, 8(11), 661-664.

Nagy, A., \& Rossant, J. (1996). Targeted mutagenesis: analysis of phenotype without germ line transmission. The Journal of clinical investigation, 97(6), 1360-1365. doi: 10.1172/JCI118555

Notarianni, E., Galli, C., Laurie, S., Moor, R. M., \& Evans, M. J. (1991). Derivation of pluripotent, embryonic cell lines from the pig and sheep. J Reprod Fertil Suppl, $43,255-260$.

Olivares, E. C., Hollis, R. P., \& Calos, M. P. (2001). Phage R4 integrase mediates sitespecific integration in human cells. Gene, 278(1-2), 167-176.

Orban, P. C., Chui, D., \& Marth, J. D. (1992). Tissue- and site-specific DNA recombination in transgenic mice. Proceedings of the National Academy of Sciences of the United States of America, 89(15), 6861-6865. 
Osterwalder, M., Galli, A., Rosen, B., Skarnes, W. C., Zeller, R., \& Lopez-Rios, J. (2010). Dual RMCE for efficient re-engineering of mouse mutant alleles. Nat Methods, 7(11), 893-895. doi: 10.1038/nmeth.1521

Palmiter, R. D., Sandgren, E. P., Avarbock, M. R., Allen, D. D., \& Brinster, R. L. (1991). Heterologous introns can enhance expression of transgenes in mice. Proceedings of the National Academy of Sciences of the United States of America, 88(2), 478482.

Park, J. K., Lee, Y. K., Lee, P., Chung, H. J., Kim, S., Lee, H. G., Seo, M. K., Han, J. H., Park, C. G., Kim, H. T., Kim, Y. K., Min, K. S., Kim, J. H., Lee, H. T., \& Chang, W. K. (2006). Recombinant human erythropoietin produced in milk of transgenic pigs. J Biotechnol, 122(3), 362-371. doi: 10.1016/j.jbiotec.2005.11.021

Park, J. Y., Park, M. R., Bui, H. T., Kwon, D. N., Kang, M. H., Oh, M., Han, J. W., Cho, S. G., Park, C., Shim, H., Kim, H. M., Kang, M. J., Park, J. K., Lee, J. W., Lee, K. K., \& Kim, J. H. (2012). alpha1,3-galactosyltransferase deficiency in germ-free miniature pigs increases $\mathrm{N}$-glycolylneuraminic acids as the xenoantigenic determinant in pig-human xenotransplantation. Cell Reprogram, 14(4), 353-363. doi: $10.1089 /$ cell.2011.0083

Park, J. Y., Park, M. R., Kwon, D. N., Kang, M. H., Oh, M., Han, J. W., Cho, S. G., Park, C., Kim, D. K., Song, H., Oh, J. W., \& Kim, J. H. (2011). Alpha 1,3galactosyltransferase deficiency in pigs increases sialyltransferase activities that potentially raise non-gal xenoantigenicity. J Biomed Biotechnol, 2011, 560850. doi: $10.1155 / 2011 / 560850$

Phelps, C. J., Koike, C., Vaught, T. D., Boone, J., Wells, K. D., Chen, S. H., Ball, S., Specht, S. M., Polejaeva, I. A., Monahan, J. A., Jobst, P. M., Sharma, S. B., Lamborn, A. E., Garst, A. S., Moore, M., Demetris, A. J., Rudert, W. A., Bottino, R., Bertera, S., Trucco, M., Starzl, T. E., Dai, Y., \& Ayares, D. L. (2003). Production of alpha 1,3-galactosyltransferase-deficient pigs. Science, 299(5605), 411-414. doi: 10.1126/science. 1078942

Polejaeva, I. A., Chen, S. H., Vaught, T. D., Page, R. L., Mullins, J., Ball, S., Dai, Y., Boone, J., Walker, S., Ayares, D. L., Colman, A., \& Campbell, K. H. (2000). Cloned pigs produced by nuclear transfer from adult somatic cells. Nature, 407(6800), 86-90. doi: $10.1038 / 35024082$

Pursel, V. G., \& Rexroad, C. E., Jr. (1993). Status of research with transgenic farm animals. J Anim Sci, 71 Suppl 3, 10-19. 
Ramsoondar, J. J., Machaty, Z., Costa, C., Williams, B. L., Fodor, W. L., \& Bondioli, K. R. (2003). Production of alpha 1,3-galactosyltransferase-knockout cloned pigs expressing human alpha 1,2-fucosylosyltransferase. Biology of reproduction, 69(2), 437-445. doi: 10.1095/biolreprod.102.014647

Raymond, C. S., \& Soriano, P. (2007). High-efficiency FLP and PhiC31 site-specific recombination in mammalian cells. PloS one, 2(1), e162. doi: 10.1371/journal.pone.0000162

Rees, W. D., Flint, H. J., \& Fuller, M. F. (1990). A molecular biological approach to reducing dietary amino acid needs. Biotechnology (N Y), 8(7), 629-633.

Reid, L. H., Shesely, E. G., Kim, H. S., \& Smithies, O. (1991). Cotransformation and gene targeting in mouse embryonic stem cells. Mol Cell Biol, 11(5), 2769-2777.

Rogers, C. S., Stoltz, D. A., Meyerholz, D. K., Ostedgaard, L. S., Rokhlina, T., Taft, P. J., Rogan, M. P., Pezzulo, A. A., Karp, P. H., Itani, O. A., Kabel, A. C., WohlfordLenane, C. L., Davis, G. J., Hanfland, R. A., Smith, T. L., Samuel, M., Wax, D., Murphy, C. N., Rieke, A., Whitworth, K., Uc, A., Starner, T. D., Brogden, K. A., Shilyansky, J., McCray, P. B., Jr., Zabner, J., Prather, R. S., \& Welsh, M. J. (2008). Disruption of the CFTR gene produces a model of cystic fibrosis in newborn pigs. Science, 321(5897), 1837-1841. doi: 10.1126/science.1163600

Ross, J. W., Whyte, J. J., Zhao, J., Samuel, M., Wells, K. D., \& Prather, R. S. (2010). Optimization of square-wave electroporation for transfection of porcine fetal fibroblasts. Transgenic Res, 19(4), 611-620. doi: 10.1007/s11248-009-9345-1

Rossant, J., \& Nagy, A. (1995). Genome engineering: the new mouse genetics. Nat Med, $1(6), 592-594$.

Rouet, P., Smih, F., \& Jasin, M. (1994). Expression of a site-specific endonuclease stimulates homologous recombination in mammalian cells. Proceedings of the National Academy of Sciences of the United States of America, 91(13), 6064-6068.

Sachs, D. H. (1994). The pig as a potential xenograft donor. Vet Immunol Immunopathol, 43(1-3), 185-191.

Saeki, K., Matsumoto, K., Kinoshita, M., Suzuki, I., Tasaka, Y., Kano, K., Taguchi, Y., Mikami, K., Hirabayashi, M., Kashiwazaki, N., Hosoi, Y., Murata, N., \& Iritani, A. (2004). Functional expression of a Delta12 fatty acid desaturase gene from 
spinach in transgenic pigs. Proceedings of the National Academy of Sciences of the United States of America, 101(17), 6361-6366. doi: 10.1073/pnas.0308111101

Sambrook, J., Fritsch, E. F., \& Maniatis, T. (1989). Molecular cloning (Vol. 1): Cold spring harbor laboratory press New York.

Sandrin, M. S., \& McKenzie, I. F. (1994). Gal alpha (1,3)Gal, the major xenoantigen(s) recognised in pigs by human natural antibodies. Immunol Rev, 141, 169-190.

Sauer, B. (1987). Functional expression of the cre-lox site-specific recombination system in the yeast Saccharomyces cerevisiae. Mol Cell Biol, 7(6), 2087-2096.

Schlaeger, T. M., Bartunkova, S., Lawitts, J. A., Teichmann, G., Risau, W., Deutsch, U., \& Sato, T. N. (1997). Uniform vascular-endothelial-cell-specific gene expression in both embryonic and adult transgenic mice. Proceedings of the National Academy of Sciences of the United States of America, 94(7), 3058-3063.

Schnieke, A. E., Kind, A. J., Ritchie, W. A., Mycock, K., Scott, A. R., Ritchie, M., Wilmut, I., Colman, A., \& Campbell, K. H. (1997). Human factor IX transgenic sheep produced by transfer of nuclei from transfected fetal fibroblasts. Science, 278(5346), 2130-2133.

Sedivy, J. M., \& Sharp, P. A. (1989). Positive genetic selection for gene disruption in mammalian cells by homologous recombination. Proceedings of the National Academy of Sciences of the United States of America, 86(1), 227-231.

Shani, M. (1986). Tissue-specific and developmentally regulated expression of a chimeric actin-globin gene in transgenic mice. Mol Cell Biol, 6(7), 2624-2631.

Smih, F., Rouet, P., Romanienko, P. J., \& Jasin, M. (1995). Double-strand breaks at the target locus stimulate gene targeting in embryonic stem cells. Nucleic Acids Res, 23(24), 5012-5019.

Smith, M. C., Till, R., Brady, K., Soultanas, P., Thorpe, H., \& Smith, M. C. (2004). Synapsis and DNA cleavage in phiC31 integrase-mediated site-specific recombination. Nucleic Acids Res, 32(8), 2607-2617. doi: 10.1093/nar/gkh538 
Smithies, O., Gregg, R. G., Boggs, S. S., Koralewski, M. A., \& Kucherlapati, R. S. (1985). Insertion of DNA sequences into the human chromosomal beta-globin locus by homologous recombination. Nature, 317(6034), 230-234.

Song, K. Y., Chekuri, L., Rauth, S., Ehrlich, S., \& Kucherlapati, R. (1985). Effect of double-strand breaks on homologous recombination in mammalian cells and extracts. Mol Cell Biol, 5(12), 3331-3336.

Soriano, P. (1999). Generalized lacZ expression with the ROSA26 Cre reporter strain. Nature genetics, 21(1), 70-71. doi: 10.1038/5007

Sternberg, N., Hamilton, D., Austin, S., Yarmolinsky, M., \& Hoess, R. (1981). Sitespecific recombination and its role in the life cycle of bacteriophage P1. Cold Spring Harb Symp Quant Biol, 45 Pt 1, 297-309.

Stice, S. L., Strelchenko, N. S., Keefer, C. L., \& Matthews, L. (1996). Pluripotent bovine embryonic cell lines direct embryonic development following nuclear transfer. Biology of reproduction, 54(1), 100-110.

Suvorava, T., \& Kojda, G. (2009). Reactive oxygen species as cardiovascular mediators: lessons from endothelial-specific protein overexpression mouse models. Biochim Biophys Acta, 1787(7), 802-810. doi: 10.1016/j.bbabio.2009.04.005

Tahara, H., Ide, K., Basnet, N. B., Tanaka, Y., Matsuda, H., Takematsu, H., Kozutsumi, Y., \& Ohdan, H. (2010). Immunological property of antibodies against Nglycolylneuraminic acid epitopes in cytidine monophospho-N-acetylneuraminic acid hydroxylase-deficient mice. Journal of immunology, 184(6), 3269-3275. doi: $10.4049 /$ jimmunol.0902857

Takahagi, Y., Fujimura, T., Miyagawa, S., Nagashima, H., Shigehisa, T., Shirakura, R., \& Murakami, H. (2005). Production of alpha 1,3-galactosyltransferase gene knockout pigs expressing both human decay-accelerating factor and Nacetylglucosaminyltransferase III. Mol Reprod Dev, 71(3), 331-338. doi: $10.1002 / \mathrm{mrd} .20305$

Takata, M., Sasaki, M. S., Sonoda, E., Morrison, C., Hashimoto, M., Utsumi, H., Yamaguchi-Iwai, Y., Shinohara, A., \& Takeda, S. (1998). Homologous recombination and non-homologous end-joining pathways of DNA double-strand break repair have overlapping roles in the maintenance of chromosomal integrity in vertebrate cells. The EMBO journal, 17(18), 5497-5508. doi: 10.1093/emboj/17.18.5497 
Tan, W., Carlson, D. F., Lancto, C. A., Garbe, J. R., Webster, D. A., Hackett, P. B., \& Fahrenkrug, S. C. (2013). Efficient nonmeiotic allele introgression in livestock using custom endonucleases. Proceedings of the National Academy of Sciences of the United States of America, 110(41), 16526-16531. doi: 10.1073/pnas.1310478110

Templeton, N. S., Roberts, D. D., \& Safer, B. (1997). Efficient gene targeting in mouse embryonic stem cells. Gene therapy, 4(7), 700-709. doi: 10.1038/sj.gt.3300457

Thomas, K. R., \& Capecchi, M. R. (1987). Site-directed mutagenesis by gene targeting in mouse embryo-derived stem cells. Cell, 51(3), 503-512.

Thorpe, H. M., \& Smith, M. C. (1998). In vitro site-specific integration of bacteriophage DNA catalyzed by a recombinase of the resolvase/invertase family. Proceedings of the National Academy of Sciences of the United States of America, 95(10), 5505-5510.

Thorpe, H. M., Wilson, S. E., \& Smith, M. C. (2000). Control of directionality in the sitespecific recombination system of the Streptomyces phage phiC31. Mol Microbiol, $38(2), 232-241$.

Thyagarajan, B., Olivares, E. C., Hollis, R. P., Ginsburg, D. S., \& Calos, M. P. (2001). Site-specific genomic integration in mammalian cells mediated by phage phiC31 integrase. Mol Cell Biol, 21(12), 3926-3934. doi: 10.1128/MCB.21.12.39263934.2001

Varki, A. (2001). Loss of N-glycolylneuraminic acid in humans: Mechanisms, consequences, and implications for hominid evolution. Am J Phys Anthropol, Suppl 33, 54-69.

Waldman, A. S., \& Liskay, R. M. (1988). Dependence of intrachromosomal recombination in mammalian cells on uninterrupted homology. Mol Cell Biol, $8(12), 5350-5357$.

Walters, E. M., Bauer, B. A., Franklin, C. L., Evans, T. J., Bryda, E. C., Riley, L. K., \& Critser, J. K. (2009). Mutational insertion of a ROSA26-EGFP transgene leads to defects in spermiogenesis and male infertility in mice. Comparative medicine, 59(6), 545-552. 
Wang, Y., Yau, Y. Y., Perkins-Balding, D., \& Thomson, J. G. (2011). Recombinase technology: applications and possibilities. Plant Cell Rep, 30(3), 267-285. doi: $10.1007 / \mathrm{s} 00299-010-0938-1$

Wheeler, M. B., \& Walters, E. M. (2001). Transgenic technology and applications in swine. Theriogenology, 56(8), 1345-1369.

Whitworth, K. M., Lee, K., Benne, J. A., Beaton, B. P., Spate, L. D., Murphy, S. L., Samuel, M. S., Mao, J., O'Gorman, C., Walters, E. M., Murphy, C. N., Driver, J., Mileham, A., McLaren, D., Wells, K. D., \& Prather, R. S. (2014). Use of the CRISPR/Cas9 system to produce genetically engineered pigs from in vitroderived oocytes and embryos. Biology of reproduction, 91(3), 78. doi: 10.1095/biolreprod.114.121723

Whyte, J. J., Samuel, M., Mahan, E., Padilla, J., Simmons, G. H., Arce-Esquivel, A. A., Bender, S. B., Whitworth, K. M., Hao, Y. H., Murphy, C. N., Walters, E. M., Prather, R. S., \& Laughlin, M. H. (2011). Vascular endothelium-specific overexpression of human catalase in cloned pigs. Transgenic Res, 20(5), 9891001. doi: $10.1007 / \mathrm{s} 11248-010-9473-7$

Whyte, J. J., Zhao, J., Wells, K. D., Samuel, M. S., Whitworth, K. M., Walters, E. M., Laughlin, M. H., \& Prather, R. S. (2011). Gene targeting with zinc finger nucleases to produce cloned eGFP knockout pigs. Mol Reprod Dev, 78(1), 2. doi: $10.1002 / \mathrm{mrd} .21271$

Wilmut, I., Schnieke, A. E., McWhir, J., Kind, A. J., \& Campbell, K. H. (1997). Viable offspring derived from fetal and adult mammalian cells. Nature, 385(6619), 810813. doi: $10.1038 / 385810 \mathrm{a} 0$

Yagi, T., Ikawa, Y., Yoshida, K., Shigetani, Y., Takeda, N., Mabuchi, I., Yamamoto, T., \& Aizawa, S. (1990). Homologous recombination at c-fyn locus of mouse embryonic stem cells with use of diphtheria toxin A-fragment gene in negative selection. Proceedings of the National Academy of Sciences of the United States of America, 87(24), 9918-9922.

Yang, D., Yang, H., Li, W., Zhao, B., Ouyang, Z., Liu, Z., Zhao, Y., Fan, N., Song, J., Tian, J., Li, F., Zhang, J., Chang, L., Pei, D., Chen, Y. E., \& Lai, L. (2011). Generation of PPARgamma mono-allelic knockout pigs via zinc-finger nucleases and nuclear transfer cloning. Cell Res, 21(6), 979-982. doi: 10.1038/cr.2011.70 
Ye, Y., Niekrasz, M., Kosanke, S., Welsh, R., Jordan, H. E., Fox, J. C., Edwards, W. C., Maxwell, C., \& Cooper, D. K. (1994). The pig as a potential organ donor for man. A study of potentially transferable disease from donor pig to recipient man. Transplantation, 57(5), 694-703.

Yoshioka, K., Suzuki, C., Tanaka, A., Anas, I. M., \& Iwamura, S. (2002). Birth of piglets derived from porcine zygotes cultured in a chemically defined medium. Biology of reproduction, 66(1), 112-119.

Zhao, J., Hao, Y., Ross, J. W., Spate, L. D., Walters, E. M., Samuel, M. S., Rieke, A., Murphy, C. N., \& Prather, R. S. (2010). Histone deacetylase inhibitors improve in vitro and in vivo developmental competence of somatic cell nuclear transfer porcine embryos. Cell Reprogram, 12(1), 75-83. doi: 10.1089/cell.2009.0038

Zhao, J., Ross, J. W., Hao, Y., Spate, L. D., Walters, E. M., Samuel, M. S., Rieke, A., Murphy, C. N., \& Prather, R. S. (2009). Significant improvement in cloning efficiency of an inbred miniature pig by histone deacetylase inhibitor treatment after somatic cell nuclear transfer. Biology of Reproduction, 81(3), 525-530. doi: 10.1095/biolreprod.109.077016

Zhou, C. Y., McInnes, E., Copeman, L., Langford, G., Parsons, N., Lancaster, R., Richards, A., Carrington, C., \& Thompson, S. (2005). Transgenic pigs expressing human CD59, in combination with human membrane cofactor protein and human decay-accelerating factor. Xenotransplantation, 12(2), 142-148. doi: 10.1111/j.1399-3089.2005.00209.x

Zhou, X., Xin, J., Fan, N., Zou, Q., Huang, J., Ouyang, Z., Zhao, Y., Zhao, B., Liu, Z., Lai, S., Yi, X., Guo, L., Esteban, M. A., Zeng, Y., Yang, H., \& Lai, L. (2015). Generation of CRISPR/Cas9-mediated gene-targeted pigs via somatic cell nuclear transfer. Cell Mol Life Sci, 72(6), 1175-1184. doi: 10.1007/s00018-014-1744-7

Zuker, M. (2003). Mfold web server for nucleic acid folding and hybridization prediction. Nucleic Acids Res, 31(13), 3406-3415. 


\section{VITA}

Benjamin Paul Beaton was born September 11, 1986 in Garden City, Kansas to Tommy and JoNell Beaton. Benjamin was raised with his three brothers, Christopher, Philip, and Douglas in Scott City, Kansas. In October of 2009, Benjamin married Whitney Blau in Garden City, Kansas. Whitney and Benjamin have a nine-year-old wiemaraner, Greyson.

In 2005, Benjamin graduated from Scott Community High School, Scott City, Kansas. In 2009, he obtained his Bachelor of Science degree in Animal Science \& Industry - Bioscience/Biotechnology Option from the Kansas State University, Manhattan, Kansas. In 2012, Benjamin conferred his Masters of Science degree in Animal Science from the University of Missouri, Columbia, Missouri under the supervision of Dr. Kevin Wells. Upon receiving his M.S. degree, he pursued a Doctor of Philosophy degree in the Division of Animal Sciences at the University of Missouri, once again under the direction of Dr. Kevin Wells. Benjamin's Ph.D. degree was in the area of Molecular Genetics/Genetic Engineering. He began his work in May 2012 and graduated in May 2015. 